\title{
T-TY Tank Farm Interim Surface Barrier Demonstration-Vadose Zone Monitoring Plan
}

ZF Zhang CE Strickland

Pacific Northwest National Laboratory

JG Field DL Parker

Washington River Protection Solutions, Inc.

September 2010

Pacific Northwest NATIONAL LABORATORY

Proudly Operated by Battelle Since 1965 


\title{
DISCLAIMER
}

This report was prepared as an account of work sponsored by an agency of the United States Government. Neither the United States Government nor any agency thereof, nor Battelle Memorial Institute, nor any of their employees, makes any warranty, express or implied, or assumes any legal liability or responsibility for the accuracy, completeness, or usefulness of any information, apparatus, product, or process disclosed, or represents that its use would not infringe privately owned rights. Reference herein to any specific commercial product, process, or service by trade name, trademark, manufacturer, or otherwise does not necessarily constitute or imply its endorsement, recommendation, or favoring by the United States Government or any agency thereof, or Battelle Memorial Institute. The views and opinions of authors expressed herein do not necessarily state or reflect those of the United States Government or any agency thereof.

\author{
PACIFIC NORTHWEST NATIONAL LABORATORY \\ operated by \\ BATTELLE \\ for the \\ UNITED STATES DEPARTMENT OF ENERGY \\ under Contract DE-AC05-76RL01830
}

Printed in the United States of America

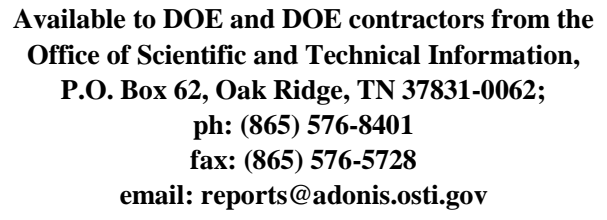

email: reports@adonis.osti.gov

\author{
Available to the public from the National Technical Information Service, \\ U.S. Department of Commerce, 5285 Port Royal Rd., Springfield, VA 22161 \\ ph: (800) 553-6847 \\ fax: (703) 605-6900 \\ email: orders@ntis.fedworld.gov \\ online ordering: http://www.ntis.gov/ordering.htm
}




\section{T-TY Tank Farm Interim Surface Barrier Demonstration-Vadose Zone Monitoring Plan}

ZF Zhang CE Strickland

Pacific Northwest National Laboratory

JG Field DL Parker

Washington River Protection Solutions, Inc.

September 2010

Prepared for

the U.S. Department of Energy

under Contract DE-AC05-76RL01830

Pacific Northwest National Laboratory

Richland, Washington 99352 



\section{Executive Summary}

The Hanford Site has 149 underground single-shell tanks that store hazardous radioactive waste. Many of these tanks and their associated infrastructure (e.g., pipelines, diversion boxes) have leaked. Some of the leaked waste has entered the groundwater. The largest known leak occurred from the T-106 Tank of the 241-T Tank Farm in 1973. Five tanks are assumed to have leaked in the TY Farm. Many of the contaminants from those leaks still reside within the vadose zone within the T and TY Tank Farms. The Department of Energy's Office of River Protection seeks to minimize the movement of these contaminant plumes by placing interim barriers on the ground surface. Such barriers are expected to prevent infiltrating water from reaching the plumes and moving them further. The soil water regime is monitored to determine the effectiveness of the interim surface barriers. Soil-water content and water pressure are monitored using off-the-shelf equipment that can be installed by the hydraulic hammer technique. Four instrument nests were installed in the T Farm in fiscal year (FY) 2006 and FY2007; two nests were installed in the TY Farm in FY2010. Each instrument nest contains a neutron probe access tube, a capacitance probe, and four heat-dissipation units. A meteorological station has been installed at the north side of the fence of the T Farm. This document summarizes the monitoring methods, the instrument calibration and installation, and the vadose zone monitoring plan for interim barriers in $\mathrm{T}$ farm and TY Farm. 



\section{Acronyms}

$\begin{array}{ll}\text { ARHCO } & \text { Atlantic-Richfield Hanford Company } \\ \text { CHG } & \text { CH2M Hill Hanford Group, Inc. } \\ \text { CP } & \text { Capacitance Probe } \\ \text { CSI } & \text { Campbell Scientific, Inc. } \\ \text { DOE } & \text { Department of Energy } \\ \text { FY } & \text { Fiscal year } \\ \text { HDU } & \text { Heat-dissipation unit } \\ \text { HMS } & \text { Hanford Meteorological Station } \\ \text { IAEA } & \text { International Atomic Energy Agency } \\ \text { ID } & \text { Inside Diameter } \\ \text { MCNP } & \text { Monte Carlo N-Particle Transport code } \\ \text { NP } & \text { Neutron Probe } \\ \text { OD } & \text { Outside Diameter } \\ \text { PMP } & \text { Project Management Plan } \\ \text { PNNL } & \text { Pacific Northwest National Laboratory } \\ \text { PVC } & \text { Polyvinyl chloride } \\ \text { QAP } & \text { Quality Assurance Plan } \\ \text { SDR } & \text { Standard Deviation Ratio } \\ \text { SST } & \text { Single-shell tank } \\ \text { WRPS } & \text { Washington River Protection Solutions }\end{array}$





\section{Contents}

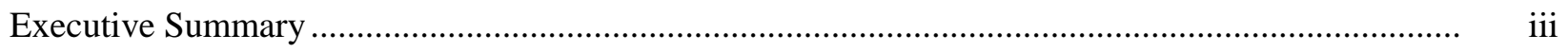

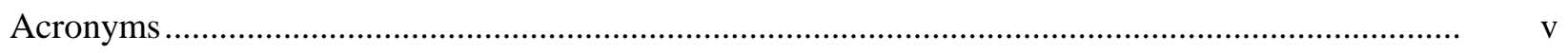

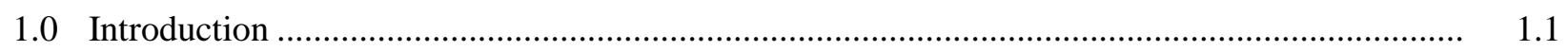

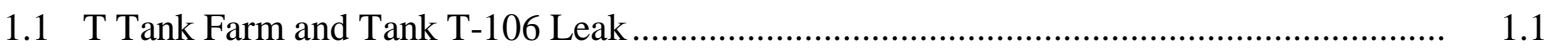

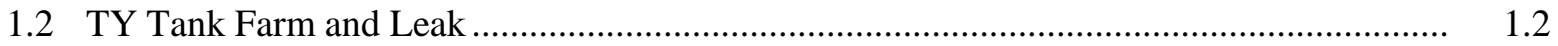

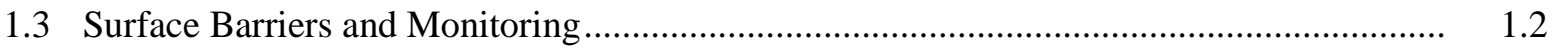

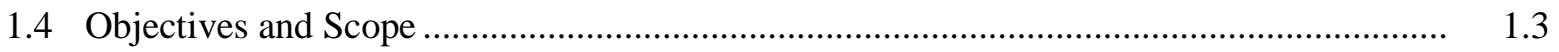

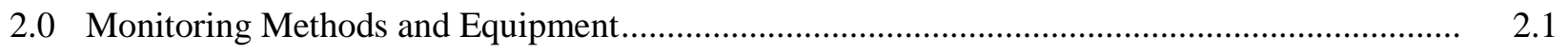

2.1 Soil Water and Environmental Variables ....................................................................... 2.1

2.2 Criteria for Method Selection..................................................................................... 2.1

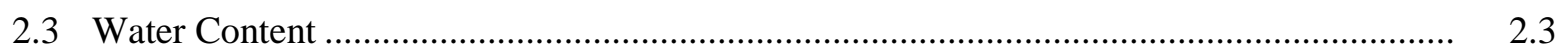

2.3.1 Neutron Probe Method .......................................................................................... 2.3

2.3.2 Capacitance Method.......................................................................................... 2.4

2.4 Soil-Water Pressure and Heat Dissipation Unit Method .................................................. 2.6

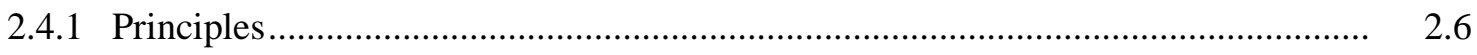

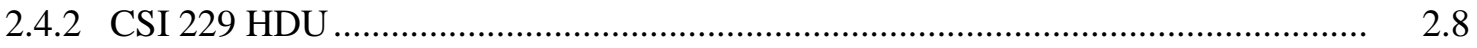

2.5 Precipitation and Air / Soil Temperature ................................................................... 2.8

2.6 Electric and Electronic Equipment...................................................................... 2.9

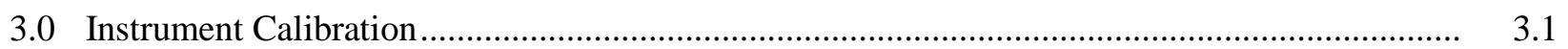

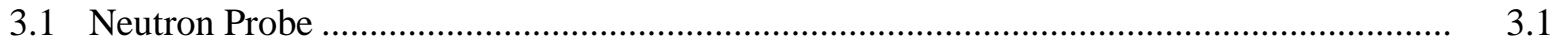

3.2 EnviroSMART Capacitance Probe …................................................................................

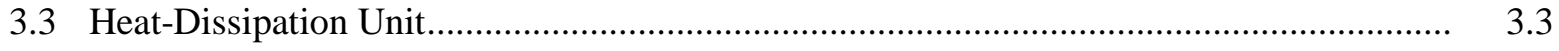

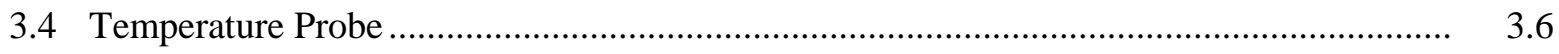

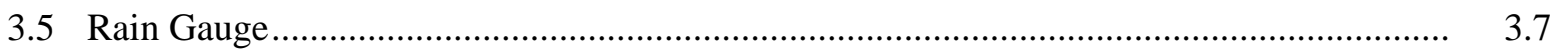

4.0 Instrument Layout and Installation................................................................................

4.1 Selection of Monitoring Locations...........................................................................

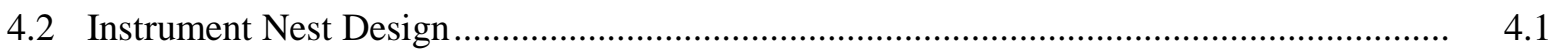

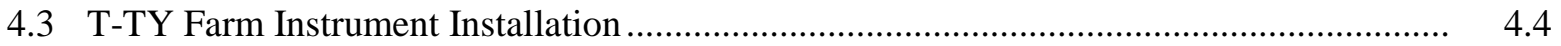

4.3.1 Neutron-Moisture-Probe Access Tubes .................................................................... 4.5

4.3.2 EnviroSMART Capacitance Probe ................................................................... 4.8

4.3.3 Heat-Dissipation Units ................................................................................. 4.12

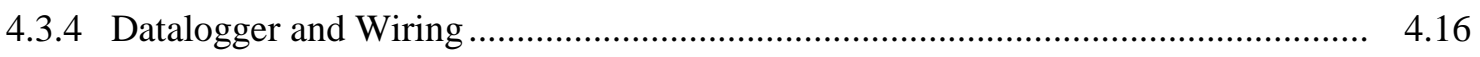

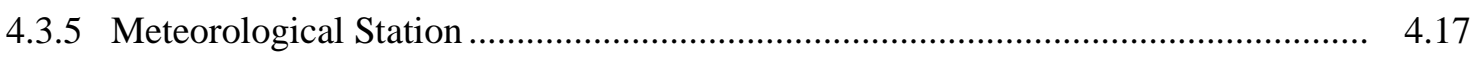

5.0 Vadose Zone Monitoring Plan........................................................................................... 5.1 
5.1 Measurement Procedures and Frequencies ............................................................. 5.1

5.2 Data Management .................................................................................................. 5.2

5.2.1 Raw Data Review and Archival ....................................................................... 5.2

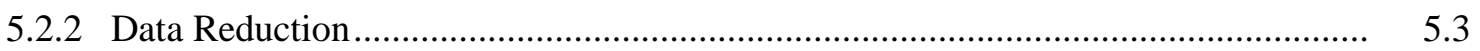

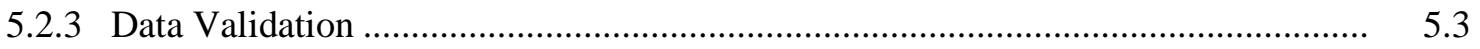

5.2.4 Data Analysis .................................................................................................... 5.3

5.3 Instrument Performance and Vadose Performance ......................................................... 5.4

5.3.1 Instrument Performance Indicators and Contingencies.......................................... 5.4

5.3.2 Vadose Zone Response Indicators ............................................................. 5.7

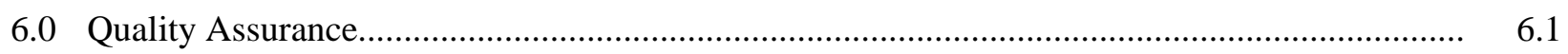

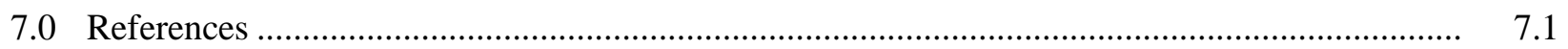

Appendix A: Normalization and Calibration Procedures for Heat Dissipation Unit (HDU)

Installed in the T Tank Farm .................................................................................. A.1

Appendix B: PNNL-SA-12 Calibration of Heat Dissipation Water Potential Sensor Using

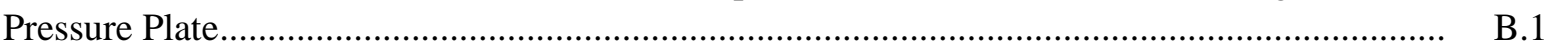

Appendix C: Raw Data of the TY Tank Farm HDU Normalization/Calibration .............................. C.1

Appendix D: Suggested Troubleshooting Procedures ............................................................... D. 1 


\section{Figures}

1.1. Location of $\mathrm{T}$ and TY Farms in 200 West Area .......................................................................

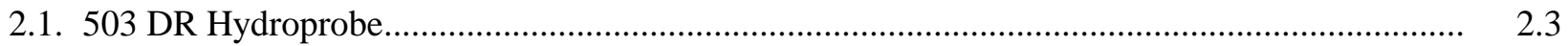

2.2. (a) EnviroSMART Probe; (b) Field Installation .........................................................................

2.3. A 229 Heat-Dissipation Matric Water Potential Sensor is Shown at the Top (the dashed line is in clear color)

3.1. Capacitance Probe Default Calibration................................................................................... 3.2

3.2. HDU Calibration Data Points and Calibration Relationship .................................................... 3.4

4.1. Plan View of T TY Tank Farm with the Approximate Locations of Monitoring Nests TA, TB, TC, TD, TYA and TYB and Approximate Interim Surface barrier Boundary as Marked by the Blue Lines.

4.2. Hydraulic Hammer Used to Install Instruments in the T Tank Farm (Photo taken in the summer of 2006).

4.3. Cone-Tipped Drive Shaft Used in Conjunction with a Hydraulic Hammer for Creating Driving Boreholes (Photo taken in the summer of 2006)

4.4. Diagram of the Installed Neutron Probe Access Tubes and Installation Procedures for Nests TA and TB

4.5. Diagram of the Installed Neutron Probe Access Tubes and Installation Procedures for Nests TC and TD

4.6. Diagram of the Installed Neutron Probe Access Tubes and Installation Procedures for Nests TYA (station \#2) and TYB (station \#1).

4.7. Capacitance Probe Cap and Protective Casing at Instrument Nest TB Before Filling With Tank Farm Surface Material.

4.8. Typical Instrument Surface Completion Showing Outer 24-In.-Diameter Corrugated Metal Pipe Sleeving and Inner Steel Casing (Nest TA; photo taken in the winter 2008; snow can be seen on the ground)

4.9. Diagram of the Installed Capacitance Probe Access Tubes in Nests TA and TB and Installation Procedures.

4.10.Diagram of the Installed Capacitance Probe Access Tubes for Nests TC and TD.

4.11.Diagram of the Installed Capacitance Probe Access Tubes for Nests TYA (station \#2) and TYB (station \#1).

4.12.Protective Casing Over the HDU Location at Instrument Nest TB (Photo taken in the summer of 2006)

4.13.Diagram of the Installed HDUs in Nests TA and TB and Packing Material Layering Scheme...

4.14.Diagram of the Installed HDUs and Packing Material Layering Scheme for Nests TC and TD.

4.15.Diagram of the Installed HDUs for Nests TYA (station \#2) and TYB (station \#1) 
4.16.Instrument Nest TB Tripod with Attached Solar Panel, Datalogger Enclosure, and Transfer Box

4.17. Meteorological Station Tripod with Attached Solar Panel, Datalogger Enclosure, Rain Gauge, and Temperature Sensor......

4.18.Wiring Diagram for $\mathrm{T}$ Tank Farm Instrument Nests and Meteorological Station

4.19.Wiring Diagram for TY Tank Farm Instrument Nests

5.1. Monitoring Components, Instrumentation, and Data Collection and Management Flow Diagram . 


\section{Tables}

2.1. Criteria For Selecting Alternative Vadose Zone Monitoring Methods...................................... 2.2

2.2. Selected Methods to Monitor Meteorological Conditions and Selection Rationale .................... 2.9

2.3. Electric and Electronic Equipment and their Function ............................................................. 2.9

3.1. Neutron Calibration Curve for the 2.5-In. Steel Casings ..............................................................

3.2. Capacitance Sensor Frequency Response in Air and Water ..................................................... 3.2

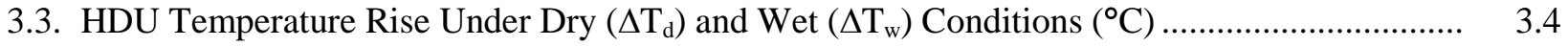

3.4. Rain-Gauge-Function Verification Results..........................................................................

4.1. Vadose Zone Monitoring Driving Boreholes Coordinates Associated Installed Instruments ...... 4.2

4.2. Instrument Vertical Placement.....................................................................................................

5.1. Data Collection Method and Approximate Frequency Under Normal Working Condition......... 5.1

5.2. Instrument Performance Indicators.............................................................................................. 5.5 



\subsection{Introduction}

The Hanford Site in southeastern Washington State has 149 underground single-shell tanks (SSTs) that store hazardous radioactive waste. Many of these tanks and their associated infrastructure (e.g., pipelines, diversion boxes) have leaked. Some of the leaked waste has entered the groundwater. The largest known leak occurred from the T-106 Tank of the 241-T Tank Farm (T tank farm) in 1973. Five tanks are assumed to have leaked in the 241-TY Tank Farm (TY tank farm). Many of the contaminants from the leaks still reside within the vadose zone within the T and TY tank farms. The Department of Energy's (DOE's) Office of River Protection seeks to minimize movement of these residual contaminant plumes by placing interim barriers on the ground surface. This monitoring plan is prepared to guide the monitoring program and will replace a previous prepared monitoring plan (Zhang et al. 2007). The location of the T and TY tank farms is shown in Figure 1.1.

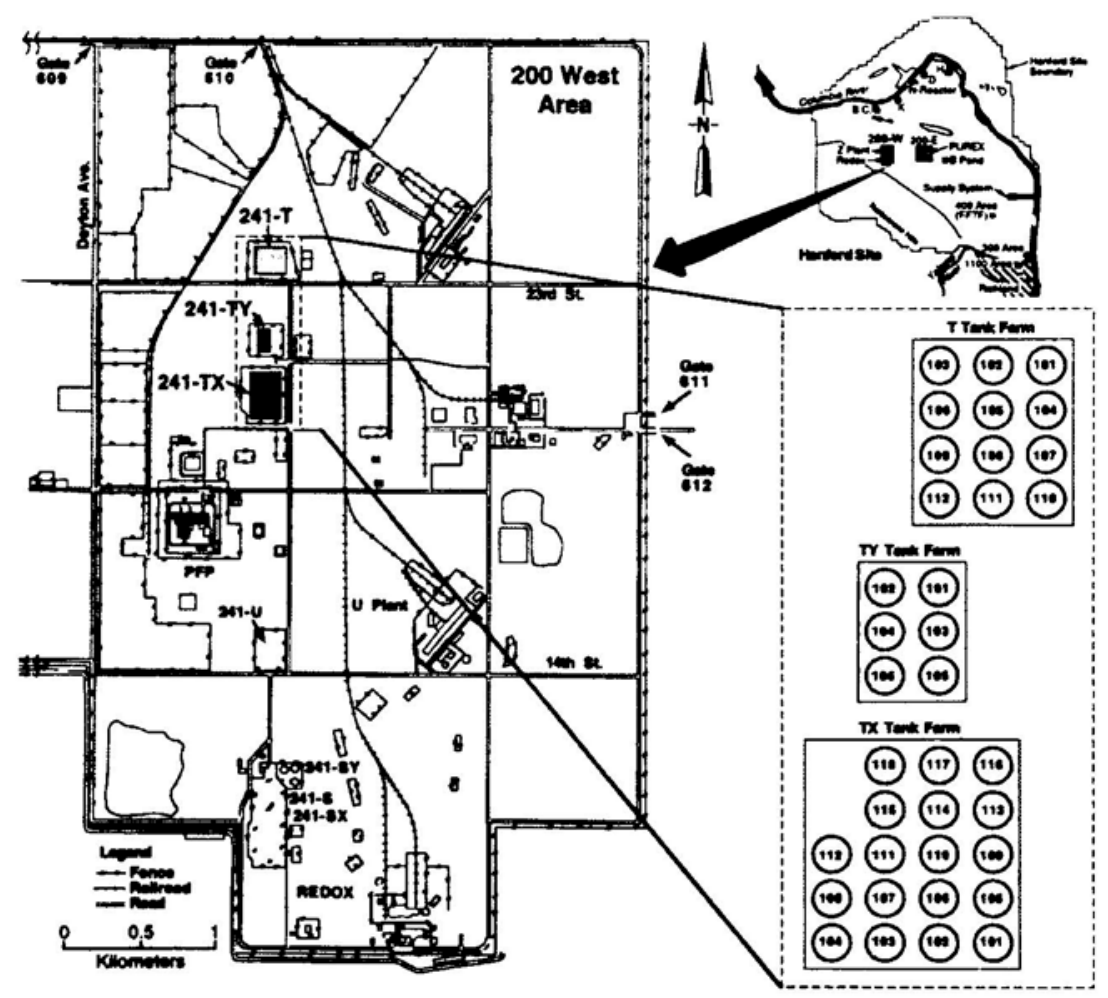

Figure 1.1. Location of $T$ and TY Farms in 200 West Area (from RPP-23752, CHG 2005)

\subsection{T Tank Farm and Tank T-106 Leak}

According to Myers (2005), the T tank farm was built from 1943 to 1944. The T tank farm contains 12 SSTs with a diameter of $23 \mathrm{~m}$ (75 ft) and a capacity of 2,006,050 L (530,000 gal), four SSTs with a

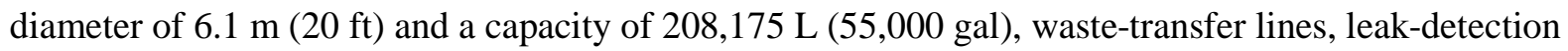
systems, and tank ancillary equipment. The soil cover from the apex of the tank domes to the ground surface is approximately $2.2 \mathrm{~m}(7.3 \mathrm{ft})$. All the tanks have a dish-shaped bottom. 
In general, the vadose zone in the $\mathrm{T}$ tank farm, from groundwater table to ground surface, consists of a portion of the thick, relatively coarse-grained sediments of the middle Ringold Formation overlain by the finer grained sediments of the upper Ringold Formation and the Plio-Pleistocene unit (also called the Cold Creek Unit), overlain by the coarser grained sands and gravels of the Hanford formation, which are

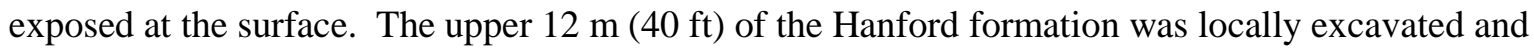
backfilled with gravelly sand when the SSTs were installed.

An accidental leak from Tank T-106 occurred in 1973; the details and chronology of the leak are well documented (ARHCO 1973, Routson et al. 1979). The leak was suspected to have started on April 20, 1973, during a routine filling operation. The leak stopped on June 10,1973, when the free liquid contents of the tank were removed. The total duration of the leak was estimated to be 51 days. Approximately 435,000 L (115,000 gal) of fluid leaked from Tank T-106. The fluid contained cesium-137, strontium-90, plutonium, and various fission products, including technetium-99. It is likely that the leak occurred in the southeast quadrant of the tank near the bottom of the tank.

\subsection{TY Tank Farm and Leak}

The TY tank farm was built in 1952 and contains six SSTs with a diameter of $23 \mathrm{~m} \mathrm{(75} \mathrm{ft)} \mathrm{and} \mathrm{a}$ capacity of 2.87 million L (0.758 million gal), waste-transfer lines, leak-detection systems, and tank ancillary equipment. The soil cover from the apex of the tank domes to the ground surface is approximately $2.4 \mathrm{~m}(8 \mathrm{ft})$. The vadose zone in the TY tank farm is composed of three major layers, which are, from groundwater table to ground surface, a portion of the relatively coarse-grained sediments of the middle Ringold Formation overlain by the finer-gained sediments of the upper Ringold Formation and the Plio-Pleistocene units, overlain by the coarse-grained sand and gravel of the Hanford formation. The upper $12 \mathrm{~m}$ (40 ft) of the Hanford formation was locally excavated and backfilled with gravelly sand when the tanks were installed, which was the same as the T tank farm.

Five of the six SSTs in the TY tank farm are assumed to have leaked about 228,600 L (60,400 gal) of mixed-radioactive waste into the vadose zone (Rodgers 2010).

\subsection{Surface Barriers and Monitoring}

The construction of an interim surface barrier using felt with a polyurea coating was completed in the $\mathrm{T}$ tank farm in April 2008. The construction of a modified asphalt interim surface barrier over the contaminant plume within the TY farm was completed in August 2010.

It is expected that the interim barriers will prevent the meteoric water from entering soil and consequently reduce the rate of downward movement of flow and dissolving contaminants. At shallower depths, there will be no water supply from above to replace the draining water, and hence, the drainage rate will decrease more quickly. At larger depths, the soil will keep receiving drainage from the soil above for some time, and the drainage rate will decrease relatively more slowly. Therefore, it may take a very long time (e.g., years) for drainage rates deep in the profile to reduce significantly. As the soil below the surface barrier becomes drier, the soil in the uncovered region near the vertical plane directly beneath the barrier edge will also become drier than would be the case if there would be no surface barrier. 
In fiscal year (FY) 2006 and FY2007, four instrument nests were installed by the hydraulic hammer technique in the T tank farm. In FY2010, two instrument nests were installed in the TY tank farm using the same technique. The soil-water content $(\theta)$, water pressure $(\psi)$, and temperature (T) were monitored using a neutron probe (NP), capacitance probes (CPs), and heat-dissipation units (HDUs). Each instrument nest contains an NP access tube and a CP with five sensors (to measure $\theta$ ), and four HDUs (to measure $\psi$ and $\mathrm{T}$ ).

\subsection{Objectives and Scope}

Subsurface monitoring is integral to achieving acceptance of the surface barriers. The subsurface water conditions are monitored to verify the impacts of the interim surface barriers in the T and TY tank farms on the soil-moisture regime.

This monitoring plan updates the previous monitoring plan by including any updates of the $\mathrm{T}$ tank farm and the monitoring system in the TY tank farm. After a brief introduction of the background information in Section 1, Section 2 presents the principles of relevant measurement methods as guidance for equipment calibration. In Section 3, equipment normalization/calibration or verification methods and results are presented. Section 4 summarizes the installation of the instrument nests. Section 5 presents the schedule of data collection, data validation and analysis, contingencies given instrument failure, and data reporting. Section 6 provides a declaration about the quality assurance plan to verify the quality of the work. 



\subsection{Monitoring Methods and Equipment}

This section describes the criteria used to select the various measurement methods, the principals of selected methods, and the description of the selected instruments.

\subsection{Soil Water and Environmental Variables}

Variables to be monitored are chosen based on their contribution to describing soil-water flux conditions. Principal variables monitored are soil-moisture content and soil-water pressure (aka soil matrix potential or soil water potential). The soil-water content ranges between zero and the porosity of the soil. The soil matrix potential is of primary importance in determining the state and movement of water in the soil. Differences in the soil-water hydraulic head between one point and another give rise to the tendency of water to flow within the soil. The soil-water pressure in the vadose zone is often negative because of the suction of soil particles on water. Unless the soil is very dry, the pressure head generally varies logarithmically with water content from zero when the soil is fully saturated to a few bars (negative pressure) when soil drainage has effectively ended. Both soil-water content and pressure describe the static state of soil water. The reasons for monitoring two types of variables are summarized below.

- Each variable reflects one aspect of the soil-moisture regime. The soil-water content shows the actual moisture contained in the soil. The soil matrix potential describes the energy level of the soil water.

- The magnitudes of changes for water content and pressure head are different under different conditions. On the one hand, the change of water content can be measured more easily than the change of pressure head under relatively wet conditions. On the other hand, the change of pressure head can be measured more easily than the change of water content under relatively dry conditions.

The soil-water flux describes the dynamic state of soil water, showing how fast soil water moves. The transport velocity of the dissolving solute is directly related to soil-water flux. However, due to very small values, especially in arid regions (e.g., on the order of a few to a few tens of mm/yr at Hanford), the measurement is often difficult. If possible, this variable should be monitored along with soil-water content and pressure. Two soil-water flux meters were installed in the T tank farm. However, they did not seem to apply to the soil at the surface of the tank farms (Zhang et al. 2008).

Secondary variables monitored include soil temperature and meteorological conditions, including precipitation and air temperature. The measured precipitation is used to estimate the total volume of water intercepted by the surface barrier.

\subsection{Criteria for Method Selection}

Table 2.1 illustrates criteria for selecting monitoring methods that were modified from criteria described by Everett et al. (1984). The criteria provide for a systematic way of determining which monitoring technologies best serve the given objectives. Because of restrictions of working within the $\mathrm{T}$ and TY tank farms, considerable attention was given to potential installation problems and constraints when selecting methods. Furthermore, only probes commercially available may be used to ensure the quality of the monitoring results. For example, the segmented time-domain reflectometry probe was excluded from measuring water content because of the significant impacts of temperature on probe 
response and impacts of cable length on signal strength; therefore, this probe was eliminated. The conepenetrometer was eliminated from measuring the soil-water pressure head because of its possible insufficient strength in gravelly soil. The advanced tensiometer was excluded because it is not commercially available. While the selected technologies may not meet all criteria, they do encompass the majority of criteria presented.

Table 2.1. Criteria For Selecting Alternative Vadose Zone Monitoring Methods

\begin{tabular}{|c|c|c|c|c|}
\hline Item & Criteria & $\begin{array}{l}\text { Neutron } \\
\text { Probe }\end{array}$ & $\begin{array}{c}\text { Capacitance } \\
\text { Probe } \\
\end{array}$ & HDU \\
\hline 1 & Applicability to Tank Farm & Yes & Yes & Yes \\
\hline 2 & Measurement accuracy & $\pm 0.016 \mathrm{~m}^{3} \mathrm{~m}^{-3(\mathrm{a})}$ & $\pm 0.03 \mathrm{~m}^{3} \mathrm{~m}^{-3(\mathrm{~b})}$ & $\begin{array}{c} \pm 20 \%^{(\mathrm{c})} \\
\pm 0.25^{\circ} \mathrm{C}^{(\mathrm{d})}\end{array}$ \\
\hline 3 & Measurement range & Zero to full saturation & Zero to full saturation & $\begin{array}{l}-0.1 \operatorname{bar}(-1 \mathrm{~m}) \text { to }-10 \\
\quad \operatorname{bar}(-100 \mathrm{~m})^{(\mathrm{e})}\end{array}$ \\
\hline 4 & Representative volume & $\sim 0.04$ to $\sim 0.7^{(\mathrm{f})} \mathrm{m}^{3}$ & $\sim 0.002^{(\mathrm{g})} \mathrm{m}^{3}$ & $1.1 \mathrm{E}-5^{(\mathrm{h})} \mathrm{m}^{3}$ \\
\hline 5 & Limitations & Cannot be automated & $\begin{array}{l}\text { Difficult to install for } \\
\text { large depth }\end{array}$ & $\begin{array}{l}\text { Difficulty to replace } \\
\text { once in place }\end{array}$ \\
\hline 6 & Cost & High & Medium & Low \\
\hline 7 & $\begin{array}{l}\text { Potential installation } \\
\text { problem }\end{array}$ & Bending access tube & $\begin{array}{l}\text { Inappropriate } \\
\text { refilling of annulus }\end{array}$ & Bad soil-sensor contact \\
\hline 8 & $\begin{array}{l}\text { Data collection system/wire } \\
\text { length effects }\end{array}$ & Manual/ No & $\begin{array}{l}\text { Automated/ } \\
\text { No }\end{array}$ & $\begin{array}{l}\text { Automated/ } \\
\text { Negligible }\end{array}$ \\
\hline 9 & $\begin{array}{l}\text { Continuous or discrete } \\
\text { sampling }\end{array}$ & Discrete & Continuous & Continuous \\
\hline 10 & Maintenance requirements & Minor & Medium & Minor \\
\hline 11 & $\begin{array}{l}\text { Effect of hazardous waste on } \\
\text { measurement }\end{array}$ & No & No & No \\
\hline 12 & Power requirements & Battery & Battery & Battery \\
\hline 13 & Multiple use capabilities & No & No & Yes \\
\hline 14 & Other concerns & Radiological Exposure & $\begin{array}{l}\text { Potential corrosion of } \\
\text { sensors or ports over } \\
\text { time }\end{array}$ & No \\
\hline \multicolumn{5}{|c|}{$\begin{array}{l}\text { (a) D Carter, CPN International, Inc., personal communication, May 24, } 2006 . \\
\text { (b) Campbell Scientific, Inc. (CSI 2007). } \\
\text { (c) Calibration dependent. Accuracy value taken from Reece (1996). } \\
\text { (d) J Ritter, CSI, personal communication, June 2, } 2006 . \\
\text { (e) Reece (1996). } \\
\text { (f) Calculated based on the information from the International Atomic Energy Agency (IAEA 1970). } \\
\text { (g) Calculated based on the information from the user's manual (CSI 2009a). } \\
\text { (h) This is the volume of the HDU. }\end{array}$} \\
\hline
\end{tabular}

Based on the criteria in Table 2.1, equipment such as a neutron probe, capacitance probes, and HDUs are used to monitor the flow regime. A rain gauge is also installed to more accurately record precipitation, especially for storms. All the equipment except the neutron probe is connected to data loggers that remotely transmit data to a computer. The following sections describe the principle of each method and specific equipment chosen. 


\subsection{Water Content}

Moisture content as a function of depth is measured to monitor the impacts of the interim surface barrier in reducing water flux from baseline conditions. Soil-water measurements are used to track wetting and drying processes and produce estimates of water fluxes using available soil-water potential data and soil hydraulic properties. Two methods, neutron moisture probe and capacitance probe, are used to monitor absolute or relative soil-moisture content. This affords the benefit of providing certain data through redundancy while at the same time offering advantages presented by each method. Additionally, both methods provide the accuracy (Table 2.1) needed to capture the predicted changes in soil-moisture content after the interim surface barrier is in place.

\subsubsection{Neutron Probe Method}

\subsubsection{Principles}

Neutron thermalization, as a method to measure soil-water content, uses a radioactive source of fast neutrons (mean energy of $5 \mathrm{MeV}$ ) and a detector of slow neutrons ( $\sim 0.025 \mathrm{eV})$. High-energy neutrons emitted from the source are either slowed through repeated collisions with the nuclei of atoms in the soil (scattering) or are absorbed by those nuclei. The most common atoms in soil (Al, $\mathrm{Si}$, and $\mathrm{O}$ ) scatter neutrons with little energy loss. If the neutron hits an $\mathrm{H}$ atom, its energy is reduced on average to about half because the mass of the $\mathrm{H}$ nucleus is the same as that of the neutron. The concentration of thermal neutrons changes mainly with the $\mathrm{H}$ content of the surrounding material, while changes in $\mathrm{H}$ content occur mainly because of changes in soil-water content. Therefore, the concentration of thermal neutrons surrounding a neutron source placed in the soil can be precisely related to the soil volumetric water content.

A profiling type neutron moisture meter

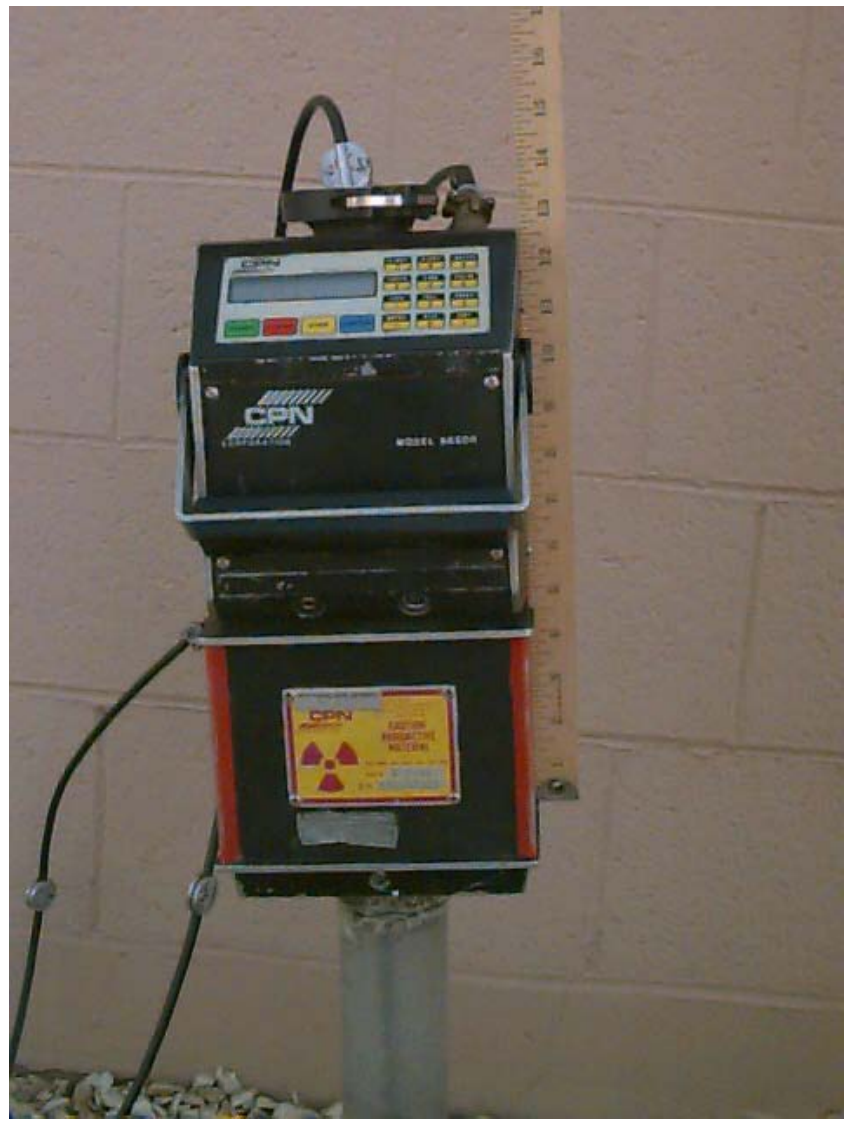

Figure 2.1. 503 DR Hydroprobe has a readout and control unit connected by cable to a cylindrical probe that is lowered into a borehole that is usually cased with an access tube. The probe is lowered into the tube and stopped at intervals to measure the thermal neutron concentration at that depth. The measurement volume is approximately a sphere with a radius of about $0.15 \mathrm{~m}$ in a wet clay soil and up to $0.5 \mathrm{~m}$ if the water content declines to $0.02 \mathrm{~m}^{3} \mathrm{~m}^{-3}$ (van Bavel et al. 1956). 


\subsubsection{Neutron Probe}

Any type of neutron probe that has been calibrated can be used to measure soil-water content. An example is the 503DR hydroprobe (Figure 2.1) manufactured by CPN International, Inc. (Martinez, CA). The 503DR hydroprobe has a history of successful use at Hanford and is currently used for a number of Hanford waste site, soil-moisture monitoring programs (DOE 2005, Ward et al. 2000). The probe includes a 50-mCi americium-241 and beryllium source and a neutron detector. The 16-sec neutron counts are recorded at different depths of 1-ft intervals. The hydroprobe should be operated according to approved procedures, for example, the "Tank Farm Plant Operating Procedure-Operate Model 503DR Hydroprobe Neutron Moisture Detection” (Ross 2007).

\subsubsection{Capacitance Method}

Capacitance, as an electromagnetic method to measure soil-water content, was introduced in the 1930s (Smith-Rose 1933) and developed rapidly with recent advances of microelectroncs in the 1990s (Paltineanu and Starr 1997). According to Starr and Paltineanu (2002), positive features of capacitance probes include robust and stable instrumentation, fast response times, accuracy with good soil-probe contact, ease of use, safety, availability of several sensor configurations, and amenability to automatic and continuous logging over large areas (up to 500-m radius).

\subsubsection{Principles}

To measure the soil-water content, the capacitance method uses the soil surrounding the electrodes as part of a capacitor in which the dipoles of water in the soil become polarized in response to the frequency of an imposed electric field. Capacitance probes consist of a capacitor connected to circuitry that oscillates at a frequency $(\mathrm{F})$ that is dependent on the inductance $(\mathrm{L})$ of an inductor and the total capacitance $(\mathrm{C})$ of the electrode-soil system. For a given probe, the value of $\mathrm{L}$ is constant, and the value of $\mathrm{C}$ is related to the bulk dielectric constant $\left(\varepsilon_{\mathrm{ra}}\right)$ of the surrounding soil:

$$
C=g \varepsilon_{r a}
$$

where $\mathrm{g}$ is a geometrical constant based on the electrode configuration (size, shape, and distance between electrodes). The output of the capacitance probe is the oscillation frequency, which is an inverse square root function of the total capacitance:

$$
F=(2 \pi \sqrt{L C})^{-1}=\left(2 \pi \sqrt{g L \varepsilon_{r a}}\right)^{-1}
$$

The bulk dielectric constant, $\varepsilon_{\text {ra }}$, is a function of volumetric soil water content, and so is the total capacitance of the soil. Hence, oscillation frequency is also a function of soil-water content.

The probe geometric constant, g, is often instrument-dependent. For one calibration equation to cover all the sensors and to allow one sensor or probe to be replaced at the same field position without loss of data continuity, a normalization process is used to minimize instrument-dependent readings. For cylindrical sensors, a scaled frequency $\left(\mathrm{S}_{\mathrm{f}}\right)$ is calculated by incorporating the raw-frequency reading in soil $(F)$ with frequency readings in air $\left(F_{a}\right)$ and in water $\left(F_{w}\right)$ (Paltineanu and Starr 1997): 


$$
S_{f}=\frac{F_{a}-F}{F_{a}-F_{w}}
$$

The relationship between $\mathrm{S}_{\mathrm{f}}$ and soil-water content can be determined empirically. Sentek Pty Ltd (2001) calibrated the capacitance using a power function:

$$
\theta_{v}=\left(\frac{S_{f}-c}{a}\right)^{\frac{1}{b}}
$$

where a, b, and c are constants.

The zone of influence has both axial (vertically along the sensor) and radial (perpendicular to the sensor) components. The extent and shape of the primary zone of influence is largely dependent on the sensor geometry. Paltineanu and Starr (1997) found the axial zone of influence to be $\pm 5 \mathrm{~cm}$, centered at the plastic ring between the two metal rings, and the radial zone of influence to be primarily within $10 \mathrm{~cm}$ of the access pipe. Both axial and radial sensitivities were affected by soilwater content and scaled frequency. This suggests the importance of good probe installation.

\subsubsection{EnviroSMART Soil-Water Content Profile Probes}

The capacitance probe to be used is a profile-type probe distributed by Campbell Scientific, Inc. (Logan, UT). It is called an EnviroSMART probe (CSI 2007, 2009a) and is made by Sentek Pty Ltd (Stepney,

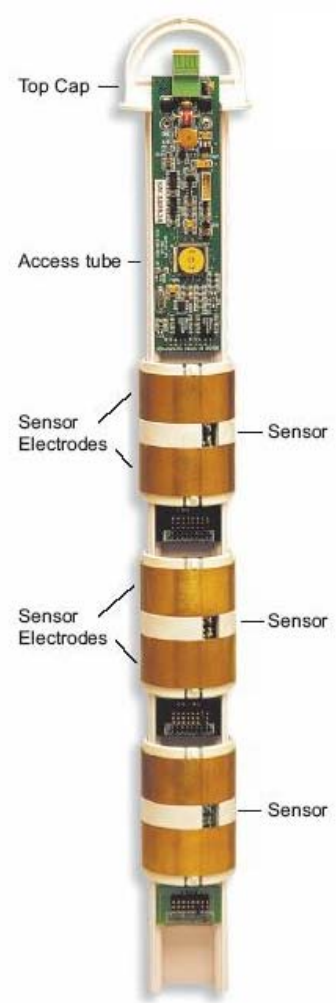

(a)

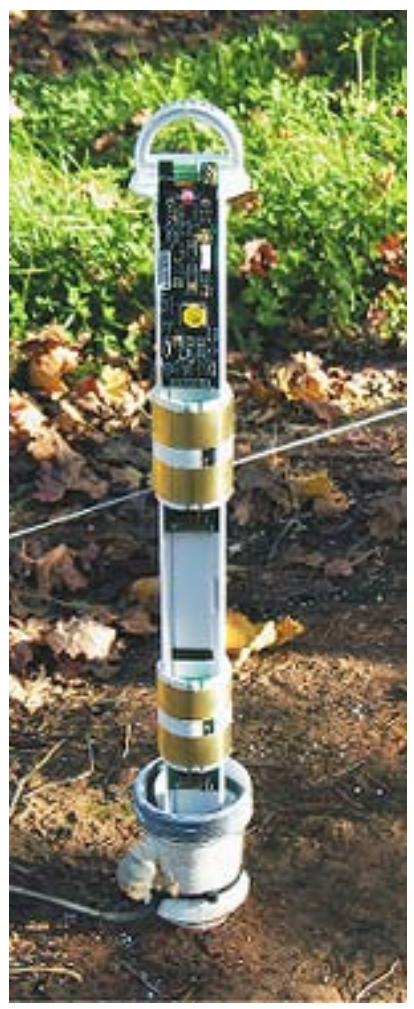

(b)

Figure 2.2. (a) EnviroSMART Probe;

(b) Field Installation

Australia). It consists of a probe with several independent sensors and an access tube (Figure 2.2).

\section{EnviroSMART Probe:}

- Multiple sensors with flexible depth placement (10-cm increments)

- Can monitor from shallow depths (0 to $10 \mathrm{~cm}$ ) to deep installations (up to 30 meters)

- Length of EnviroSMART probe can be customized to suit a wide range of applications

- Up to 16 sensors per probe 
- In-built probe orientation and depth settings to increase sensor repeatability

- A range of connectivity for integration is available, including SDI-12, voltage output, current output, RS-485 (Modbus), and RS-232 (Modbus).

Access Tube:

- Customized access tube increases sensor accuracy

- Sensors have no direct contact with the soil

- Specially sealed to guarantee long-term operation

- No preferential path flow of water alongside the probe body

- Probe and sensors are readily accessible and serviceable without destroying the site

- Easily change sensor configuration

- Minimized soil and root disturbance.

\subsection{Soil-Water Pressure and Heat Dissipation Unit Method}

Soil-water-pressure measurements can be used to track wetting or drying processes, identify pressure gradients, and produce estimates of water fluxes using available soil-water-pressure data and soil hydraulic properties.

An HDU can be used to indirectly measure the soil water-pressure (h) by measuring the thermal conductivity (k) of the reference matrix, which is part of an HDU and often is made of porous ceramics. The water content of the ceramic matrix $\left(\theta_{\mathrm{vc}}\right)$ changes with the matric potential of the ceramic matrix $\left(\mathrm{h}_{\mathrm{c}}\right)$ and causes a corresponding change in $\mathrm{k}$. Because the equilibrium between the sensor and the soil is a matric potential (i.e., $h_{s}=h_{c}$ ) rather than a water-content equilibrium, the measured thermal conductivity of the reference matrix is related to the matric potential of the soil. HDU measurement and calibration are independent of soil texture because the heat pulse is restricted to the ceramic. It is also independent of salinity because the method is independent of electrical conductivity.

\subsubsection{Principles}

HDUs consist of a heater and a temperature sensor in a porous matrix material. The HDU is heated for a fixed time period. The rate of heat dissipation is controlled by the water content of the porous matrix because water conducts heat much more readily than air. The temperature increase measured by the temperature sensor at time $t$ represents the heat that is not dissipated at this time. The time dependence of temperature, $\mathrm{T}$, in a line heat source buried in an infinite medium can be approximated by Shiozawa and Campbell (1990):

$$
T-T_{0}=\frac{q}{4 \pi k} \ln \left(t-t_{0}\right)
$$

where $\mathrm{T}_{0}$ is the initial temperature, $\mathrm{q}$ is the heat input, and $\mathrm{t}_{0}$ is an offset time. The heat dissipation is generally determined as the difference between two temperatures, one measured after 1 seconds of 
heating and the other measured after a heating time that can vary from 20 to 30 seconds (CSI HDUs). Whatever time period is chosen for laboratory calibration should also be used for field monitoring.

It is critical to maintain good hydraulic contact between sensors and surrounding soil in the field. However, good contact may be difficult to attain in very coarse sediments, such as gravel. Wet silica flour is often used during installation to confirm that there is good contact between the sensor and surrounding soil. Fredlund et al. (2000) found that HDUs do not provide reliable matric-potential measurements in freezing or thawing soils because the voltage drops as a result of the effect of the latent heat of fusion on thermal conductivity. However, freeze-thaw cycles did not affect the capability of HDUs to function upon return to normal conditions.

The heat-dissipation method as currently applied requires constant power dissipation at the heating element. A constant voltage source cannot be used in place of a constant current source because there is a voltage drop in the cable. Thus, if a voltage source were used, different calibrations for sensors with different cable lengths would be required. Variation in applied power during measurement or between measurements will cause the temperature increase to change, thus introducing an error in application.

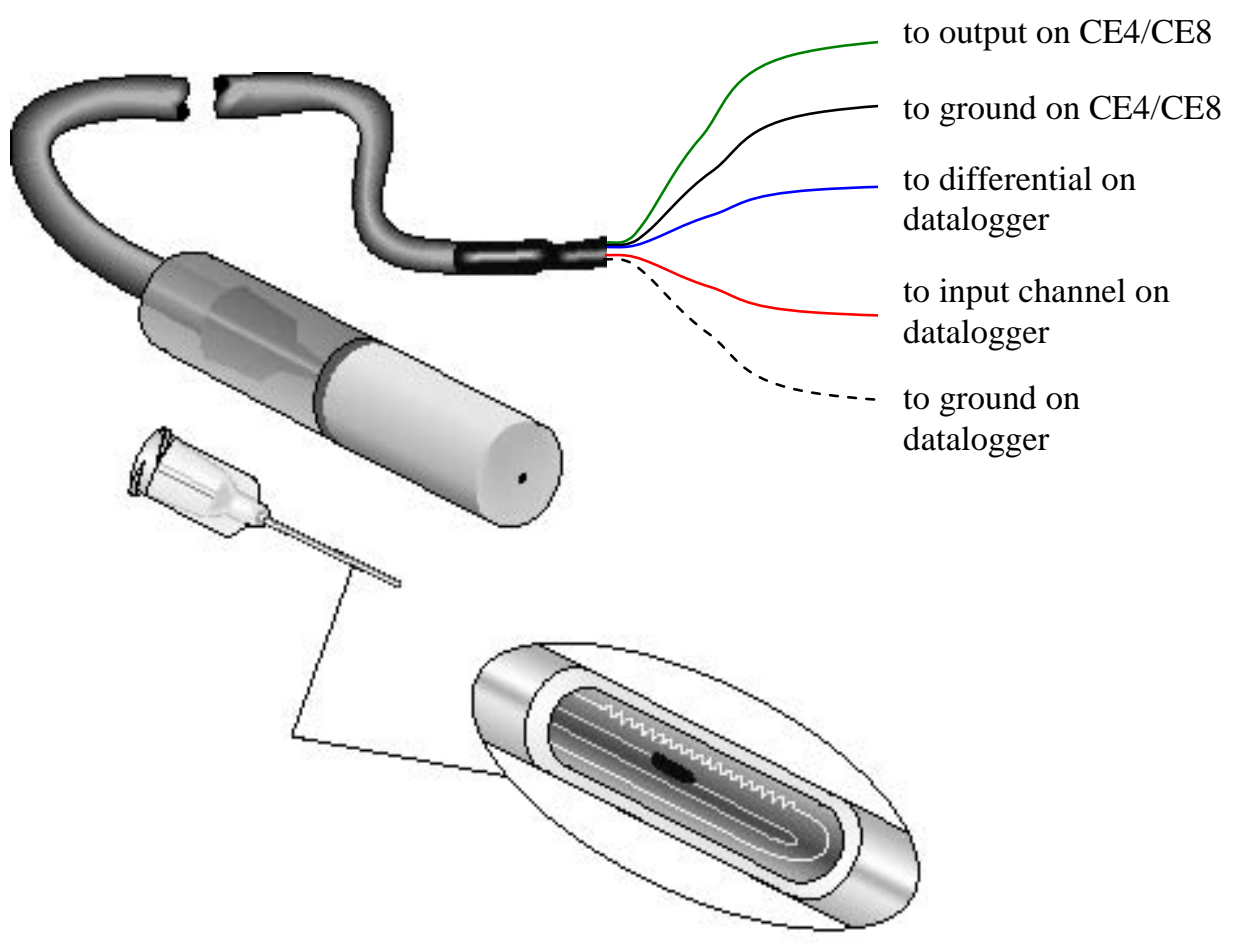

Figure 2.3. A 229 Heat-Dissipation Matric Water Potential Sensor is Shown at the Top (the dashed line is in clear color). The hypodermic assembly (without epoxy and ceramic) is shown just below. A cutaway view shows the longitudinal section of the needle with the heater and thermocouple junction. 


\subsubsection{CSI 229 HDU}

The HDU to be used is made by Campbell Scientific, Inc. and is called the " 229 Heat Dissipation Matric Water Potential Sensor” (Figure 2.3). The sensor has a cylindrically shaped porous ceramic body. A heating element that has the same length as the ceramic body is positioned at the center of the cylinder. A thermocouple is located at mid-length of the ceramic and heating element. The position of the heating element and the thermocouple is maintained by placing both inside a hypodermic needle, which also protects the delicate wires. The volume inside the needle, which is not occupied by wiring, is filled with epoxy.

HDUs provide affordable measurements of soil matric potential and also the added benefit of measuring soil temperature. The size of a single HDU is also a benefit, with the CSI HDU (Model 299) dimensions being $1.5 \mathrm{~cm}$ in diameter and $6 \mathrm{~cm}$ in length.

Using the 229 HDU sensor requires a power source that is a constant current source. This can be achieved by using CSI's CE4 or CE8 current excitation modules, which provide regulated outputs of $50 \pm 0.25 \mathrm{~mA}$. The $L$ option on the model 229 sensor indicates that the cable length is user specified. The 229 sensor is compatible with the 21X, CR7, CR10(X), CR23X, CR800, CR1000, and CR3000 dataloggers.

\subsection{Precipitation and Air / Soil Temperature}

Precipitation and air temperature are continuously monitored at a single meteorological station. Monitoring precipitation directly at the tank farms is useful in determining the total amount of meteoric water and the amount of water intercepted by the surface barrier. Localized thunderstorms that occasionally occur at Hanford produce spatially variable short-term, high-energy precipitation events. Such events require a local meteorological monitoring station to document potential localized precipitation events. Site-specific measurement of precipitation is used to assess the quantity of precipitation intercepted by the barrier.

Power requirements necessary for a heated rain gauge necessitated that the rain gauge not be heated because there is no AC power in the tank farms. As such, the rain gauge may not accurately measure precipitation during periods of snowfall. Given the proximity of the Hanford Meteorological Station (HMS) and the uniformity of snowfall across the Hanford Site, it is acceptable to conclude that snowfall measured by the HMS will approximately describe the snowfall at the tank farms. Table 2.2 gives the manufacturer's documented instrument accuracy along with summarizing the rationale for using the chosen monitoring method.

The soil temperature is measured and recorded during set time intervals at various locations. Measuring the soil temperature provides information on soil-temperature gradients that may contribute to liquid water and vapor movement in the subsurface. Automated soil-temperature measurements are made using HDUs, which provide measurements of both soil temperature and soil-water pressure. HDUs provide an efficient method to measure soil temperature, given that they have already been used for measuring soil-water pressure. 
Table 2.2. Selected Methods to Monitor Meteorological Conditions and Selection Rationale

\begin{tabular}{cccc}
\hline $\begin{array}{c}\text { Selected Monitoring } \\
\text { Method(s) }\end{array}$ & Manufacturer & Accuracy & Rationale \\
\hline Rain gauge & Texas Electronics & $\pm 1 \%{ }^{(\mathrm{a})}$ & $\begin{array}{l}\text { Standard methods. Capable of } \\
\text { (distributed by CSI) }\end{array}$ \\
Thermometer & CSI & $\pm 0.1^{\circ} \mathrm{C}^{(\mathrm{b})}$ & \\
\hline
\end{tabular}

(a) (CSI 2009c).

(b) (CSI 2009b).

\subsection{Electric and Electronic Equipment}

The measurement and control device for the equipment (i.e., the HDUs, capacitance probes, and precipitation and temperature sensors at a meteorological station) is the CR10X or other compatible datalogger manufactured by CSI (Logan, UT). The datalogger allows the data to be measured, processed, stored, and retrieved. However, permanent power does not exist near the proposed placement of the data logger. This requires that the data logger and peripherals be powered by a battery that can be recharged with a solar panel.

For automatic monitoring and data collection, compatible electric and electronic equipment are needed. Table 2.3 summarizes this equipment and its functions.

Table 2.3. Electric and Electronic Equipment and their Function

\begin{tabular}{ll}
\hline \multicolumn{1}{c}{ Equipment/Instrument } & \multicolumn{1}{c}{ Functions } \\
\hline Datalogger & Data collection and storage \\
Rechargeable Battery w/charger & Power supply \\
Solar Panel w/cable & Power source for the rechargeable battery \\
Mulitiplexer & To connect to multiple HDUs \\
Excitation Module & Create a constant current power source for HDU \\
Network Link, Radio, Antenna, interface & Wireless data communication \\
Software & Software to control the datalogger \\
\hline
\end{tabular}





\subsection{Instrument Calibration}

All monitoring instruments installed at $\mathrm{T}$ and $\mathrm{TY}$ farms were verified to be functioning before field installation. The temperature and rain gauge sensors arrived calibrated, and the sensor output was related to the measurement parameter. The neutron probe, capacitance probes, and HDUs do not come from the manufacturer with the necessary calibration or normalization information, requiring that instrument normalization be performed (capacitance probes and HDUs) and calibrations be developed (neutron probe and HDUs). This section documents the instrument verifications and calibrations in addition to sensor normalizations. The instruments in the T Farm are grouped into four nests (i.e., TA, TB, TC, and TD), and those in the TY Farm are grouped into two nests (i.e., TYA and TYB).

\subsection{Neutron Probe}

The neutron probe measures relative soil wetness, which is proportional to, but not equal to, the absolute soil-water content. Neutron-probe monitoring of the interim surface barrier in the T and TY tank farms uses a 503DR hydroprobe manufactured by CPN International, Inc. (Martinez, California), which was described in detail in Section 2.3.1. The 2.5-in.-OD, 0.375-in.-thick, 4140 carbon steel casings are used for NP access.

Ward and Wittmand (2009) calibrated the neutron probe using the Monte Carlo N-Particle Transport (MCNP) computer code (X-5 Monte Carlo Team) by performing theoretical analysis of neutron diffusion in air, the probe shield, and in the soil. The calibration curves for 2.5-in. steel casings are summarized in Table 3.1.

Table 3.1. Neutron Calibration Curve for the 2.5-In. Steel Casings (Ward and Wittmand 2009)

\begin{tabular}{cccc}
\hline Model & Equation & $\mathrm{A}$ & $\mathrm{B}$ \\
\hline$\# 1$ & $\theta_{v}=\exp (A) N^{B}$ & -17.9364 & 1.8648 \\
$\# 2$ & $\theta_{v}=\exp (A)\left(N / N_{s}\right)^{B}$ & -1.6622 & 1.8648 \\
$\# 3$ & $\theta_{v}=\exp (A)\left(N / N_{s w}\right)^{B}$ & -0.6115 & 1.8648 \\
\hline N - 16-sec neutron counts; $\mathrm{N}_{\mathrm{s}}-$ standard neutron counts in the shield; $\mathrm{N}_{\mathrm{s}}$ - standard \\
neutron counts in water; A and B - fitting coefficients.
\end{tabular}

\subsection{EnviroSMART Capacitance Probe}

Two components exist as part of the EnviroSMART capacitance probe calibration. First is normalization or scaling of the EnviroSMART capacitance sensor output. Due to slight sensor-to-sensor variations, normalization is necessary to allow for direct comparison of results from each capacitance sensor and also allows for a single calibration to be used to relate sensor output to volumetric moisture content. The second component is the actual calibration, which is developed using scaled sensor response and associated moisture content.

Normalization: Normalization is performed by measuring the response of each sensor in open air and when surrounded by water. The normalization procedure is thoroughly documented in Appendix B of the 
EnviroSMART user's manual (CSI 2009a). For that reason, details of the method are not duplicated here. The values obtained from the open-air and water measurements are used to normalize sensor output using Eq. (2.3).

The open-air measurements were performed while holding the probe out at arm's length into the air, verifying that the sensors are a distance away from any other objects that may affect the measurement. The water measurements were taken with the sensors inside the water-tight access tube that was placed in a 10-in.-diameter cylindrical water vessel or in the normalization chamber. Table 3.2 presents the water and open-air measurement output for each sensor.

Table 3.2. Capacitance Sensor Frequency Response in Air and Water. Values are used to normalize capacitance sensor output using Eq. 2.3.

\begin{tabular}{cccccccccccc}
\hline \multirow{2}{*}{ Farm } & & \multicolumn{2}{c}{$0.6 \mathrm{~m}$} & \multicolumn{2}{c}{$0.9 \mathrm{~m}$} & \multicolumn{2}{c}{$1.3 \mathrm{~m}$} & \multicolumn{2}{c}{$1.8 \mathrm{~m}$} & \multicolumn{2}{c}{$2.3 \mathrm{~m}$} \\
\cline { 3 - 12 } & Nest & Air & Water & Air & Water & Air & Water & Air & Water & Air & Water \\
\hline \multirow{4}{*}{ T } & TA & 37522 & 28657 & 37583 & 28413 & 37584 & 28503 & 37170 & 28219 & 37728 & 28863 \\
& TB & 37448 & 28395 & 37048 & 28148 & 37323 & 28227 & 37720 & 28468 & 37180 & 27835 \\
& TC & 35956 & 27169 & 36556 & 27383 & 36275 & 27152 & 36451 & 27641 & 36713 & 27817 \\
& TD & 37353 & 27134 & 36751 & 27148 & 36225 & 27622 & 38346 & 28328 & 37643 & 27621 \\
\hline \multirow{2}{*}{ TY } & TYA & 37099 & 24853 & 37456 & 25176 & 37170 & 24856 & 37151 & 24811 & 37401 & 24936 \\
& TYB & 36653 & 24707 & 36752 & 24650 & 36881 & 24710 & 36591 & 24704 & 36986 & 24833 \\
\hline
\end{tabular}

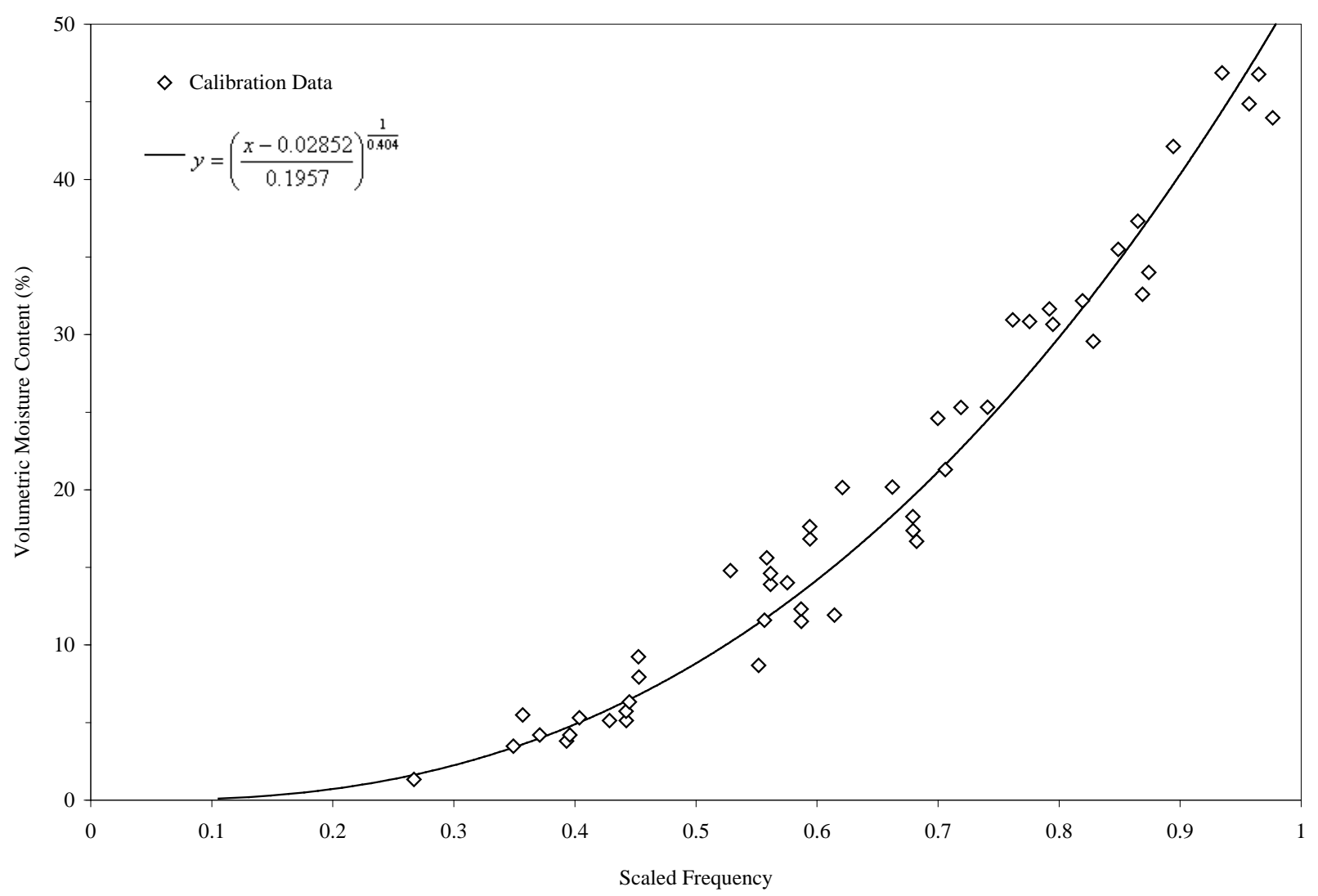

Figure 3.1. Capacitance Probe Default Calibration (Sentek Pty Ltd 2001) 
Calibration: The capacitance probe calibration documentation (Sentek Pty Ltd. 2001) provides a default calibration developed using sand, loam, and clay-loam soils. This calibration was developed by performing nonlinear regression on frequency data for paired volumetric moisture content and capacitance sensor scales (Figure 3.1). The default calibration is sufficient to show relative changes in soil-water content, which is the primary interest in this study. The manufacturer's developed calibration follows the form,

$$
\theta_{v}=\left(\frac{S_{f}-c}{a}\right)^{\frac{1}{b}}
$$

where a is 0.1957 , b is 0.404 , and $\mathrm{c}$ is 0.02852 .

\subsection{Heat-Dissipation Unit}

As explained by Scanlon et al. (2002), a variety of procedures can be used to calibrate heatdissipation sensors. The sole requirement is that the matric potential of the medium surrounding the sensor be known. Similar to the capacitance probe, there are two elements to the HDU calibration: 1) a normalization procedure to remove variation between the HDU sensors (the normalization of temperature rise is sensor specific, and thus all sensors need to be normalized) and 2) a calibration procedure to develop the relationship between soil matric potential and the normalized temperature rise measured by the HDU. This relationship is general for all the sensors, and hence only a selected few sensors need be used to develop this relationship.

Normalization:

Due to the variability of the heat-transfer properties of individual HDUs, the relationship between temperature increase and matric potential is sensor-dependent. Flint et al. (2002) evaluated calibration equations for six HDUs and suggested normalizing the temperature increase according to:

$$
S_{\Delta T}=\frac{\Delta T_{d}-\Delta T}{\Delta T_{d}-\Delta T_{w}}
$$

where $S_{\Delta T}$ is the scaled temperature rise during a fixed time period (30 seconds for the HDUs used in the $\mathrm{T}$ and TY farms) , $\Delta \mathrm{T}$ is the temperature increase, and subscripts "d" and " $\mathrm{w}$ " denote the temperature increases for a dry and water-saturated ceramic matrix, respectively. This relation results in a range of 0 to 1 for dimensionless temperature. The matric potential is related to the dimensionless temperature rise by an empirical model.

Much of the HDU sensor-to-sensor variation is due to variation in the heater-ceramic contact. If the same heating method and heating time are used for each HDU sensor, then the variation between sensors can be removed by normalizing the measurements. A normalization procedure of Flint et al. (2002), described by Eq. (3.2), was used to calculate a dimensionless temperature rise. These procedures are summarized in Appendix A. The HDU temperature-rise measurement under dry conditions $\left(\Delta \mathrm{T}_{\mathrm{d}}\right)$ was 
made after the HDU had been placed over oven-dried desiccant in a sealed container for a length of time (approximately 24 hours). For the HDU temperature-rise measurement under water-saturated conditions $\left(\Delta \mathrm{T}_{\mathrm{w}}\right)$, the sensor was submerged in water for 24 to 48 hours and then removed before the HDU measurement. Flint et al. (2002) report that this method of saturating the HDU is sufficient for conditions that will remain drier than $-1 \mathrm{~m}$, which are the expected field conditions for this project. All readings were taken with a constant line-heat source current of $50 \mathrm{~mA}$ and measurement times of 1 second and 30 seconds after HDU heating was initiated. Table 3.3 summarizes the normalization results.

Table 3.3. HDU Temperature Rise Under Dry $\left(\Delta \mathrm{T}_{\mathrm{d}}\right)$ and Wet $\left(\Delta \mathrm{T}_{\mathrm{w}}\right)$ Conditions $\left({ }^{\circ} \mathrm{C}\right)$

\begin{tabular}{cccccccccc}
\hline \multirow{2}{*}{$\begin{array}{c}\text { Tank } \\
\text { Farm }\end{array}$} & & \multicolumn{2}{c}{$1 \mathrm{~m}$} & \multicolumn{2}{c}{$2 \mathrm{~m}$} & \multicolumn{2}{c}{$5 \mathrm{~m}$} & \multicolumn{2}{c}{$10 \mathrm{~m}$} \\
\cline { 2 - 9 } & Nest & $\Delta \mathrm{T}_{\mathrm{d}}$ & $\Delta \mathrm{T}_{\mathrm{w}}$ & $\Delta \mathrm{T}_{\mathrm{d}}$ & $\Delta \mathrm{T}_{\mathrm{w}}$ & $\Delta \mathrm{T}_{\mathrm{d}}$ & $\Delta \mathrm{T}_{\mathrm{w}}$ & $\Delta \mathrm{T}_{\mathrm{d}}$ & $\Delta \mathrm{T}_{\mathrm{w}}$ \\
\hline \multirow{4}{*}{$\mathrm{T}$} & TA & 2.59 & 0.79 & 2.65 & 0.82 & 2.68 & 0.80 & 2.79 & 0.83 \\
& $\mathrm{~TB}$ & 2.74 & 0.84 & 2.79 & 0.82 & 2.62 & 0.79 & 2.66 & 0.82 \\
& $\mathrm{TC}$ & 2.53 & 0.81 & 2.87 & 0.84 & 2.82 & 0.83 & 2.64 & 0.82 \\
& $\mathrm{TD}$ & 2.80 & 0.79 & 2.75 & 0.82 & 2.71 & 0.80 & 2.85 & 0.83 \\
\hline \multirow{2}{*}{$\mathrm{TY}$} & TYA & 3.48 & 0.74 & 3.26 & 0.71 & 3.34 & 0.75 & 3.63 & 0.78 \\
& TYB & 3.30 & 0.77 & 3.32 & 0.70 & 3.45 & 0.75 & 3.61 & 0.79 \\
\hline
\end{tabular}

\section{Calibration:}

The HDUs installed in the T tank farm in 2006 and 2007 were calibrated in the laboratory across the range of expected field soil-water pressures using the procedures described in Appendix A. The calibration was performed using a bucket packed with Hanford's Warden silt loam and containing six HDUs and two tensiometers with pressure transducers for independent matric potential measurements. Warden silt loam was used because its water-retention characteristics allow for creating a soil-water matric potential over the desired range. HDU calibration is independent of soil texture, permitting the use of Warden silt loam without introducing error into the calibration.

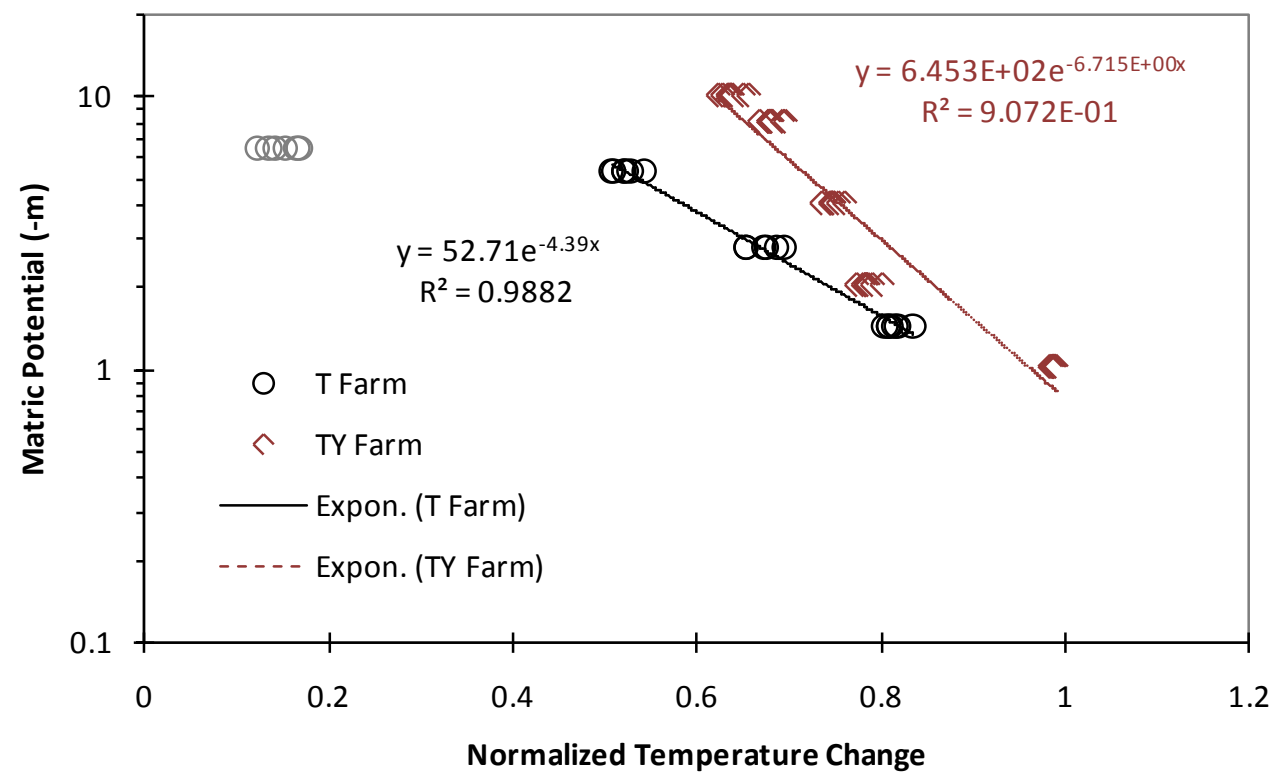

Figure 3.2. HDU Calibration Data Points and Calibration Relationship 
The appropriate amount of soil and water was mixed together to attain the desired water content and hence desired matric potential. Uniform mixing of the soil and water was achieved before packing the soil in the bucket. During packing of the soil, the HDUs and tensiometers were added to the bucket, and soil was packed around the instruments. After packing the bucket, the surface was covered to reduce evaporation. The HDUs and tensiometer pressure transducers were controlled by a single datalogger. The HDU measurements were taken continuously for at least 24 hours or until steady-state conditions were achieved, as indicated by HDU and tensiometer measurements. HDU readings were taken with a $50 \mathrm{~mA}$ current applied to the heating element for 30 seconds. After the measurement set was completed, the procedure was repeated for a different water content (matric potential).

The HDUs installed in the TY tank farm in 2010 were calibrated in the laboratory across the range of expected field soil-water pressures using the procedures described in Appendix B. A pressure chamber packed with the Warden loam soil and up to 16 HDUs was used. The advantage of using a pressure chamber over a tensiometer is that the former can measure much higher tension and provides more stable pressure over time. HDU measurements were taken continuously for at least 48 hours or until steadystate conditions were achieved, as indicated by HDU measurements.

Using the normalized HDU temperature rise and tensiometer readings under steady-state soil conditions, empirical calibration equations were developed by fitting the paired pressure head (in meters) and normalized HDU data points [Eq. (3.3) and (3.4)]. We have noticed that these data pairs for the two batches of HDUs, respectively, installed in the T and TY tank farms are significantly different (Figure 3.2). A possible cause is that the materials used for making the HDUs might be different because they were made about 3 years apart. After further examination of the calibration results for the HDUs installed in the $\mathrm{T}$ tank farm, we found that the tensiometer readings at the driest soil water condition were questionable (the dimmed the circles in Figure 3.2). Hence, the T tank farm HDU calibration was redeveloped after removing the questionable point. We found that an exponential function, as exemplified in CSI (2009a), can describe the calibration (Figure 3.2):

$$
\begin{array}{cc}
\text { T farm HDUs } & \psi=-52.71 \times \exp \left(-4.39 S_{\Delta T}\right), \mathrm{r}^{2}=0.9882 \\
\text { TY farm HDUs } & \psi=-645.3 \times \exp \left(-6.715 S_{\Delta T}\right), \mathrm{r}^{2}=0.9072
\end{array}
$$

\section{Correction of Temperature Effects}

The heat conductivity of the HDUs is temperature dependent, and thus, the measurements that deviate from a reference temperature need to be corrected to the reference temperature. Flint et al. (2002) developed the following equations to correct for temperature effects for HDUs calibrated at $20^{\circ} \mathrm{C}$ :

$$
\begin{gathered}
S_{\Delta T}^{*}=S_{\Delta T}-S(T-20) \\
S=c_{0}+C_{1} S_{\Delta T}+C_{2} S_{\Delta T}^{2}+C_{3} S_{\Delta T}^{3}+C_{4} S_{\Delta T}^{4}+C_{5} S_{\Delta T}^{5}
\end{gathered}
$$


where $\mathrm{S}_{\Delta \mathrm{T}}{ }^{*}=$ corrected $\mathrm{S}_{\Delta \mathrm{T}}$

$$
\begin{aligned}
\mathrm{s} & =\text { an intermediate variable } \\
\mathrm{T} & =\text { the field temperature } \\
\mathrm{C}_{0} & =0.0013 \\
\mathrm{C}_{1} & =0.011 \\
\mathrm{C}_{2} & =0.0203 \\
\mathrm{C}_{3} & =-0.0747 \\
\mathrm{C}_{4} & =0.0559 \\
\mathrm{C}_{5} & =-0.0133 .
\end{aligned}
$$

The upper measurement range of the HDUs is controlled by the air-entry pressure (bubbling pressure) of the matrix material of the probe, which is generally $-10 \mathrm{kPa}(-1 \mathrm{~m})$. Matric potentials above the airentry pressure (i.e., between 0 and $-10 \mathrm{kPa}[-1 \mathrm{~m}]$ ) cannot be measured because the matrix material is essentially saturated. The lower measurement limit is generally considered to be about $-1 \mathrm{MPa}(-100 \mathrm{~m})$ (Reece 1996). However, less-accurate measurements can be made between -1 and -35 MPa (-100 and $-3500 \mathrm{~m})$.

\subsection{Temperature Probe}

The temperature probes come from the manufacturer already calibrated and do not require a field calibration. Two different CSI models, Model 107 and Model 109, of temperature probes are used. The Model 107 temperature probe is used as a reference temperature probe and is located within the enclosure boxes housing the dataloggers that control the instrument inside the T and TY tank farms. The Model 107 temperature probe is described by a fifth-order polynomial equation relating thermistor resistance, Rs (Ohms), to temperature, $\mathrm{T}\left({ }^{\circ} \mathrm{C}\right)$ by (CSI 2004),

$$
T=C_{0}+C_{1} R s+C_{2} R s^{2}+C_{3} R s^{3}+C_{4} R s^{4}+C_{5} R s^{5}
$$

$$
\text { where } \begin{aligned}
C_{0} & =-53.4601 \\
C_{1} & =90.807 \\
C_{2} & =-83.257 \\
C_{3} & =52.283 \\
C_{4} & =-16.723 \\
C_{5} & =2.211
\end{aligned}
$$

The temperature sensor used as part of the meteorological station is a Model 109 temperature probe. This temperature sensor relates thermistor resistance to temperature using the relationship (CSI 2004),

$$
T=\left\{\frac{1}{A+B \ln (R s)+C[\ln (R s)]^{3}}\right\}-273.15
$$

where A is $1.129241 \times 10-3$, B is $2.341077 \times 10^{-4}$, and C is $8.775468 \times 10^{-8}$. 


\subsection{Rain Gauge}

The rain gauge is factory calibrated and does not require a field calibration. The calibration produces an equivalent height of water of $0.254 \mathrm{~mm}$ per tip. Before field installation, the functionality of the rain gauge was confirmed by applying a known volume of water to the rain gauge with a graduated $60-\mathrm{mL}$ syringe while monitoring for tips. The volume of water applied for each tip was compared to the manufacturer's calibration (8.3 mL per tip) to see that there was general agreement between the two. Table 3.4 presents results from this analysis. Differences between the calibrated tipping volume and the volume of water applied were no more than the resolution volume of the syringe $(0.5 \mathrm{~mL})$. The results confirm that the rain gauge is functioning.

Table 3.4. Rain-Gauge-Function Verification Results

\begin{tabular}{cc}
\hline Test & Volume Applied per Tip (mL) \\
\hline 1 & 8.5 \\
2 & 8.5 \\
3 & 8.5 \\
\hline
\end{tabular}





\subsection{Instrument Layout and Installation}

The monitoring instrument Nests TA and TB and a meteorological station were installed within T Tank Farm in FY06; Nests TC and TD were installed in FY07; and Nests TYA and TYB were installed within the TY Farm in FY10. Each of the instrument nests within the tank farms included its own datalogger as did the meteorological station outside the $\mathrm{T}$ farm. This section updates the Monitoring Plan (Zhang et al. 2007) to include the information of Nests TC, TD, TYA, and TYB.

\subsection{Selection of Monitoring Locations}

The instruments were installed both under the interim surface barrier and outside of the surface barrier for purposes of monitoring surface-barrier impacts on the subsurface water regime. Threedimensional (Zhang and Keller 2006) and two-dimensional simulations (McMahon 2007) suggest that the measurable changes in subsurface conditions 3 years after surface barrier placement in the $\mathrm{T}$ farm will primarily be contained in the top $15 \mathrm{~m}$ of sediment. Longer time periods are required before measurable changes propagate to deeper depths. As such, a combination of shallow and deep instrument placement is incorporated into the monitoring design.

Nest placement is guided by three primary factors: 1) the capability to distinguish the differences in soil-water regimes in the regions with and without a surface barrier, 2) the capability to investigate edge effects, and 3) the locations of existing underground utilities (e.g., pipelines, electrical conduits) or structures and the geometry of the planned interim surface barrier. The nest placement should provide the greatest opportunity for monitoring instruments to detect changing subsurface soil-water conditions. For example, in the region with a surface barrier, the water content of the soil close to or between tanks is expected to have a larger reduction than the soil far away from the tanks.

The monitoring system also needs to consider that soil attributes may vary in space. This requires that the monitoring of a flow variable should be taken at multiple locations, if possible. There are three options for measurements with spatial coverage: 1) multiple measurements horizontally, 2) multiple measurements vertically, and 3) multiple measurements both horizontally and vertically. Other factors to be considered include the cost constraint for instrument purchase, installation and monitoring, the method of installation, and the depth of a surface barrier that affects the soil-water regime within the time frame of monitoring. The use of options 1) and 3) are more costly than option 2) to achieve similar number measurement repetition. Hence, option 2) was used for instrument placement as a general guidance. Option 3) was applied only in the T farm within the barrier footprint.

\subsection{Instrument Nest Design}

As described above, the instruments in the T Farm are grouped into four nests (i.e., TA, TB, TC, and TD), and those in the TY Farm are grouped into two nests (i.e., TYA and TYB), each of which includes a neutron access tube, a capacitance probe with five sensors, and four HDUs. Nests TA and TYA are placed in the area without a cover and serve as a control. Control nests need to be at least $5 \mathrm{~m}$ away from the closest edge of the surface cover to prevent measurable impacts from the cover. Nest TB is placed at the edge of the surface barrier to monitor the edge effect of the surface barrier on the soil-water regime. Nests TC and TD are duplicates and are placed inside the covered area in the T Farm; Nest TYB is placed in the covered area in the TY Farm. The nests under the barrier need to be at least $5 \mathrm{~m}$ from the closest 
edge of the surface barrier and between two or more tanks where the largest change of soil-water content, and hence water flux, is expected after the emplacement of the surface barrier.

Vertically, the monitoring depths go to 15-m bgs. Considering that, upon the emplacement of the surface barrier, the changes of soil moisture are more significant in shallower depths; more intensive and frequent measurements are taken at shallow depths. All instrument nests lie within backfill material, except for the lower part of the neutron access tubes, which extend into the undisturbed Hanford formation below the tanks.

Nests TA and TB were installed in late FY 2006, and monitoring was initiated in September 2006. Nests TC and TD were installed in FY 2007, and monitoring was initiated in May 2008. Nests TYA and TTB were installed in FY 2010, and monitoring was initiated in March 2010. Figure 4.1 shows the approximate location of each instrument installation. Table 4.1 provides the coordinates of each well using the Washington Coordinate System, NAD83(91) datum and Hanford Coordinates. Table 4.2 summarizes the vertical placement of instrument or measurement points.

Table 4.1. Vadose Zone Monitoring Driving Boreholes Coordinates Associated Installed Instruments (CHG 2006, 2007; DOE-ORP 2010)

\begin{tabular}{|c|c|c|c|c|c|c|c|}
\hline \multirow{2}{*}{\multicolumn{2}{|c|}{$\begin{array}{c}\text { Instrument } \\
\text { Nest }^{(a)}\end{array}$}} & \multirow[b]{2}{*}{ Well Number } & \multirow[b]{2}{*}{ Instrument } & \multicolumn{2}{|c|}{ Washington Coordinates $^{(\mathrm{b})}$} & \multicolumn{2}{|c|}{$\begin{array}{c}\text { Hanford } \\
\text { Coordinates }^{(\mathrm{c})}\end{array}$} \\
\hline & & & & Northing (m) & Easting (m) & Northing (ft) & Easting (ft) \\
\hline \multirow{4}{*}{\multicolumn{2}{|c|}{ Nest TA }} & C5306 & Drain Gauge & 136762.16 & 566752.82 & 43640.53 & -75915.61 \\
\hline & & C5307 & Neutron Access Tube & 136761.16 & 566752.82 & 43637.25 & -75915.61 \\
\hline & & C5309 & HDUs & 136760.16 & 566751.82 & 43633.97 & -75918.89 \\
\hline & & C5310 & Capacitance Probe & 136761.16 & 566751.82 & 43637.25 & -75918.89 \\
\hline \multirow{4}{*}{\multicolumn{2}{|c|}{ Nest TB }} & C5311 & Drain Gauge & 136739.59 & 566753.47 & 43566.49 & -75913.49 \\
\hline & & C5312 & Neutron Access Tube & 136738.59 & 566753.47 & 43563.20 & -75913.49 \\
\hline & & C5314 & HDUs & 136737.59 & 566752.47 & 43559.92 & -75916.78 \\
\hline & & C5315 & Capacitance Probe & 136738.59 & 566752.47 & 43563.20 & -75916.78 \\
\hline \multirow{3}{*}{\multicolumn{2}{|c|}{ Nest TC }} & C5696 & Neutron Access Tube & 136720.98 & 566768.77 & 43505.16 & -75863.34 \\
\hline & & C5697 & Capacitance Probe & 136720.93 & 566767.76 & 43505.16 & -75866.63 \\
\hline & & C5698 & HDUs & 136720.91 & 566766.76 & 43505.16 & -75869.90 \\
\hline \multirow{3}{*}{\multicolumn{2}{|c|}{ Nest TD }} & C5699 & Neutron Access Tube & 136714.87 & 566789.75 & 43485.23 & -75794.55 \\
\hline & & C5700 & Capacitance Probe & 136714.85 & 566788.13 & 43485.23 & -75799.83 \\
\hline & & C5701 & HDUs & 136714.89 & 566787.11 & 43485.23 & -75803.11 \\
\hline \multirow{3}{*}{\multicolumn{2}{|c|}{ Nest TYA }} & C7773 & Neutron Access Tube & 136346.2 & 566725.5 & 42276.5 & 76008.6 \\
\hline & & C7774 & Capacitance Probe & 136346.2 & 566726.5 & 42276.5 & 76005.3 \\
\hline & & C7775 & HDUs & 136346.2 & 566727.5 & 42276.5 & 76002.1 \\
\hline \multirow{3}{*}{\multicolumn{2}{|c|}{ Nest TYB }} & C7776 & Neutron Access Tube & 136397.0 & 566731.8 & 42443.1 & 75987.9 \\
\hline & & C7777 & Capacitance Probe & 136397.0 & 566732.8 & 42443.1 & 75984.7 \\
\hline & & C7778 & HDUs & 136397.0 & 566733.8 & 42443.1 & 75981.4 \\
\hline \multirow{2}{*}{\multicolumn{8}{|c|}{$\begin{array}{l}\text { (a) Nests TA, TB, TC, and TD were referred to as Nests 1, 2, 3, and 4, respectively, in CHG }(2006,2007) . \text { Nests TYA and } \\
\text { TYB were referred to as Nests \#2 and \#1, respectively, in WRPS (2010). } \\
\text { (b) Washington Coordinate System, NAD83(91) datum. }\end{array}$}} \\
\hline & & & & & & & \\
\hline \multicolumn{8}{|c|}{$\begin{array}{l}\text { (c) Coordinates for Nests TA and TB were from CHG (2006), those for Nests TC and TD from CHG (2007), and those for } \\
\text { Nests TYA and TYB from WRPS (2010). }\end{array}$} \\
\hline
\end{tabular}



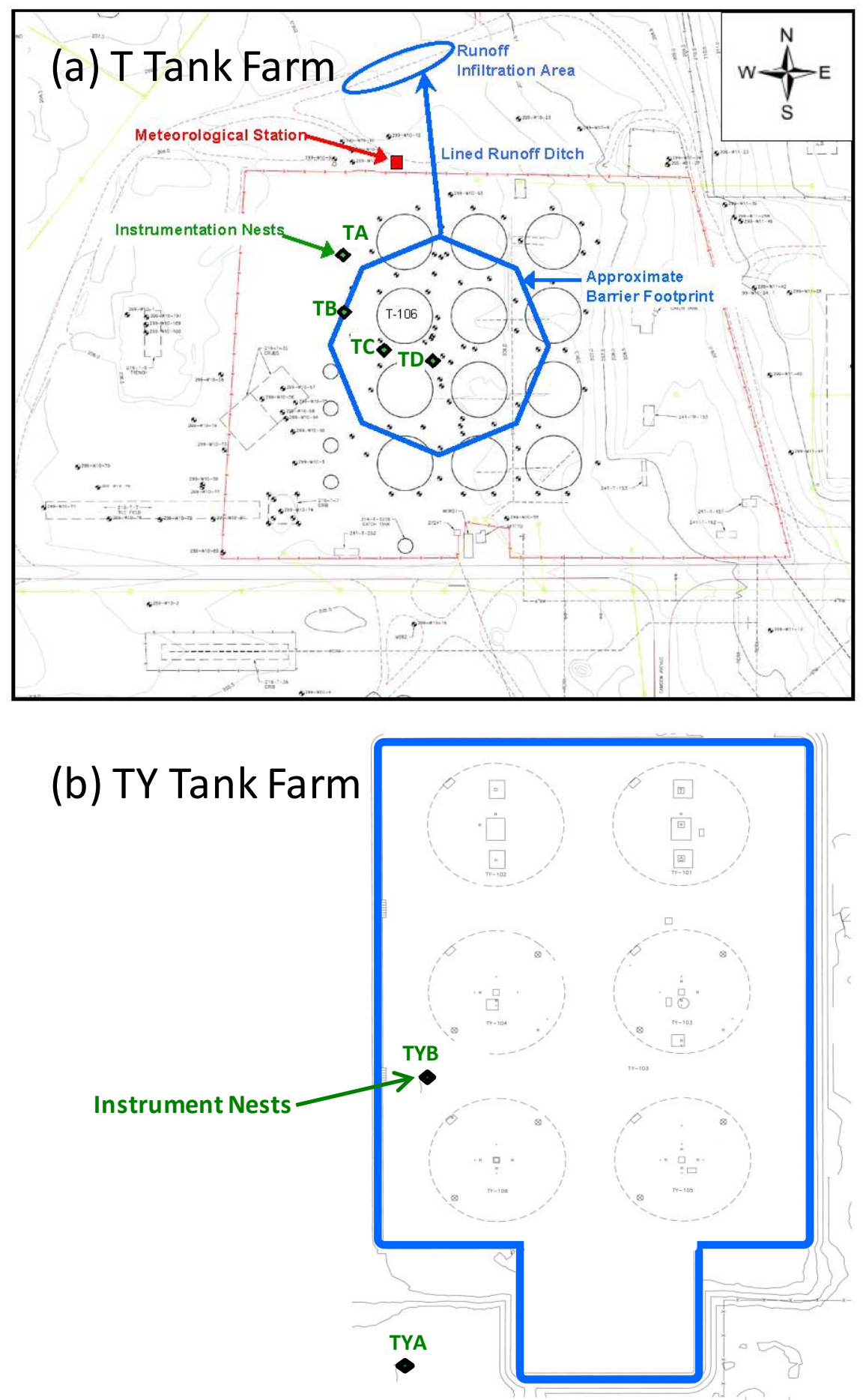

Figure 4.1. Plan View of T TY Tank Farm with the Approximate Locations of Monitoring Nests TA, TB, TC, TD, TYA and TYB and Approximate Interim Surface barrier Boundary as Marked by the Blue Lines. (The schematic is not to scale.)

Table 4.2. Instrument Vertical Placement 


\begin{tabular}{lccc}
\hline Methods & Nest & $\begin{array}{c}\text { No. of Sensors/ } \\
\text { Measurement } \\
\text { Points }\end{array}$ & $\begin{array}{c}\text { Depth of Sensors/ } \\
\text { Measurement Points }\end{array}$ \\
\hline Capacitance Probe & TA, TB, TC, TD, TYA, TYB & 5 & $0.6,0.9,1.3,1.8$, and $2.3 \mathrm{~m}$ \\
Neutron Probe & TA, TB, TC, TD, TYA, TYB & 50 & $\begin{array}{l}\text { from 0.3 to } 15 \mathrm{~m}(1 \text { to } 50 \mathrm{ft}) \\
\text { bgs at } 1 \text {-ft interval }\end{array}$ \\
HDU & TA, TB, TC, TD, TYA, TYB & 4 & $1,2,5$, and $10^{(\mathrm{a})} \mathrm{m}$ \\
Drain Gauge & TA, TB & 1 & ground surface \\
\hline $\begin{array}{l}\text { (a) } 10 \mathrm{~m} \text { for Nests A, B, and D and } 9 \mathrm{~m} \text { for Nest C. } \\
\text { (b) Per the FY07 report (Zhang et al. 2008), the use of drain gauges to monitor water flux has been abandoned since }\end{array}$ \\
FY08.
\end{tabular}

\subsection{T-TY Farm Instrument Installation}

The instrument nests were installed following the placement and methods described below. Instruments were placed in an open driving borehole created by pounding a cone-tipped, hollow drive shaft into the ground using a hydraulic hammer (Figure 4.2).

Figure 4.3 shows a typical cone-tipped drive shaft used for driving boreholes. The benefit of using the hydraulic hammer to create a borehole as opposed to drilling is that the hydraulic-hammer technique avoids bringing potentially contaminated soil to the surface. The cone tip on the drive shaft has the capability to be removed once the desired driving depth is reached. This allows instruments to be placed down the borehole through the inside of the drive shaft as the drive shaft is removed from the soil. Likewise, the drive shaft can remain in the soil as a permanent access tube. The diameter of the borehole can be increased or decreased using differing drive-shaft and drive-head diameters.

The following discussion provides specific details of each instrument installation and is adapted from Zhang and Keller (2006) to reflect installation modifications. Both metric and English units of measurement are reported in this section to be consistent with the English units used by the drillers to measure and report depths and instrument-installation details. The adjacent instruments in a nest were kept $1 \mathrm{~m}$ apart except that the distance between the neutron-probe access tube and the CP access tube in Nest TD was $1.6 \mathrm{~m}$.

Each instrument nest within the tank farm was designed to have a dedicated datalogger adjacent to the instrument nest. A CR10X Campbell Scientific datalogger is used for instrument Nests A and B and the meteorological station, and a CR1000 Campbell Scientific datalogger is planned for instrument Nests C and D.

The datalogger and peripherals are powered by a 12-volt rechargeable battery, which is charged by a solar panel attached to the tripod. The battery is placed within the enclosure. Data from the datalogger are transmitted remotely by a $900-\mathrm{MHz}$ spread spectrum radio to a receiving computer located outside of the tank farm. 


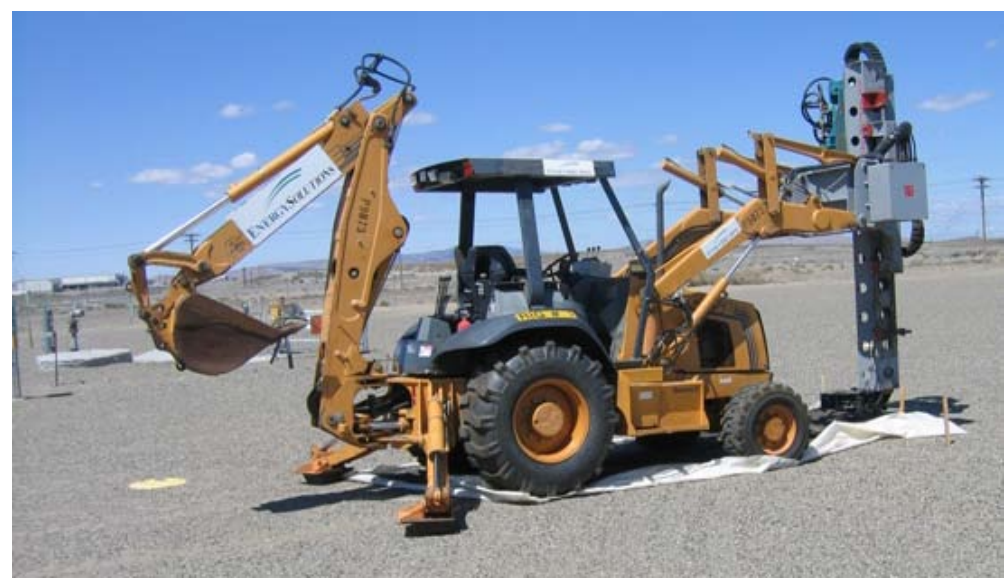

Figure 4.2. Hydraulic Hammer Used to Install Instruments in the T Tank Farm (Photo taken in the summer of 2006)

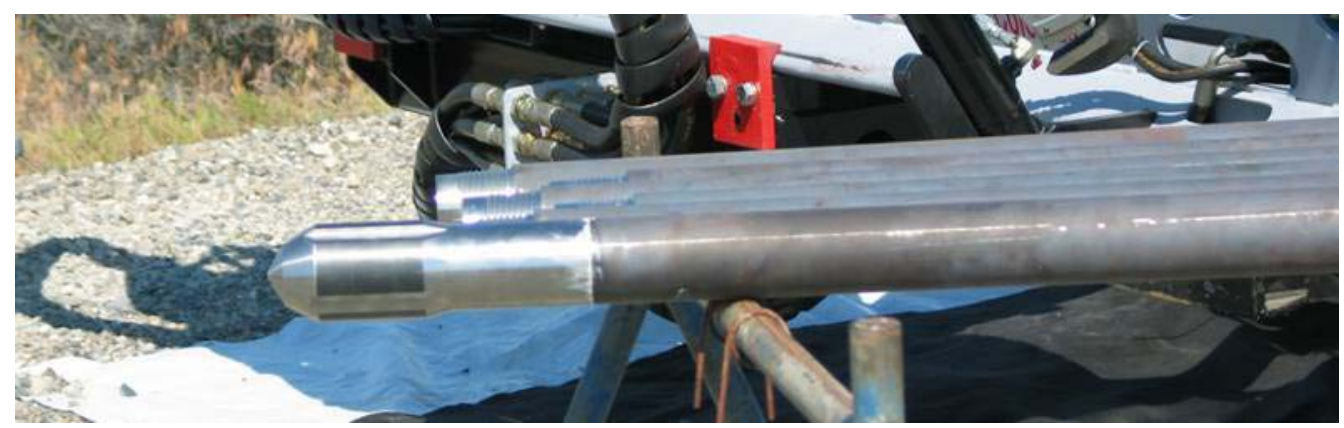

Figure 4.3. Cone-Tipped Drive Shaft Used in Conjunction with a Hydraulic Hammer for Creating Driving Boreholes (Photo taken in the summer of 2006)

\subsubsection{Neutron-Moisture-Probe Access Tubes}

Each neutron-probe access tube was installed using the basic function of the hydraulic hammer. A steel access tube $4.45 \mathrm{~cm}$ ID, $6.35 \mathrm{~cm}$ OD (1.75 in. ID, $2.5 \mathrm{in}$. OD) was driven vertically by the hydraulic hammer to a depth of $15.24 \mathrm{~m}(50 \mathrm{ft})$. A cap on the access tube was used to prevent precipitation from entering the access tube. Figure 4.4 to Figure 4.6 show the diagrams of the installed neutron-probe access tubes and installation procedures. 


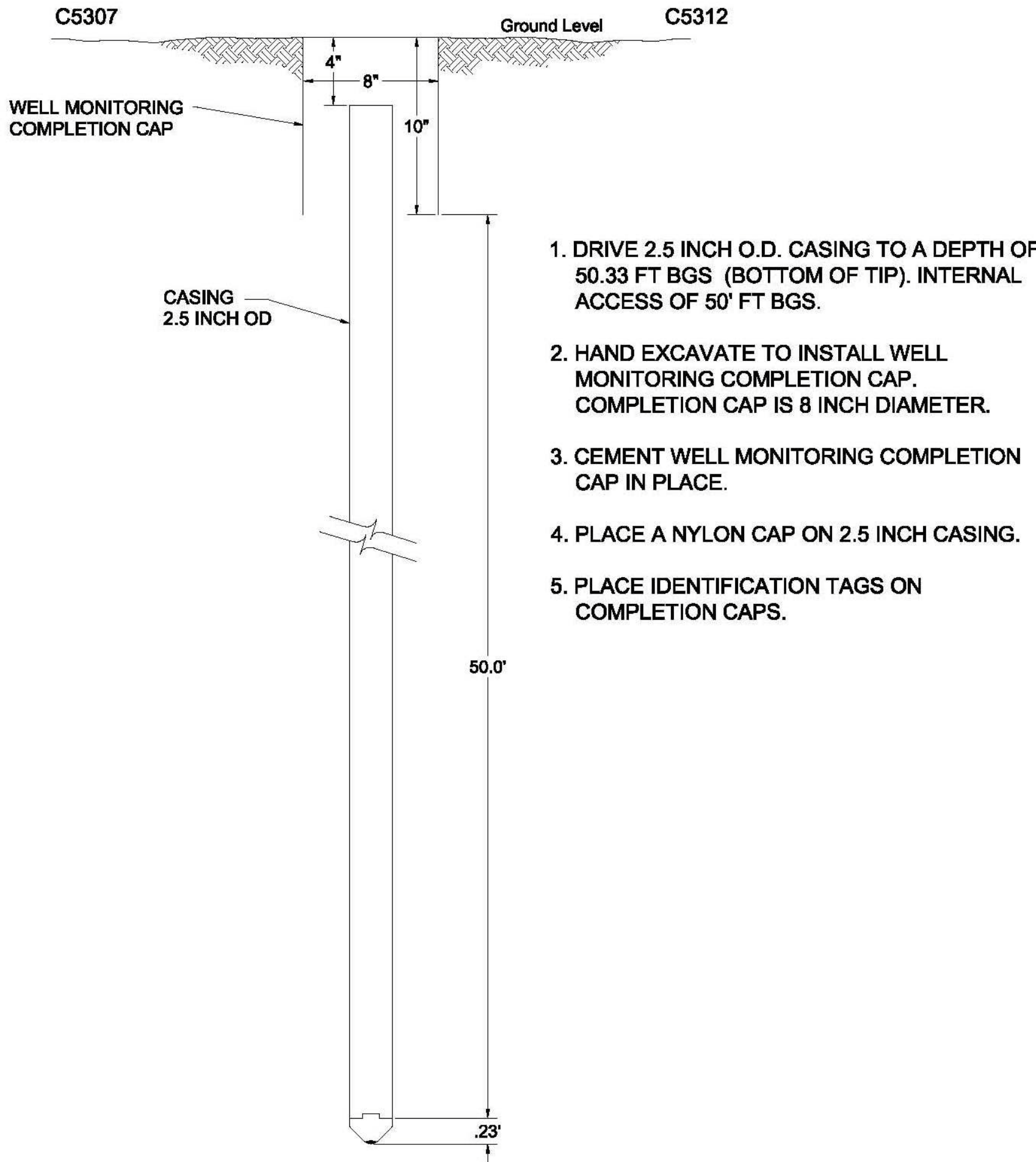

Figure 4.4. Diagram of the Installed Neutron Probe Access Tubes and Installation Procedures for Nests TA and TB (after CHG 2006) 


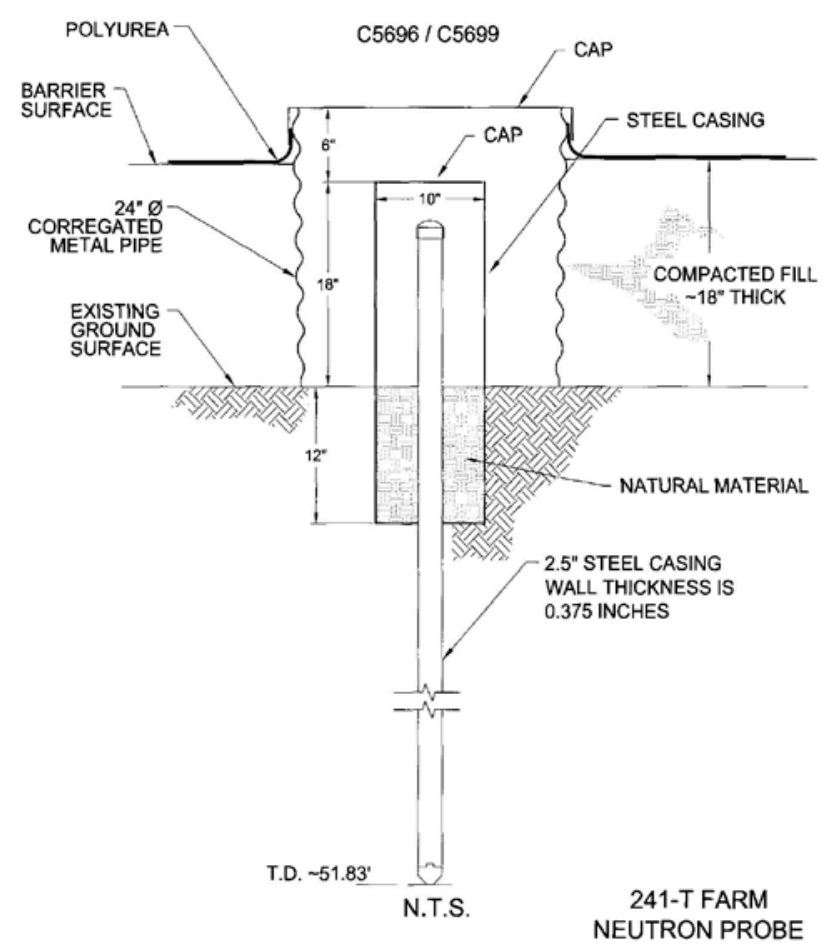

Figure 4.5. Diagram of the Installed Neutron Probe Access Tubes and Installation Procedures for Nests TC and TD (after CHG 2007)

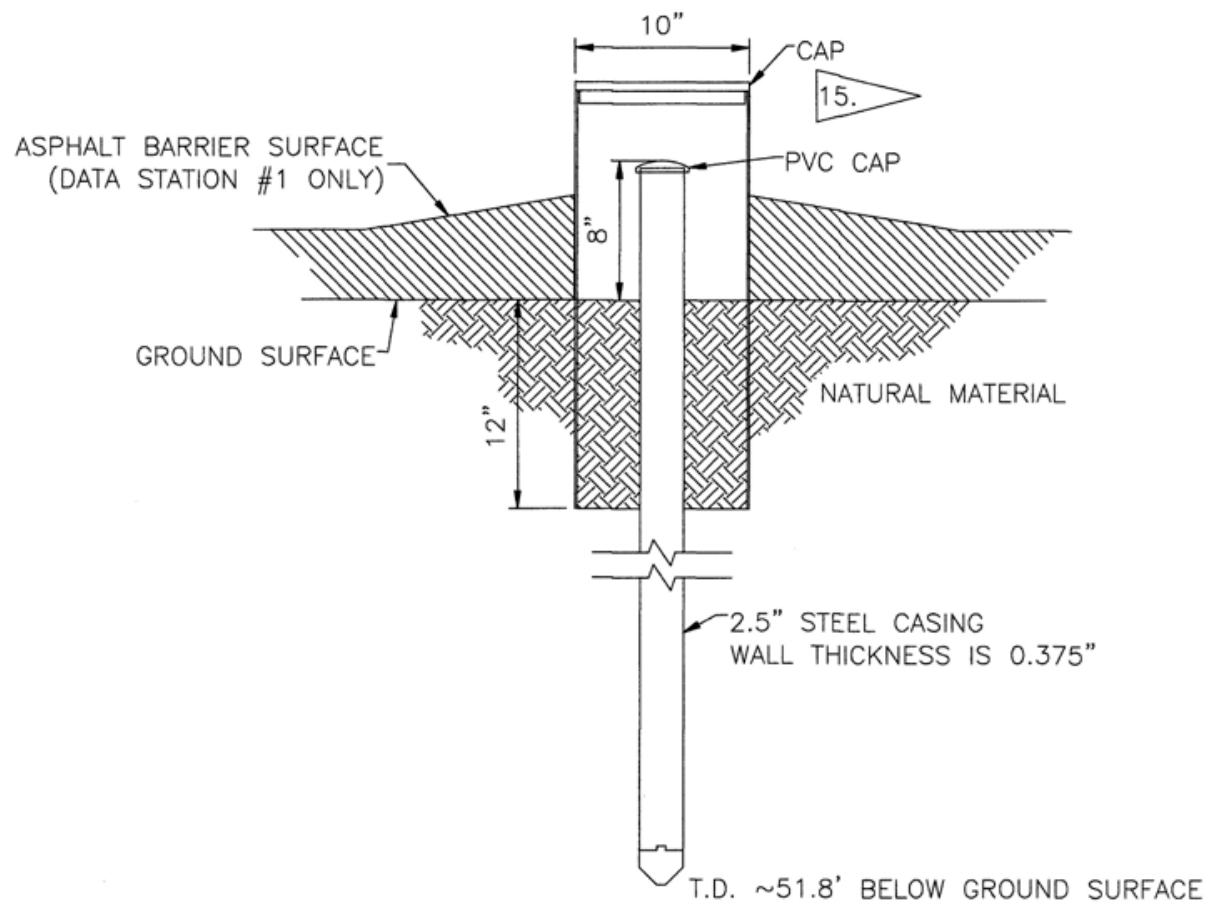

Figure 4.6. Diagram of the Installed Neutron Probe Access Tubes and Installation Procedures for Nests TYA (station \#2) and TYB (station \#1) (after DOE-ORP 2010) 


\subsubsection{EnviroSMART Capacitance Probe}

To allow the capacitance probe access tube with a $5.65 \mathrm{~cm}(2.22 \mathrm{in.} \mathrm{OD)} \mathrm{to} \mathrm{be} \mathrm{placed} \mathrm{into} \mathrm{the} \mathrm{ground}$ through the drive shaft, an 8.48-cm (3.34-in.) ID drive rod was used.

The OD of this drive shaft was $10.16 \mathrm{~cm}$

(4.00 inches), resulting in an annulus of $4.51 \mathrm{~cm}$

(1.78 inches). The drive rod was driven to a depth of approximately $3.50 \mathrm{~m}(11.50 \mathrm{ft})$. Once the target depth was reached, the drive cone was detached from the shaft, and the cone was isolated from the capacitance probe by surrounding it with $20 / 40$ clean sand until the borehole depth was approximately $2.83 \mathrm{~m}(9.28 \mathrm{ft})$. The EnviroSMART PVC access tube was then placed at depth through the drive rod, with the top of the probe being approximately $0.30 \mathrm{~m}$ $(0.98 \mathrm{ft})$ below ground surface. As the drive rod was extracted, 20/40 clean sand was packed in the annulus surrounding the polyvinyl chloride (PVC) access tube.

The drive-rod diameter was selected to create as small of an annulus as possible. However, the annulus

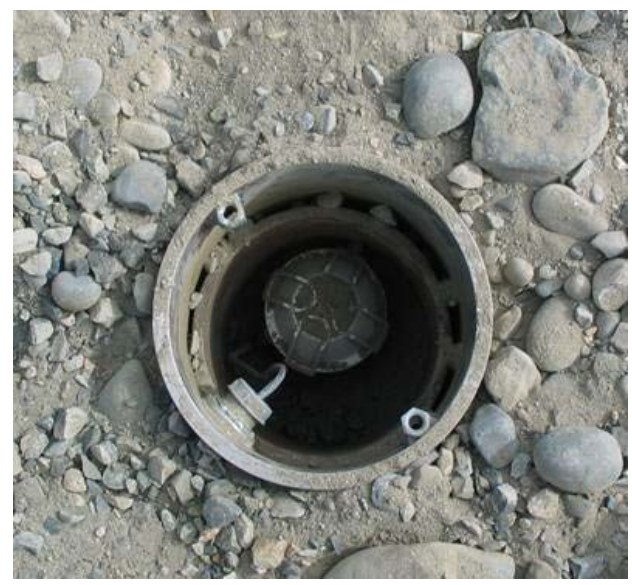

Figure 4.7. Capacitance Probe Cap and Protective Casing at Instrument Nest TB Before Filling With Tank Farm Surface Material size still required packing the 20/40 sand around the access tube to eliminate any air gaps around the access tube. Keeping the size of the annulus to a minimum was important so that the measured moisture content of the capacitance probe is not heavily skewed by the moisture content of the packing material. The manufacturer of the probe states that $99 \%$ of the probe reading is taken within a 10 -cm radius from the outside of the capacitance-probe access tube. Given that the radial thickness of the 20/40 clean sand packed in the annulus is $4.51 \mathrm{~cm}$ (1.78 inches), this suggests that approximately $45 \%$ of the capacitance-probe reading is interrogating the 20/40 clean-sand material. While the sand pack will skew absolute soil-watercontent values, relative trends over depth and time will still be valuable. Near the top of the borehole, an approximately 5-cm (1.97-in.) thick layer of hydrated bentonite crumbles was added to the annulus to reduce the potential for preferential flow through the 20/40 sand pack material. After the PVC access tube and packing material was emplaced, accumulated soil and dust within the access tube was removed, and the sensors were placed within the access tube as was desiccant. The access tube was then capped and sealed with a water-tight and weather-resistant sealant.

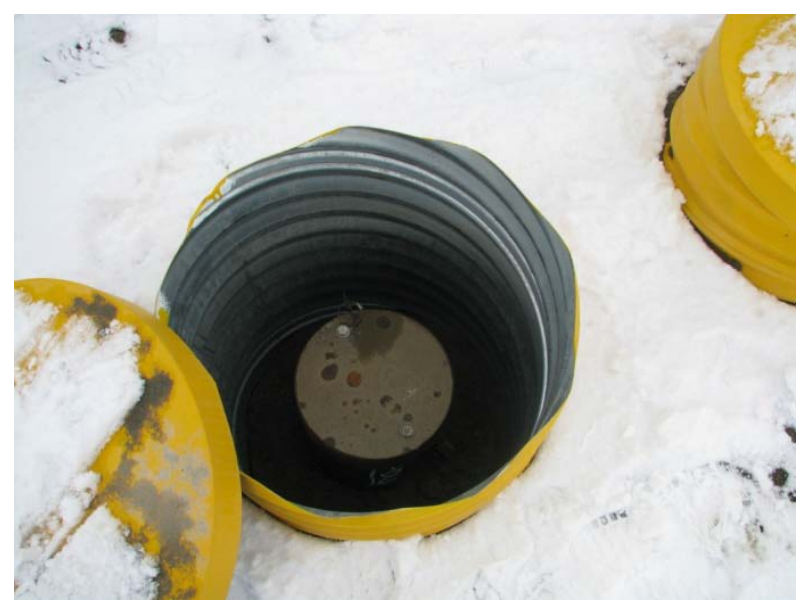

Figure 4.8. Typical Instrument Surface Completion Showing Outer 24-In.-Diameter Corrugated Metal Pipe Sleeving and Inner Steel Casing (Nest TA; photo taken in the winter 2008; snow can be seen on the ground) 
To protect the probe from surface traffic, a $25.4-\mathrm{cm}$ (10-in.) diameter steel casing was placed around the access tube, extending from the surface to a depth of $0.30 \mathrm{~m}$ (1 foot). The casing was then filled with soil material from the tank farm surface. Figure 4.7 shows the capacitance probe cap and protective casing before filling the casing with the tank-farm surface material.

For nests within the barrier footprint, additional sleeving was installed around each instrument head consisting of 24-in.-diameter corrugated metal pipe (Figure 4.8). The sleeving was added to accommodate fill material to be placed at these locations during construction of the interim surface barrier (CHG 2007).

Figure 4.9 through Figure 4.11 show the diagram of the installed capacitance probe access tubes and installation procedures.

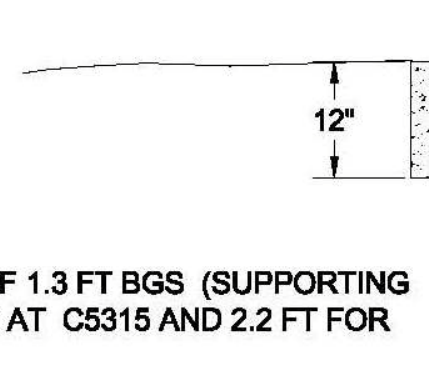

2. DRIVE 4 INCH CASING TO A DEPTH OF 11.5 FT BGS.

3. KNOCK OUT DRIVE TOP AND BACK PULL CASING.

4. PLACE SAND TO A DEPTH OF 9.3 FT BGS

5. INSTALL THE CAPACITANCE PROBE (TOP AT 11.81 INCHES).

6. BACK PULL CASING ADDING CLEAN 20/40 SAND. COMPACT SAND AS DRIVE CASING IS BACK PULLED TO 1 FT BGS.

7. PLACE 10 INCH SURFACE PROTECTION. A $1-1 / 16^{\text {n }}$ HOLE IS DRILLED IN PROTECTIVE CASING FOR CONDUIT.

8. CEMENT 10 INCH SURFACE PROTECTION (OUTSIDE).

9. PLACE SOIL MATERIAL TO THE SURFACE. SOIL MATERIAL CONSISTS OF SOIL FROM TANK FARM SURFACE.

10. RUN LEADS THROUGH CONDUIT AND ATTACH TO DATA LOGGER.

Ground Level

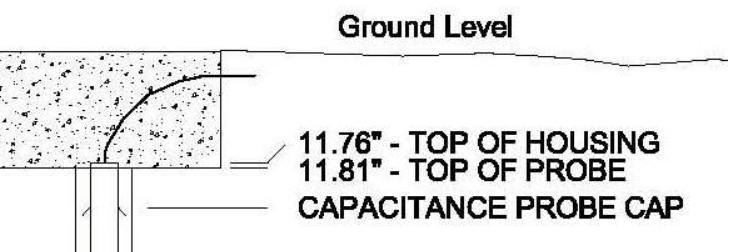

1. HAND DIG TO A DEPTH OF 1.3 FT BGS (SUPPORTING SURFACE PROTECTION) AT C5315 AND 2.2 FT FOR C5311. 


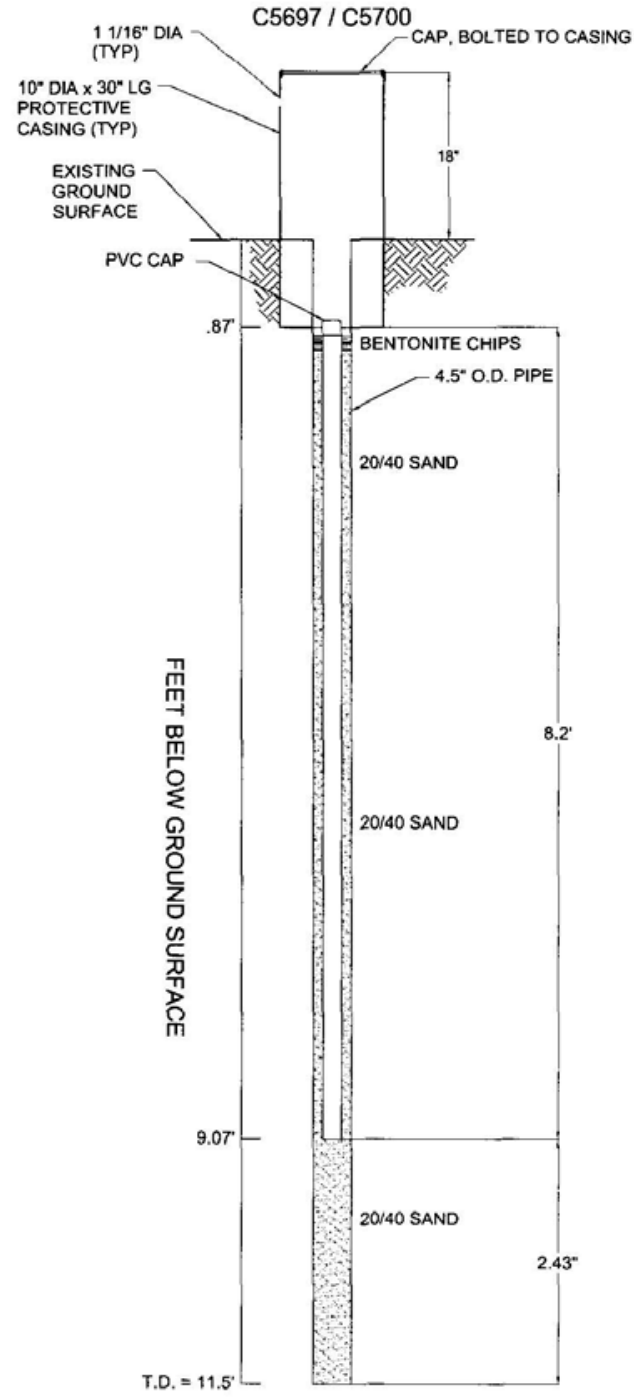

Figure 4.10. Diagram of the Installed Capacitance Probe Access Tubes for Nests TC and TD (after CHG 2007). Outer corrugated metal pipe sleeving is not shown. 


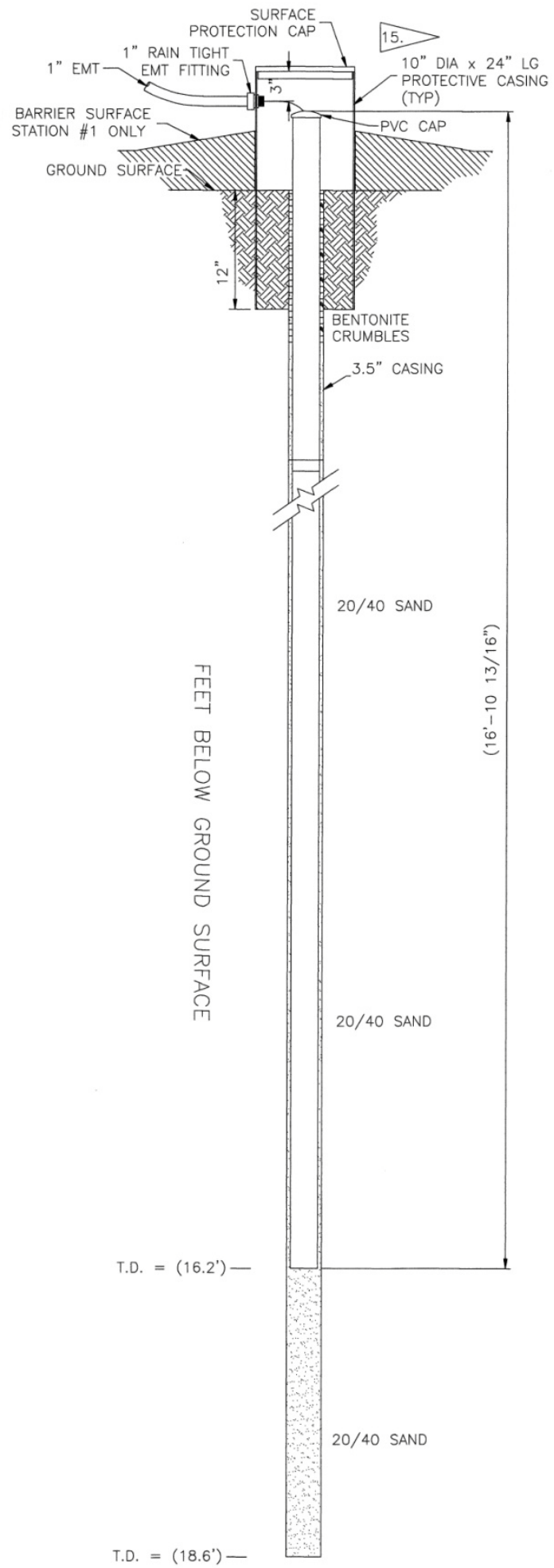

Figure 4.11. Diagram of the Installed Capacitance Probe Access Tubes for Nests TYA (station \#2) and TYB (station \#1) (after DOE-ORP 2010) 


\subsubsection{Heat-Dissipation Units}

HDUs were installed within a borehole created by driving a 4.45-cm-ID, 6.35-cm-OD (1.75-in.-ID, 2.5-in.-OD) steel drive shaft and drive head set to a depth of $10.97 \mathrm{~m}(36.0 \mathrm{ft})$ using the hydraulic hammer. Once the drive shaft was at depth, the drive cone was disconnected from the drive shaft, and as the rod was removed, 20/40 clean sand was added to bring the level to approximately $10.0 \mathrm{~cm}$ (3.9 inches) below the bottom HDU depth of $10.0 \mathrm{~m}$ (32.8 ft). The HDU and silica flour were added for a total of 20.0-cm (7.9-in.) thickness of silica flour. Silica flour was packed around the HDU to supply optimum contact between the sensor and surrounding soil material. The silica flour was moistened slightly before adding to the borehole to improve the packing of the flour and to reduce HDU equilibration time with the surrounding sediment. Approximately $20.0 \mathrm{~cm}$ (7.9 inches) of 20/40 sand was then added on top of the silica flour, followed by hydrated bentonite crumbles to a depth of approximately $30.0 \mathrm{~cm}$ (11.8 inches) below the next instrument depth of $5.0 \mathrm{~m}(16.4 \mathrm{ft})$. Then 20/40 sand was added to bring the level to approximately $10.0 \mathrm{~cm}$ (3.9 inches) below the instrument depth. The next HDU and silica flour were then added as was done with the previous HDU. This sequence was repeated until all HDUs were installed. After the last HDU was installed, $20.0 \mathrm{~cm}$ (7.9 inches) of 20/40 clean sand was added before the borehole was completed to the surface with hydrated bentonite crumbles. To protect wiring and instruments from vehicle traffic, a $20.3-\mathrm{cm}(8.0-\mathrm{in}$.) diameter steel casing was placed over the borehole to a depth extending $0.30 \mathrm{~m}(1.0 \mathrm{ft})$ below the soil surface, and the casing was capped.

Figure 4.12 shows the HDU installation before placing a cap on the protective casing. Note the HDU cabling that runs to the datalogger. Figure 4.13 through Figure 4.15 show the diagram of the installed HDUs.

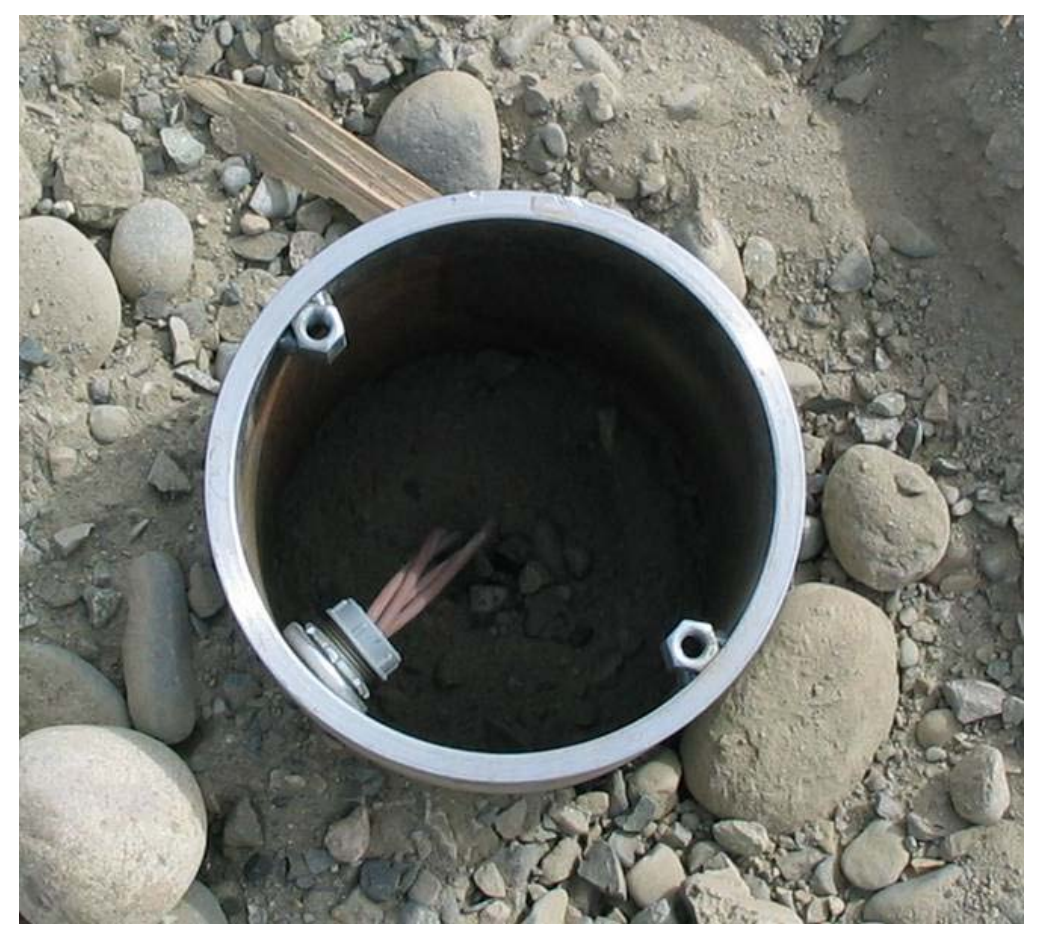

Figure 4.12. Protective Casing Over the HDU Location at Instrument Nest TB (Photo taken in the summer of 2006) 


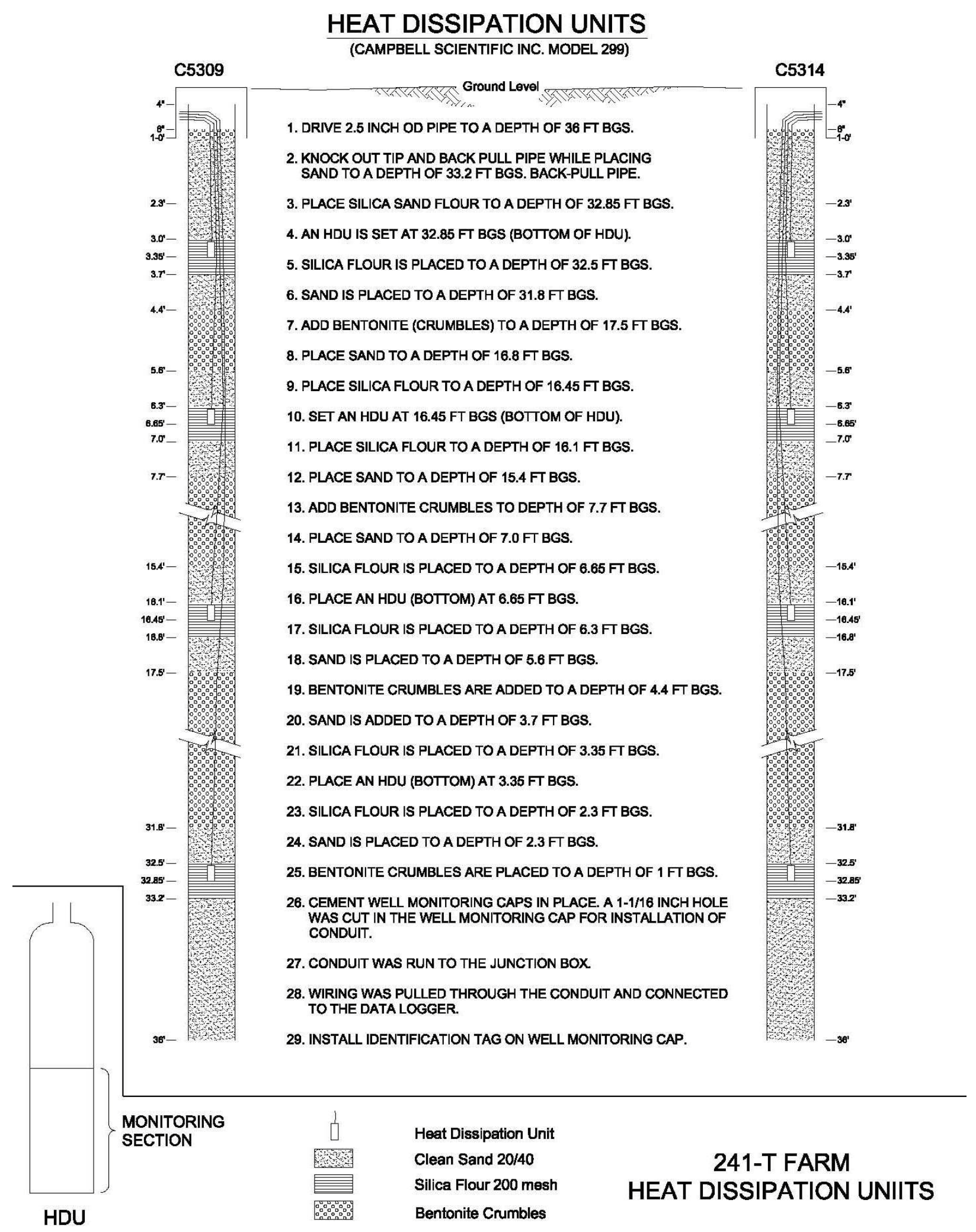

Figure 4.13. Diagram of the Installed HDUs in Nests TA and TB and Packing Material Layering Scheme (after CHG 2006) 


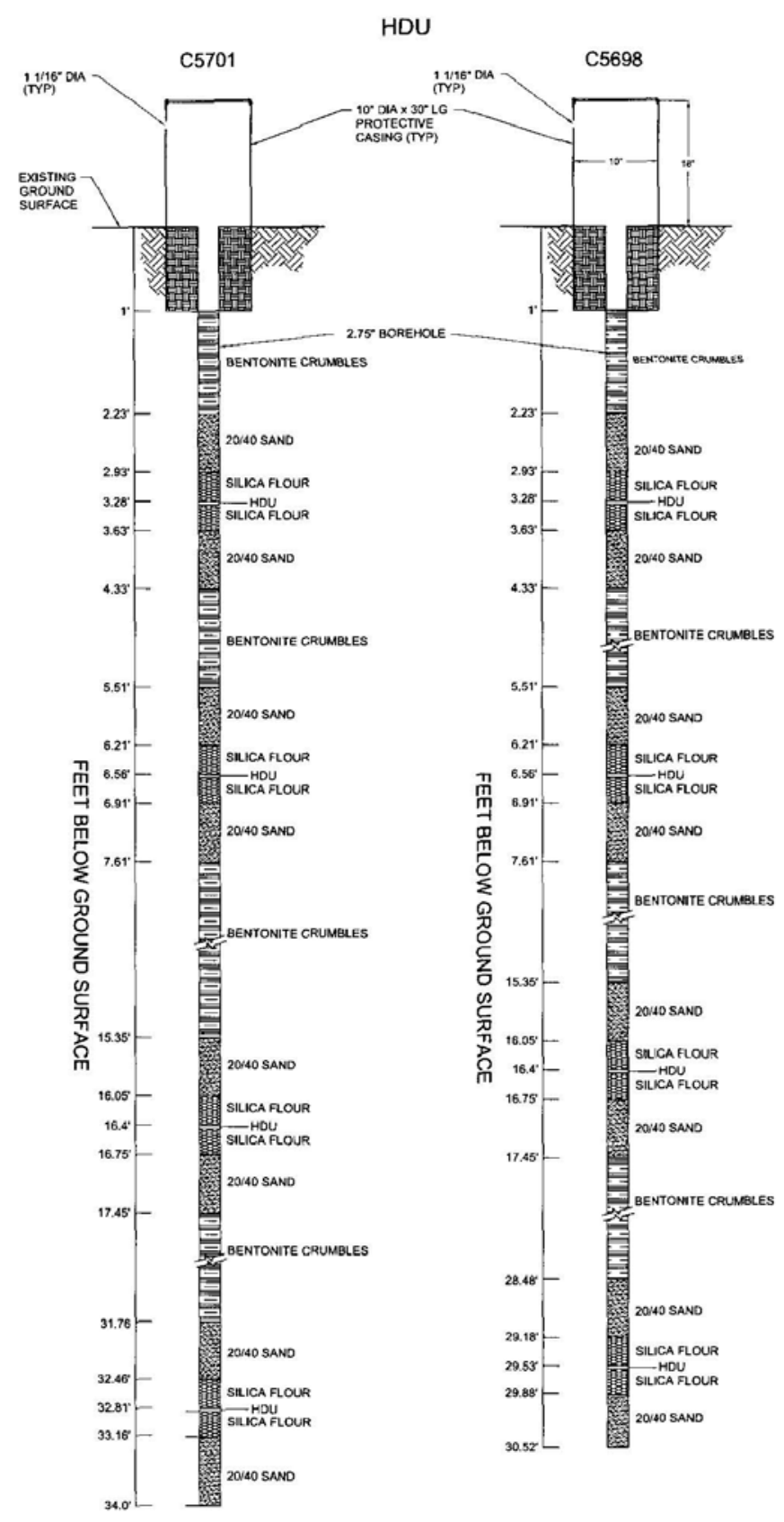

Figure 4.14. Diagram of the Installed HDUs and Packing Material Layering Scheme for Nests TC and TD (after CHG 2007). Outer corrugated metal pipe sleeving is not shown. 


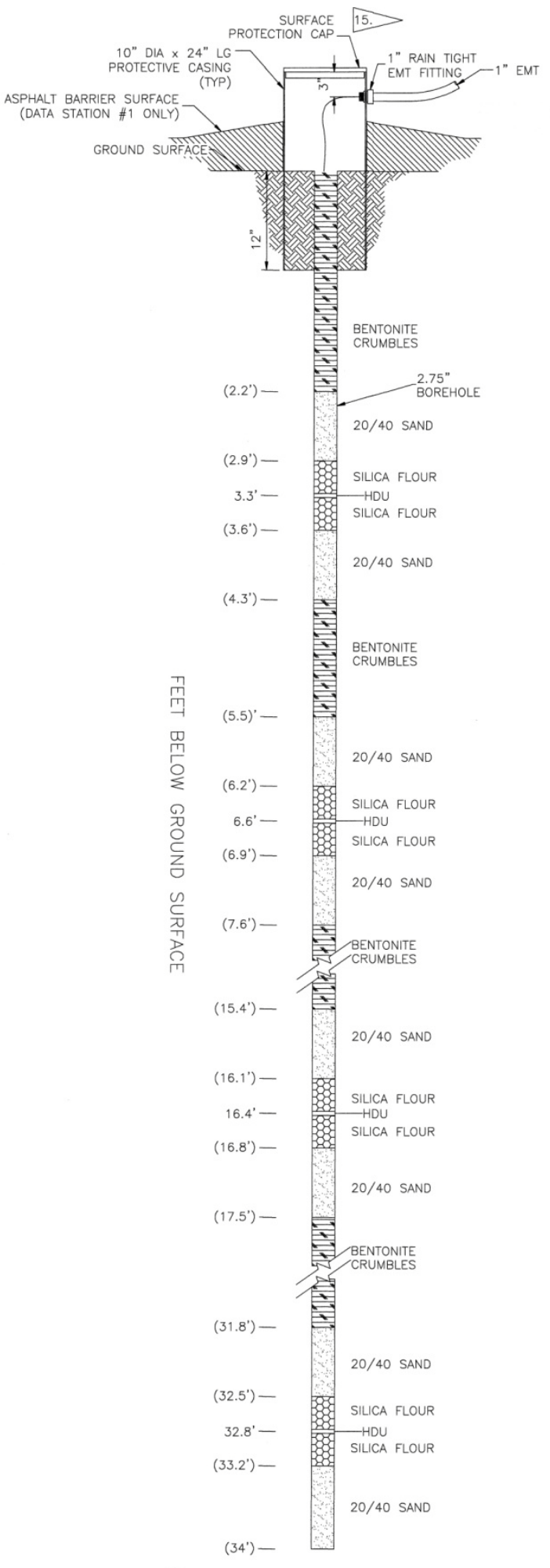

Figure 4.15. Diagram of the Installed HDUs for Nests TYA (station \#2) and TYB (station \#1) (after DOE-ORP 2010) 


\subsubsection{Datalogger and Wiring}

Each instrument nest within the tank farms is connected to a dedicated datalogger adjacent to the instrument nest. Figure 4.16 shows the datalogger enclosure and other infrastructure associated with the datalogger station controlling an instrument Nest. Wiring from each instrument is run through buried conduit that terminates at a transfer box. The wiring then runs from the transfer box to the datalogger enclosure box through a single line of conduit. The datalogger is installed in a weather-tight enclosure containing desiccant bags to reduce moisture inside the box. The enclosure and transfer box are attached to a 6-ft-tall galvanized steel tripod that is securely anchored using 12-in.-long rebar ground stakes. The tripod is grounded to a 5-in. grounding rod.

The datalogger and peripherals are powered by a 12-volt rechargeable battery, which is charged by a solar panel attached to the tripod. The battery is placed within the enclosure. Data from the datalogger are transmitted remotely by a $900-\mathrm{MHz}$ spread spectrum radio to a receiving computer located outside of the tank farm. Each instrument nest is surrounded by T-posts and rope to deter vehicle traffic. The wiring diagrams for the instrument nests inside the T and TY tank farms are given in Figure 4.18 and Figure 4.19, respectively.

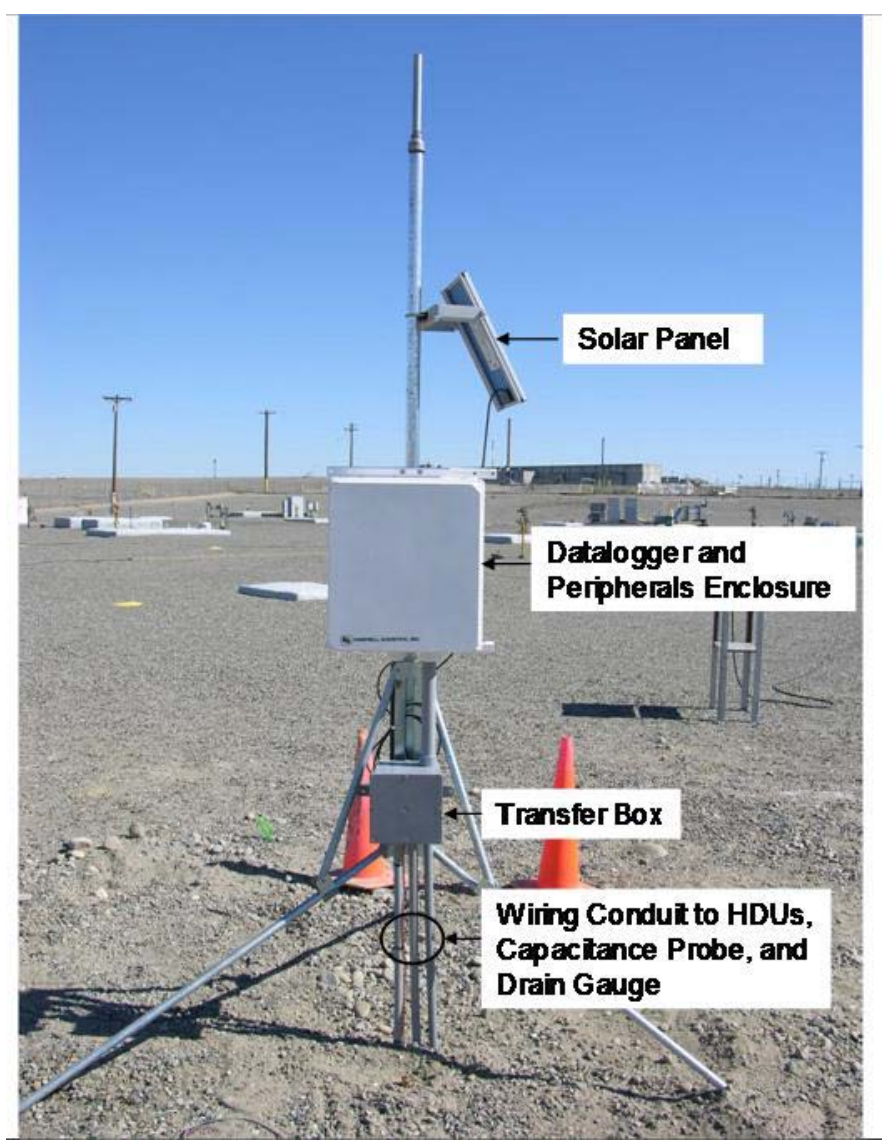

Figure 4.16. Instrument Nest TB Tripod with Attached Solar Panel, Datalogger Enclosure, and Transfer Box 


\subsubsection{Meteorological Station}

The meteorological station was installed along the north fence line, just outside of the $\mathrm{T}$ tank farm. The datalogger and meteorological instruments are mounted on a 6-ft-tall galvanized steel tripod that is securely anchored using 12-in.-long rebar ground stakes. The datalogger controlling the instruments is placed inside a weather-resistant enclosure. The datalogger is powered by a 12-volt rechargeable battery that is charged by a solar panel attached to the tripod. The battery is placed within the enclosure. Data from the datalogger are transmitted remotely by a $900-\mathrm{MHz}$ spread spectrum radio to a receiving computer. Figure 4.17 shows the meteorological station instruments and control components. The wiring diagram for the meteorological station is presented in Figure 4.18.

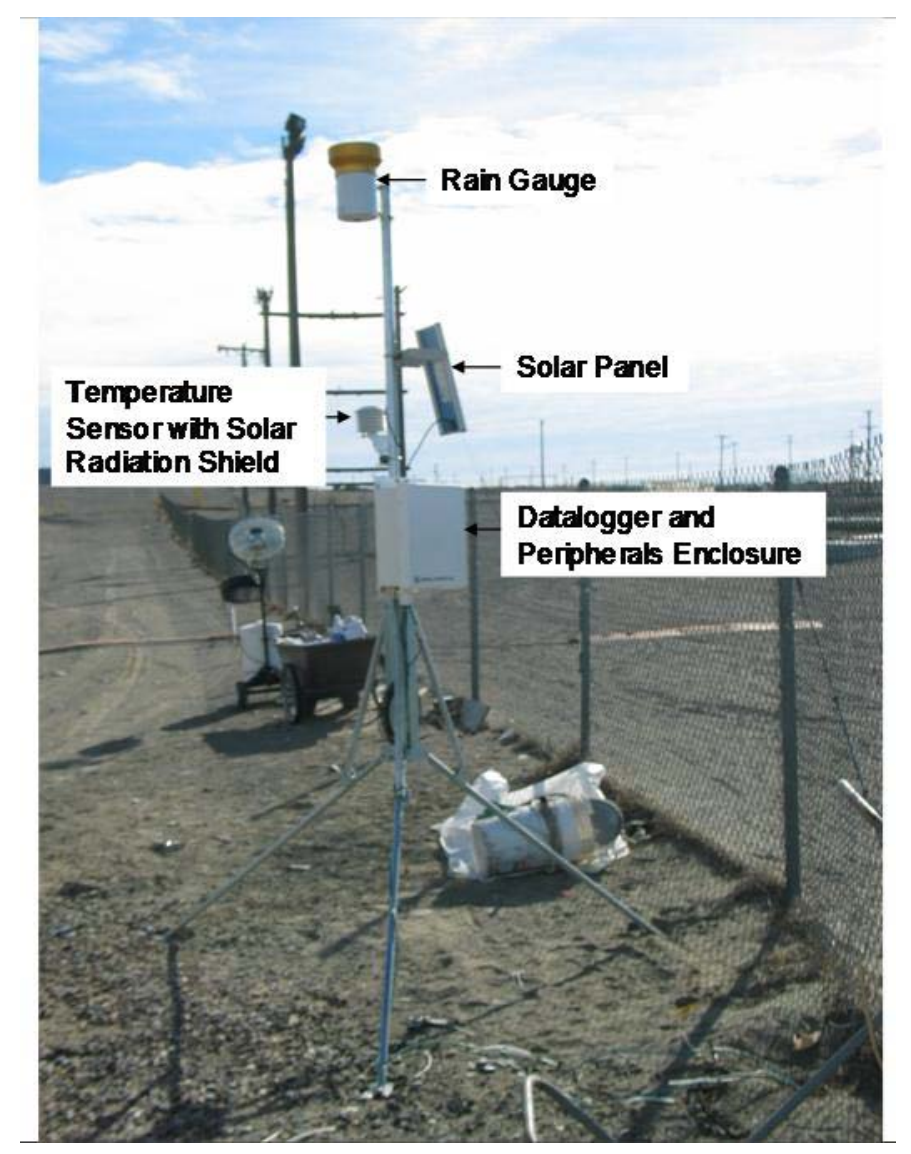

Figure 4.17. Meteorological Station Tripod with Attached Solar Panel, Datalogger Enclosure, Rain Gauge, and Temperature Sensor 


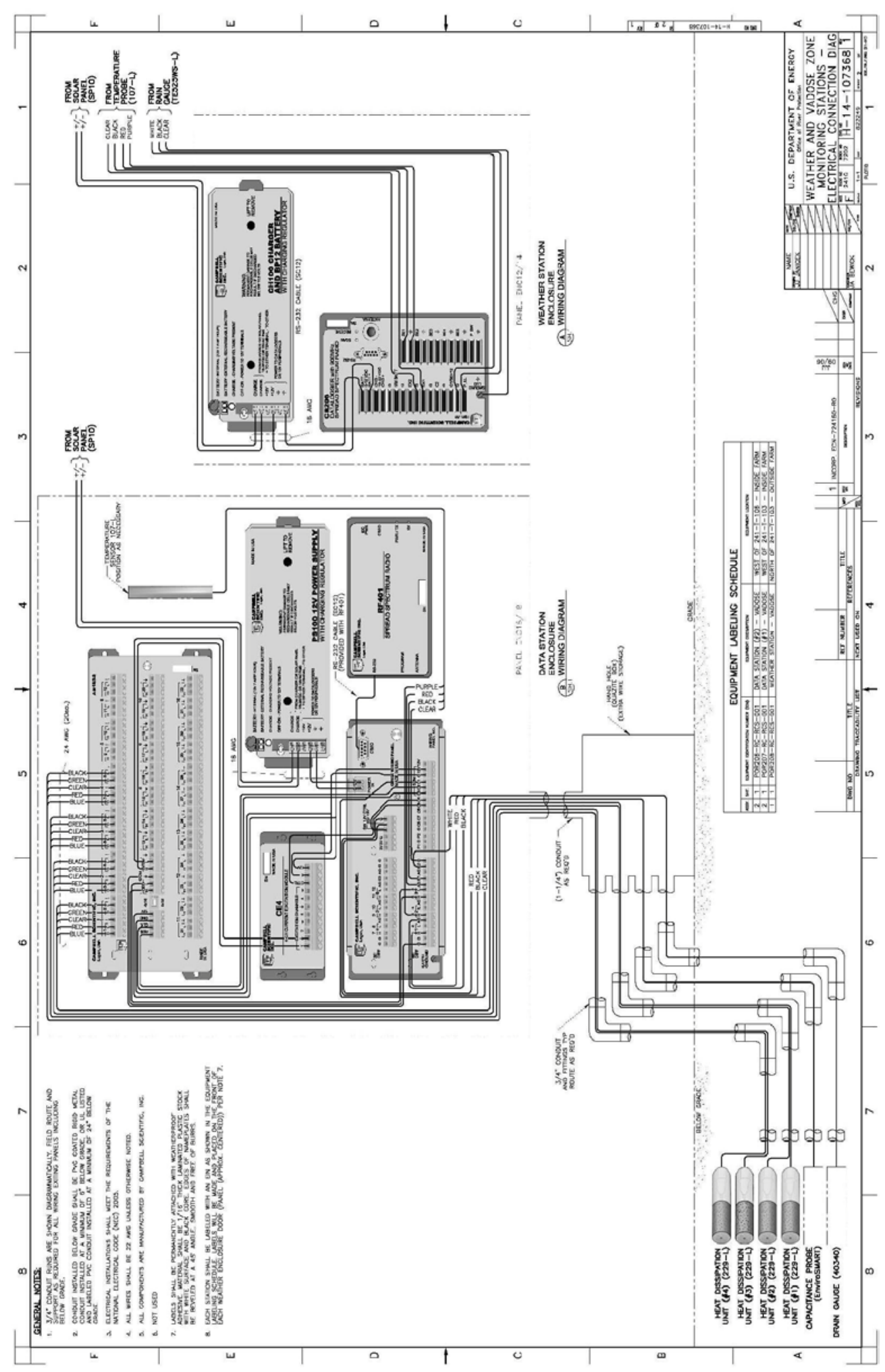

Figure 4.18. Wiring Diagram for $\mathrm{T}$ Tank Farm Instrument Nests and Meteorological Station (after CHG 2006) 


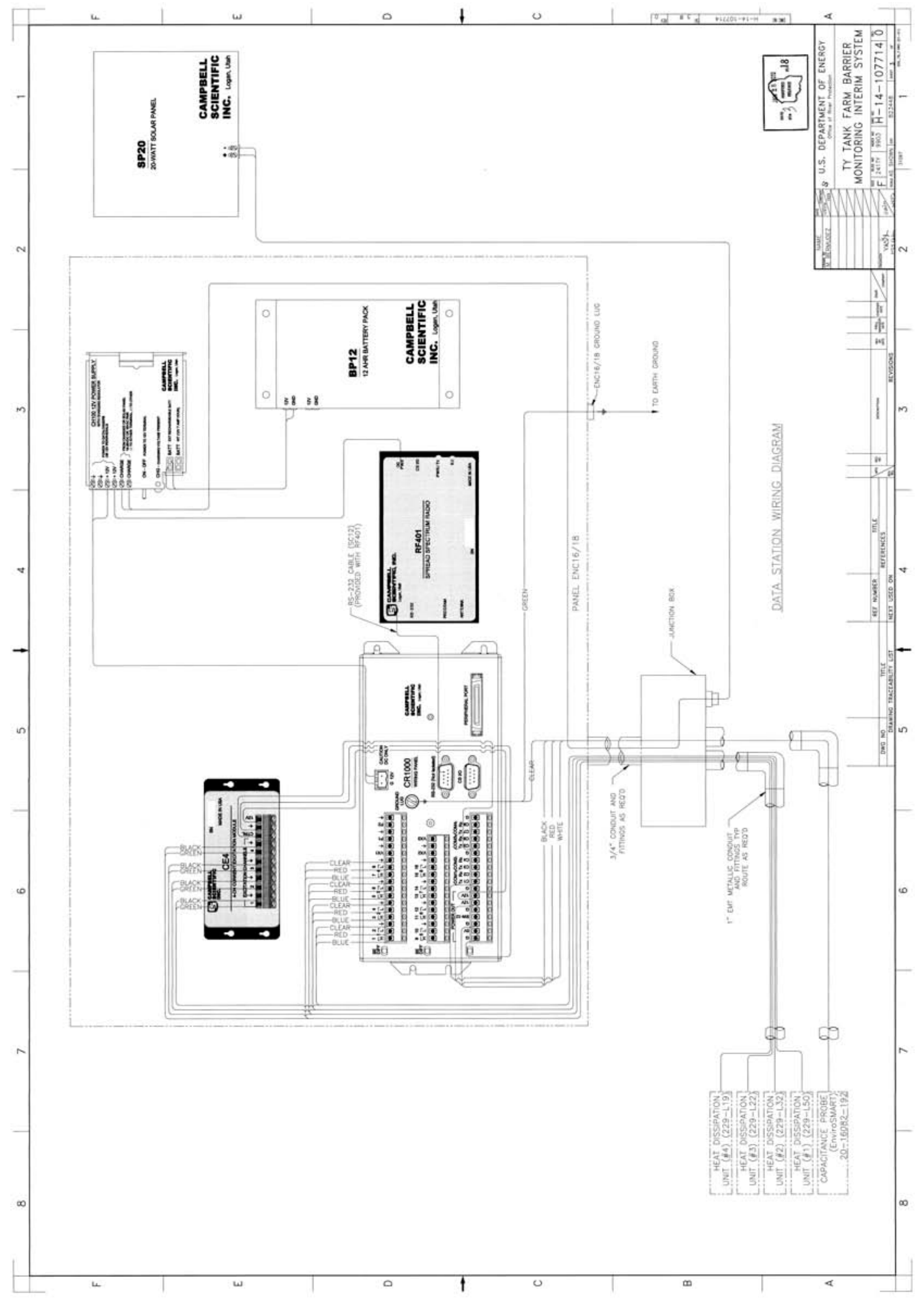

Figure 4.19. Wiring Diagram for TY Tank Farm Instrument Nests (after DOE-ORP 2010) 



\subsection{Vadose Zone Monitoring Plan}

This section presents a monitoring plan to document vadose zone response to the placement of an interim surface barrier in the T and TY tank farms. The monitoring plan employs the measurement of subsurface hydraulic conditions directly beneath and outside of the interim surface barriers as well as meteorological conditions. This section details aspects of the monitoring plan, including:

- the method, frequency, and schedule of data collection

- data archival, reduction, validation, and analysis

- instrument performance and vadose zone response indicators

- contingencies given instrument failure

- data reporting.

\subsection{Measurement Procedures and Frequencies}

This section describes the standard procedures to be used for collecting data under the monitoring design described in Section 4.0 as well as the measurement schedule. Table 5.1 summarizes the five monitoring variables, the monitoring methods, and the approximate monitoring frequency. The monitoring procedures and frequency may be adjusted as more experience is gained.

Table 5.1. Data Collection Method ${ }^{(a)}$ and Approximate Frequency Under Normal Working Condition

\begin{tabular}{lll}
\hline Monitoring Component & \multicolumn{1}{c}{ Monitoring Method } & Monitoring Frequency \\
\hline Soil-Water Content & Neutron Moisture Probe & Quarterly \\
Soil-Water Content & Capacitance Probe & Every 6 hours \\
Soil-Water Pressure & Heat Dissipation Unit & Every 6 hours \\
Soil Temperature & Heat Dissipation Unit & Every 6 hours \\
Air Temperature & Thermister & Hourly \\
Precipitation & Rain Gauge & Hourly \\
\hline
\end{tabular}

(a) All measurements except neutron probe are controlled by dataloggers and taken automatically.

Neutron-moisture-probe measurements are performed manually. The measurements are made once every 3 months, but may vary according to the needs and the variation of soil-water content. Following the neutron-probe-measurement procedures documented in CHG (Ross 2007), profile measurements are made at 1-ft intervals to the depths of the access tubes.

The dataloggers control the probe and store the measurement data of moisture content from capacitance sensors, soil-water pressure and soil temperature from HDUs, precipitation from the rain gauge, and air temperature from the thermister. Soil-moisture-content measurements made with the capacitance probe and HDU measurements to monitor soil-water pressure and soil temperature are taken once or more every 6 hours. At this measurement frequency, a fully charged 7-amp/hour battery (used in TA, TB, and T Met stations) or 12-amp/hour battery (used in TC, TD, TYA, TYB) can last for 
approximately 30 or 50 days without being charged by the solar panel. A concern for a more frequent measurement is that the HDU may drain too much power from the battery, especially in the winter months when cloud cover reduces the capability of the solar panel to charge the battery. Air temperature in the meteorological station is measured every hour or shorter considering that air temperature changes quicker than other variables. Precipitation is measured continuously but reported hourly. The data are transmitted to the project server on a weekly basis.

\subsection{Data Management}

Given the variety and volume of data to be collected, it is critical that the data generated under the monitoring plan be consistently managed in a high-quality format and continuously validated. Doing so allows for reliable routine review and assessment of the functionality of the sensors. The following sections discuss the review and archival of raw data collected by the instrument/datalogger, the reduction of the data into meaningful parameter quantities, and data validation.

\subsubsection{Raw Data Review and Archival}

The data from the dataloggers are in ASCII format and treated as raw data. These data are reviewed before they are archived in a central server. In the case when the data are not complete, the data are reretrieved from the dataloggers. The files from the instrument nests have the same or similar format as described below. However, the file formats are subject to change if needed. The actual format of each data file is described in a data-configuration-information file, which is prepared when a data file is archived.

- The files contain multiple rows of comma-delimited data measured at different times. The commadelimited values for Nests TA and TB correspond to the following variables sequentially:

o Columns 1 to 5: Array No., Year, Day of year, Hour/Min, Seconds

o Columns 6 to 7: Battery voltage (V), Reference temperature $\left({ }^{\circ} \mathrm{C}\right)$

o Columns 8 to 11: HDU initial temperature at 1, 2, 5, $10 \mathrm{~m}$ bgs $\left({ }^{\circ} \mathrm{C}\right)$

o Columns 12 to 15: Temperature difference between 1 second and 30 seconds for HDUs at 1, 2, 5, $10 \mathrm{~m}$ bgs $\left({ }^{\circ} \mathrm{C}\right)$

o Columns 16 to 20: Capacitance-probe scaled frequency from sensors at 0.6, 0.9, 1.3, 1.8, and $2.3 \mathrm{~m}$ bgs

o Columns 21 to 25: Capacitance probe soil-moisture content from sensors at 0.6, 0.9, 1.3, 1.8, and $2.3 \mathrm{~m}$ bgs (volume \%)

- The comma-delimited values for Nests TC, TD, TYA, and TYB correspond to the following variables sequentially:

o Columns 1 to 2: date-time, record number

o Column 3 to 22: the same as those for Nests TA and TB from columns 6 to 25.

- The file from the Meteorological Station contains the comma-delimited values corresponding to the following variables sequentially:

o Column 1: Date/Time

o Column 2: Record number 
o Column 3: Battery voltage (V)

o Column 4: Rain gauge (inch)

o Column 5: Air temperature (deg C).

Note that in case measurement frequencies do not match, the same value for the less-frequent measurements is repeated to keep the same data format as described above. Should there be additional data output, they are added after the above-mentioned data items in a row.

\subsubsection{Data Reduction}

All monitoring data to be collected require a calibration to relate the measured instrument output of an electric signal to a meaningful parameter value. In instances where the instrument calibration is stable and does not change with time, the datalogger performs the calculation, and the calculated value is included in the data file. For other instruments, the application of the calibration equation is done through post processing of the data file. Applying the calibration during post processing allows for the datalogger data file to remain consistent in terms of output fields and to derive the values in the data file.

Data collected under the monitoring plan are managed in a centralized electronic database repository. The database is backed up daily with an automated back-up routine. Except for the neutron moisture probe data, data are automatically or manually downloaded from the datalogger to the project server using a combination of radio-frequency telemetry and/or telephone communication. Data are downloaded from the datalogger to the project server approximately once a week. Neutron-moisture-probe data are copied to the project server after measurements are made. The daily average was determined for the temporally continuous data to reduce the quantity of data and for further analysis. Templates (e.g., EXCEL) are used to apply the specific instrument calibration and to produce time series plots of the data. The processed data and plots are stored in the project server. Figure 5.1 presents a flow diagram describing the monitoring components, instrumentation, and data collection and management.

\subsubsection{Data Validation}

Monitoring data that have been copied to the central server are screened regularly for anomalies by comparing recent data to historical data and using performance indicators defined in the next section. Anomalous data are flagged and further investigated following procedures identified in the data-analysis section. If the data are proven to be erroneous, the data are either corrected, if possible, or noted as suspect. Generally, the data are validated approximately quarterly, but the validation frequency may be adjusted as more experience is gained.

\subsubsection{Data Analysis}

Data analysis is consistent with the purpose, goals, and objectives of the interim-surface-barrier monitoring plan to assess the performance of the interim barrier. Data represent measurements at selected monitoring locations at selected times and include soil-water content, soil-water pressure, soil temperature, and meteorological conditions. 


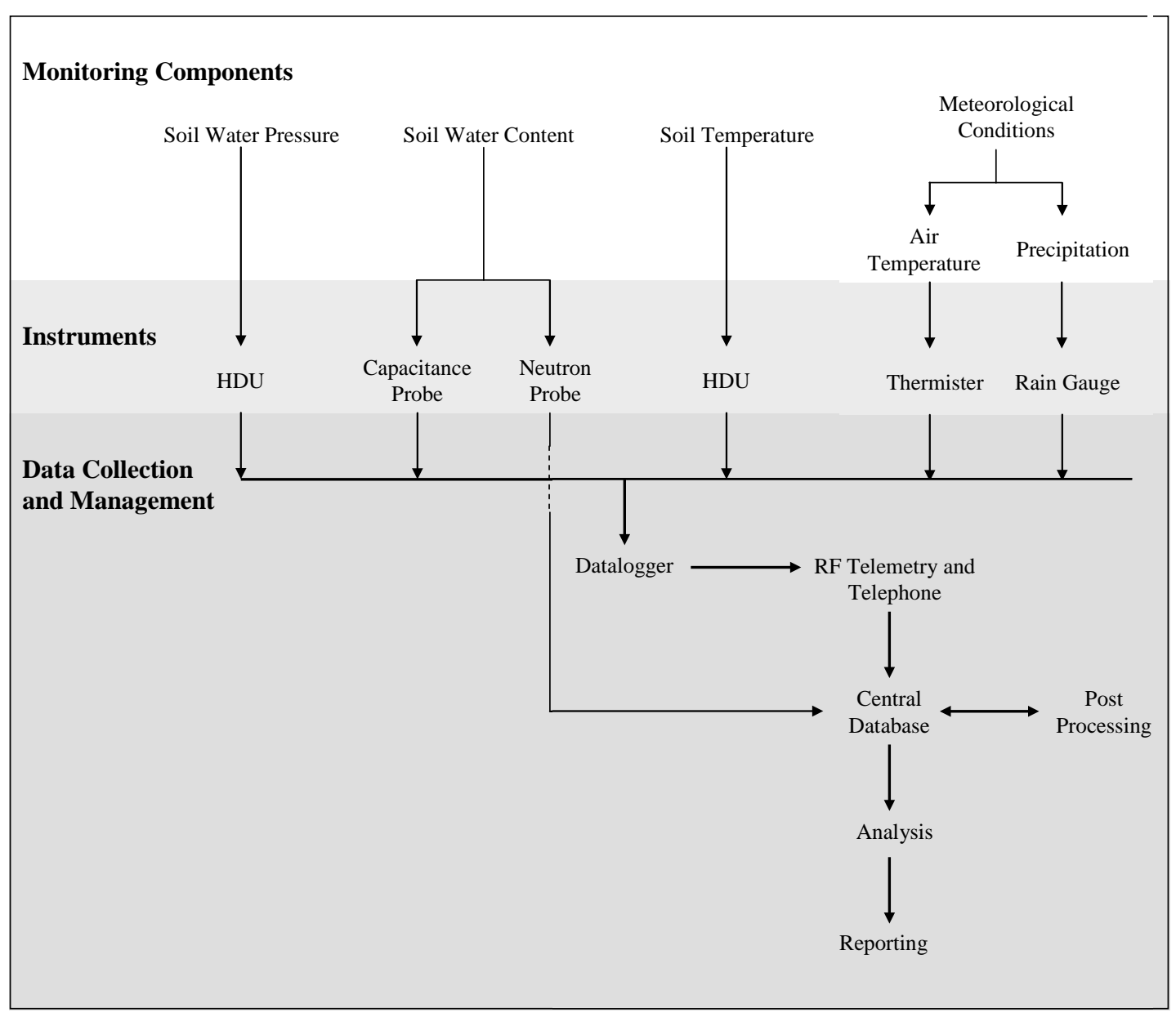

Figure 5.1. Monitoring Components, Instrumentation, and Data Collection and Management Flow Diagram

\subsection{Instrument Performance and Vadose Performance}

This section provides a general discussion of the analysis and assessment of the measurement data, with an emphasis on instrument performance indicators and vadose zone response indicators. If necessary to better represent subsurface conditions, performance indicators may be revised in the future in response to measured background data. The data are summarized in reports that will include tabular and graphical summaries of the monitoring data. The reports will identify any potentially significant anomalies that may require attention.

\subsubsection{Instrument Performance Indicators and Contingencies}

Performance indicators to evaluate instrument functionality are presented. Unmet performance indicators may be a result of real unexpected subsurface conditions, data-transmittal error, postprocessing error, or instrument malfunction. In the case of unexpected subsurface conditions, the performance indicators may require adjustment after baseline data are collected. For instances when performance indicators are not met, suggested troubleshooting methods are presented as contingencies. Table 5.2 summarizes the performance indicators outlined in this section. 
Table 5.2. Instrument Performance Indicators

\begin{tabular}{lll}
\hline \multicolumn{1}{c}{ Monitoring Method } & \multicolumn{1}{c}{ Monitoring Component } & \multicolumn{1}{c}{ Performance Indicator } \\
\hline Neutron Moisture Probe & Soil-Water Content $\left(\theta_{\mathrm{v}}\right)$ & $0.75 \leq \mathrm{SDR} \leq 1.25$ \\
Capacitance Probe & Soil-Water Content $\left(\theta_{\mathrm{v}}\right)$ & $0 \leq \theta_{\mathrm{v}} \leq \theta_{\mathrm{s}}$ \\
Heat Dissipation Unit & Soil-Water Pressure $(\psi)$ & $-100 \mathrm{~m} \leq \psi \leq-0.5 \mathrm{~m}$ \\
Heat Dissipation Unit & Soil Temperature $\left(\mathrm{T}_{\text {soil }}\right)$ & $-5^{\circ} \mathrm{C} \leq \mathrm{T}_{\text {soil }} \leq 35^{\circ} \mathrm{C}$ \\
Rain Gauge & Precipitation $(\mathrm{P})$ & Annual value is within $\pm 50 \%$ \\
Thermister & Air Temperature $\left(\mathrm{T}_{\text {air }}\right)$ & HMS measured P \\
\hline $\begin{array}{l}\text { SDR-standard deviation ratio of neutron count } \\
\mathrm{P}_{\text {winter }} \text {-precipitation from November through March }\end{array}$ & \\
$\theta_{\mathrm{s}}$-saturated water content & \\
\hline
\end{tabular}

\section{$\underline{\text { Neutron Moisture Probe }}$}

Indicators of neutron-probe performance can be acquired using a standard count analysis. A standard count is to be taken before neutron logging as described in Section 2.1. From this analysis, the ratio of the measured standard deviation to the theoretical standard deviation, also called the chi-squared test, is calculated and for a properly functioning probe should be between 0.75 and 1.25 . If the ratio consistently falls outside these limits, then the probe may be experiencing problems.

Appendix A and B of the CPN International users manual (CPN International) and the CHG procedure guide (Ross 2007) provide a list of error messages and their meanings as well as a troubleshooting guide. In addition to the information provided in this document, troubleshooting should include evaluating the post processing of the data to verify that the error does not exist in this step. If problems with the neutron probe are not correctable, another neutron probe may be used.

\section{Capacitance Probe}

The capacitance-probe performance can be examined using published information (e.g., from the Hanford vadose zone hydrogeology data package by Last et al. 2006). The saturated moisture content value serves as the upper-boundary indicator for capacitance-probe-measured moisture content.

Alternatively, a moisture content of zero is set as the lower boundary indicator for the probe. Measurements of capacitance-probe moisture content that fall outside these established boundaries may be considered suspect. Because of subsurface heterogeneities, property uncertainties, and calibration errors, the capacitance-probe performance may be reevaluated after sufficient baseline capacitance probe data are acquired.

If the capacitance-probe measurements do not meet the indicators specified, follow the suggested troubleshooting steps presented in Appendix D to identify the problem. If the problem still cannot be solved, remove the capacitance probe from its access tube and visually inspect the probe for damage and moisture accumulation. Replace sensors on the probe and test, and/or bring the probe in from the field for additional examination and possible repair.

If the above steps do not produce a reasonable result, a new probe can be installed using the existing access tube. 


\section{Heat Dissipation Unit}

Soil-water pressures over the depth of measurement should not be greater than zero, indicating full saturation. However, there is no minimum for soil-water pressure theoretically. The upper bound of the HDU measurement is about $-1.0 \mathrm{~m}$, which is the air-entry pressure of the ceramics of the HDU. Due to the uncertainty of the HDU properties and the error in the calibration function, the values of above $-1.0 \mathrm{~m}$ may be measured (Flint et al. 2002). In this monitoring plan, the HDU measurement range of soil-water pressure, from $-0.5 \mathrm{~m}$ to $-100 \mathrm{~m}$, is used as the performance indicators. Because of subsurface heterogeneities and property uncertainties, the HDU performance may be reevaluated after sufficient baseline capacitance probe data are acquired.

A 50-year monitoring record of soil temperature (Hoitink et al. 2005) in a bare surfaced gravelly sand soil near the HMS provides a range of soil temperatures to expect in T tank farm. At the 0.9-m depth, the Hoitink et al. (2005) data show that hourly extremes at this site were a minimum temperature of $0.1^{\circ} \mathrm{C}$ and a maximum of $29.6^{\circ} \mathrm{C}$. Given the observed results, soil-temperature measurements at a 1-m depth or deeper should not exceed $30^{\circ} \mathrm{C}$ and should not be less than $0^{\circ} \mathrm{C}$. After baseline HDU data are acquired, this performance indicator may be adjusted based on the HDU measurements. However, depending on the color, the surface barrier may transmit heat into the sub-surface soil that may exceed $30^{\circ} \mathrm{C}$. So it is expected that the thermal regime under the surface barrier may be quite different than that outside the barrier. In this monitoring plan, the HDU measurement range of soil temperature, from -5 to $35^{\circ} \mathrm{C}$, is used as the performance indicators.

If the HDU soil-water pressure or soil temperature measurements do not meet the indicators specified, follow the suggested troubleshooting steps presented in Appendix D to identify the problem. If the above steps do not produce a functioning probe, the installation of new HDUs may be necessary.

\section{Precipitation and Air Temperature}

Performance bounds for the rain-gauge and air-temperature sensors are set relative to those at the HMS. For calendar year 2004, annual precipitation and annual average temperature measured at the 200W monitoring station varied between $-35.3 \%$ and $-1.3 \%$, respectively, from those measured at the HMS (Hoitink et al. 2005). Using this information, the performance indicator for the rain gauge at the $\mathrm{T}$ tank farm is set to be $\pm 50 \%$ of the HMS precipitation. The annual average air temperature is set as the performance indicator for the thermisters in the T and TY tank farms and is $\pm 5 \%$ of the HMS-measured annual average temperature.

If the rain-gauge or air-temperature measurements do not meet the indicators specified, follow the suggested troubleshooting steps presented in Appendix D to identify the problem. If the problem of the rain gauge still cannot be solved, apply water to the rain gauge to see if a tipping event is observed.

If the above steps do not produce a functioning gauge or thermister, the instrument may be removed, and a new instrument may need to be installed. 


\subsubsection{Vadose Zone Response Indicators}

The vadose zone response is monitored by examining systematic changes of subsurface conditions over time as represented by time-history trends at the monitoring locations. The trends in subsurface conditions beneath the interim surface barrier are used to help answer whether the surface barrier significantly and adequately reduces the downward flux of soil water relative to background conditions.

A clear vadose zone response indicator is a near-surface instrument response after precipitation or snow-melt events. Adequate surface-barrier performance should result in no observable increases in moisture content, drainage, or soil-water pressure (less negative) immediately after precipitation or snowmelt events. Such instrument responses would indicate percolating water and general surface-barrier failure, provided the instruments are functioning.

A secondary component of surface barrier performance is the potential advective movement and buildup of water vapor immediately beneath the low-permeable surface barrier. Condensation of the water vapor would result in increased soil-water content immediately below the surface barrier. The vaporization-condensation process does not indicate any problem of the surface barrier because there is no net gain or loss of water mass across the barrier. The seasonal water movement that might observed by the capacitance probe monitoring will most likely be because of thermally induced vapor and liquid flow as described above, and it is expected that this fluctuation will persist for the life of the barrier. The magnitude of the water content changes and the depth of penetration depend on the soil type and initial water content of the soil, but for typical Hanford conditions, it should not extend deeper than a few 10s of centimeters into the subsurface. 



\subsection{Quality Assurance}

To verify the quality of the project, the organization performing the monitoring has prepared a project management plan (PMP) and a quality assurance plan (QAP). The PMP and QAP may be revised in the course of the monitoring. Quality specialists provide quality assurance support for the project. Project members are required to follow the PMP and QAP. 



\subsection{References}

ARHCO_Atlantic-Richfield Hanford Company. 1973. 241-T-106 Tank leak investigation. ARH_2874, Atlantic-Richfield Hanford Company, Richland, Washington.

CHG_-CH2M HILL Hanford Group, Inc. 2005. Field Investigation Report for Waste Management Areas T and TX-TY, Rev. 0-A. RPP-23752, Richland, Washington.

CHG—CH2M HILL Hanford Group, Inc. 2006. "Weather and Vadose Zone Monitoring Stations, Electrical Connection Diagram,” Rev. 0, Sheet 2, H-14-107368, Richland, Washington.

CHG-CH2M HILL Hanford Group, Inc. 2007. 241-T Tank Farm Vadose Zone Instrumentation. CH2M HILL Engineering Change Notice, ECN-724716 R2, CH2M HILL Hanford Group, Inc., Richland, Washington.

CSI—Campbell Scientific, Inc. 2004. Model 107 Temperature Probe Instruction Manual.

CSI_Campbell Scientific, Inc. 2007. "Soil Volumetric Water Content/Salinity Probes Models EasyAG II and EnviroSMART,” (brochure). Logan, Utah.

CSI-Campbell Scientific, Inc. 2008. Model 107 Temperature Probe Instruction Manual Revision 10/08. Logan, Utah.

CSI-Campbell Scientific, Inc. 2009a. EnviroSMART Soil Water Content Profile Probes - Instruction Manual Revision 3/09. Logan, Utah.

CSI_Campbell Scientific, Inc. 2009b. “Temperature Probes Models 107 and 108,” (brochure). Logan, Utah.

CSI—Campbell Scientific, Inc. 2009c. E525-series Texas Electronics Tipping Bucket Rain Gages, (brochure). Logan, Utah.

DOE_U.S. Department of Energy. 2005. Hanford Tank Farms Vadose Zone Monitoring Project, Annual Monitoring Report for Fiscal Year 2004. DOE-EM/GJ777-2004, Grand Junction Office, Grand Junction, Colorado.

DOE-ORP-U.S. Department of Energy-Office of River Protection. 2010. TY Tank Farm Barrier Monitoring System. H-14-107714 Rev. 0, Richland Washington.

Everett LG, LG Wilson, and EW Hoylman. 1984. Vadose Zone Monitoring for Hazardous Waste Sites. Noyes Data Corporation, Parkridge, New Jersey.

Flint AL, GS Campbell, KM Ellett, and C Calissendorff. 2002. "Calibration and temperature correction of heat dissipation matric potential sensors.” Soil Sci. Soc. Am. J. 66:1439-1445. 
Fredlund DG, F Shuai, and M Feng. 2000. "Use of a new thermal conductivity sensor for laboratory suction measurement.” In: Unsaturated soil for Asia. Rahardjo et al. (ed.). Proc. of the Asian Conf. on Unsaturated Soils Unsat-Asia 2000. P. 275-280. Singapore.

Hoitink DJ, KW Burk, JV Ramsdell Jr, WJ Shaw. 2005. Hanford Site Climatological Summary 2004 with Historical Data. PNNL-15160, Pacific Northwest National Laboratory, Richland, Washington.

IAEA-International Atomic Energy Agency. 1970. Neutron Moisture Gauges. Tech. Rep. Ser. No. 112, Vienna, Austria.

Last GV, EJ Freeman, KJ Cantrell, MJ Fayer, GW Gee, WE Nichols, BN Bjornstad, and DG Horton. 2006. Vadose Zone Hydrogeology Data Package for Hanford Assessments . PNNL-14702 Rev. 1, Pacific Northwest National Laboratory, Richland, WA.

McMahon WJ. 2007. "Performance Simulations of an Interim Surface Barrier Over the 241-T-106 Tank Release.” In: Design Analysis for T-Farm Interim Surface Barrier (TISB), RE Bauer (ed). RPP-33431 Rev. 0, Section 8. CH2M Hill Hanford Group, Inc., Richland, Washington.

Myers DA. 2005. Field Investigation Report for Waste Management Areas T-TX-TY. RPP-23752, CH2M Hill Hanford Group, Richland, Washington.

Paltineanu IC and JL Starr. 1997. "Real-time soil water dynamics using multisensor capacitance probes: laboratory calibration.” Soil Sci. Soc. Am. J. 61:1576-1585.

Reece C. 1996. "Evaluation of a line heat dissipation sensor for measuring soil matric potential.” Soil Sci. Soc. Am. J. 60:1022-1028.

Rodgers MJ. 2010. Waste tank summary status report for month ending December 31, 2009. HNF-EP0182, 2010, rev. 261, Washington River Protection Solutions, Richland, Washington.

Ross L. 2007. “Tank Farm Plant Operating Procedure - Operate Model 503DR Hydroprobe Neutron Moisture Detection.” TO-320-022, B-8. CH2M Hill Hanford Group, Richland, Washington.

Routson RC, WH Price, DJ Brown, and KR Fecht. 1979. High-level waste leakage from the 241-T-106 tank at Hanford. RHO-ST-14, Rockwell Hanford Operations, Richland, Washington.

Scanlon BR, BJ Andraski, and J Bilskie. 2002. "Miscellaneous methods for measuring matric or water potential.” In: Methods of Soil Analysis Part 4 Physical Methods. Dane JH and GC Topp (eds.), pp. 643654. Soil Science Society of America Inc. Madison, Wisconsin.

Sentek Pty Ltd. 2001. Calibration of the Sentek Pty Ltd Soil Moisture Sensors. Stepney, Australia.

Shiozawa S and GS Campbell. 1990. “Soil thermal conductivity.” Remote Sens. Rev. 5:301-310.

Smith-Rose RL. 1933. “The electrical properties of soils for alternating currents at radio frequencies.” Proc. R. Soc. London 140:359. 
Starr JL and IC Paltineanu. 2002. “Capacitance Devices.” In: Methods of soil analysis Part 4 Physical methods, Dane JH and GC Topp (eds.), pp. 463-475. Soil Science Society of America, Inc., Madison Wisconsin.

van Bavel CHM, N Underwood, and RW Swanson. 1956. "Soil moisture measurement by neutron moderation.” Soil Sci. 82:29-41.

Ward AL, TC Caldwell, and GW Gee. 2000. Vadose Zone Transport Field Study: Soil Water Content Distribution by Neutron Moderation. PNNL-13795, Pacific Northwest National Laboratory, Richland, Washington.

Ward AL and RS Wittman. 2009. Calibration of a Neutron Hydroprobe for Moisture Measurements in Small-Diameter Steel-Cased Boreholes. PNNL-18539, Pacific Northwest National Laboratory, Richland, Washington.

Zhang ZF and JM Keller. 2006. T Tank Farm Interim Cover Test - Design Plan. PNNL-15913 Rev. 0, Pacific Northwest National Laboratory, Richland, Washington.

Zhang ZF, JM Keller, and CE Strickland. 2007. T Tank Farm Interim Surface Barrier Demonstration Vadose Zone Monitoring Plan. PNNL-16538, Pacific Northwest National Laboratory, Richland, Washington.

Zhang ZF, CE Strickland, JM Keller, CD Wittreich, and HA Sydnor. 2008. T Tank Farm Interim Surface Barrier Demonstration -Vadose Zone Monitoring FY07 Report. PNNL-17306, Pacific Northwest National Laboratory, Richland, Washington. 

Appendix A

Normalization and Calibration Procedures for Heat Dissipation Unit (HDU) Installed in the T Tank Farm 



\section{Appendix A: Normalization and Calibration Procedures for Heat Dissipation Unit (HDU) Installed in the T Tank Farm}

This procedure was used for the T tank farm HDUs. It is adapted from HDU normalization and calibration procedures discussed in Scanlon et al. (2002) and Flint et al. (2002).

Normalization

1. Place oven-dried desiccant and one or more HDUs in a sealed container and allow to equilibrate for a minimum of 24 hours. If the HDU ceramic has been previously wetted, the HDU is best dried in an oven not to exceed $60^{\circ} \mathrm{C}$.

2. Measure temperature rise in an HDU using the same heat source current and heating time to be used for the field measurements. This is the temperature rise for dry ceramic $\left(\Delta \mathrm{T}_{\mathrm{d}}\right)$. Repeat Step 2 for other HDUs.

3. Place one or more HDUs in deaired water and allow to equilibrate for a minimum of 24 hours.

4. Remove an HDU from water and immediately measure the HDU temperature rise using the same heat source current and heating time to be used for the field measurements. This is the temperature rise for saturated ceramic $\left(\Delta \mathrm{T}_{\mathrm{w}}\right)$. Repeat Step 4 for other HDUs.

\section{Calibration}

1. Wet soil to desired soil water pressure condition. Wet soil by thoroughly mixing soil and adding water. The amount of water needed to obtain a specified soil water pressure condition can be approximated with prior knowledge of the soil's water characteristics curve and the mass of soil.

2. Obtain a minimum of two tensiometers to provide an independent reading of soil water pressure.

3. Pack wetted soil, HDUs, and tensiometers into a bucket of 5 gallons or larger. A minimum of three HDUs should be used to obtain the calibration.

4. Seal the top of the bucket to reduce evaporative water loss from the soil.

5. Measure HDU temperature rise using the same heat source current and heating time to be used for the field measurements.

6. Measure tensiometer pressure.

7. Once the HDU temperature rise and tensiometer pressure measurements stabilize, record tensiometer pressure and HDU temperature rise. This is one calibration point.

8. Repeat steps 1 through 7 with a different soil water content until all desired calibration points are obtained. Obtain a minimum of three calibration points. The calibration points should span the anticipated HDU measurement range in the field.

9. Fit appropriate calibration curve to paired soil water pressure and normalized HDU data points. 


\section{$\underline{\text { References }}$}

Flint AL, GS Campbell, KM Ellett, and C Calissendorff. 2002. "Calibration and temperature correction of heat dissipation matric potential sensors.” Soil Sci. Soc. Am. J. 66:1439-1445.

Scanlon BR, BJ Andraski, and J Bilskie. 2002. "Miscellaneous methods for measuring matric or water potential.” In: Methods of Soil Analysis Part 4 Physical Methods, JH Dane and GC Topp (eds.).

P. 643-654. Soil Science Society of America Inc., Madison, Wisconsin. 
Appendix B

PNNL-SA-12 Calibration of Heat Dissipation Water Potential Sensor Using Pressure Plate 



\section{Appendix B: PNNL-SA-12 Calibration of Heat Dissipation Water Potential Sensor Using Pressure Plate}

\begin{tabular}{|c|c|c|c|}
\hline \multicolumn{2}{|c|}{ PNWD Procedure } & \multicolumn{2}{|l|}{ Page 1 of 5} \\
\hline \multicolumn{2}{|c|}{$\begin{array}{l}\text { Title: Calibration of Heat Dissipation } \\
\text { Water Potential Sensor using Pressure } \\
\text { Plate }\end{array}$} & \multicolumn{2}{|c|}{$\begin{array}{l}\text { Org. Code: D38445 } \\
\text { Procedure No.: PNNL-SA-12 Calibration of Heat Dissipation } \\
\text { Water Potential Sensor using Pressure Plate } \\
\text { Rev. No.: } 0\end{array}$} \\
\hline \multicolumn{2}{|c|}{$\begin{array}{l}\text { Work Location: } \\
\text { General }\end{array}$} & \multicolumn{2}{|c|}{ Effective Date: January 2010} \\
\hline \multicolumn{2}{|c|}{ Author: CE Strickland } & \multicolumn{2}{|l|}{ Supersedes Date: } \\
\hline \multirow{2}{*}{\multicolumn{2}{|c|}{$\begin{array}{l}\text { Identified Hazards: } \\
\square \text { Radiological } \\
\square \text { Hazardous Materials } \\
\square \text { Physical Hazards } \\
\square \text { Hazardous Environment } \\
\square \text { Other: }\end{array}$}} & \multicolumn{2}{|c|}{ 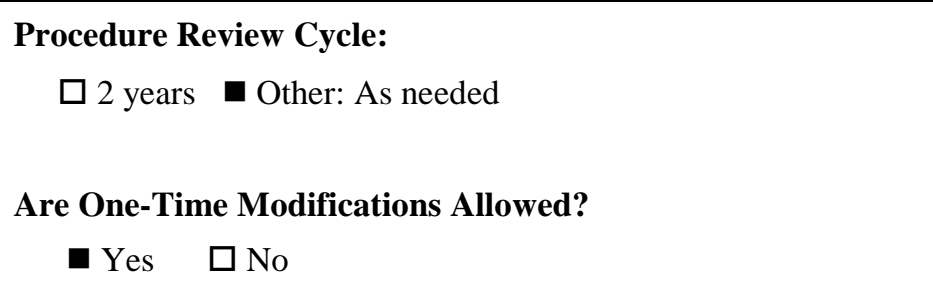 } \\
\hline & & \multicolumn{2}{|c|}{$\begin{array}{l}\text { Identified Use Category: } \\
\text { घandatory Use } \\
\square \text { Reference Use }\end{array}$} \\
\hline & Person Signing & Signature & Date \\
\hline \multicolumn{4}{|c|}{ Author } \\
\hline \multicolumn{4}{|c|}{ Technical Reviewer (optional) } \\
\hline \multicolumn{4}{|c|}{ Immediate or Project Manager (Approval) } \\
\hline \multicolumn{4}{|c|}{ Concurrence as appropriate: } \\
\hline & Building Manager & & \\
\hline$\square$ & Safety and Health & & \\
\hline$\square$ & Quality Engineer & & \\
\hline$\square$ & Radiological Control & & \\
\hline$\square$ & Cognizant Space Manager & & \\
\hline & Other & & \\
\hline
\end{tabular}




\section{PNWD Procedure}

Org. Code: D38445

Procedure No.: PNNL-SA-12

Rev. No.: 1

Title: Calibration of Heat Dissipation Water Potential Sensor using Pressure Plate

Purpose/Scope (optional)

This procedure describes the calibration and use of the Heat Dissipation Unit (HDU) manufactured by Campbell Scientific, Inc. and is called “229 Heat Dissipation Matric Water Potential Sensor” (Figure 1). This procedure is derived from operating instructions found in the 229 Heat Dissipation Matric Water Potential Sensor Instruction Manual (Campbell Scientific, Inc. 2009).

Soil-water-pressure measurements can be used to track wetting or drying processes, identify pressure gradients, and produce estimates of water fluxes using available soil-water-content data and soil hydraulic properties.

An HDU can be used to indirectly measure the soil matric potential $(\psi s)$ by measuring the thermal conductivity (k) of the reference matrix, which is part of an HDU and often is made of porous ceramics. The water content of the ceramic matrix $\left(\theta_{\mathrm{vc}}\right)$ changes with the matric potential of the ceramic matrix $\left(\psi_{\mathrm{c}}\right)$ and causes a corresponding change in $\mathrm{k}$. Because the equilibrium between the sensor and the soil is a matric potential (i.e., $\psi_{\mathrm{s}}=\psi_{\mathrm{c}}$ ) rather than a water-content equilibrium, the measured thermal conductivity of the reference matrix is related to the matric potential of the soil. HDU measurement and calibration are independent of soil texture because the heat pulse is restricted to the ceramic. It is also independent of salinity because the method is independent of electrical conductivity.

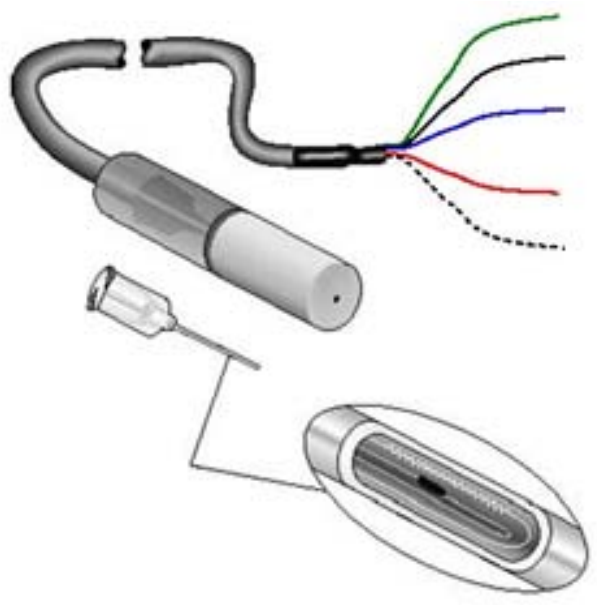

Figure 1. A 229 Heat-Dissipation Matric Water Potential Sensor is shown at the top (the dashed line is in clear color). The hypodermic assembly (without epoxy and ceramic) is shown just below. A cutaway view shows the longitudinal section of the needle with heater and thermocouple junction. 
Applicability

This procedure applies to the general operation and calibration of the Heat Dissipation Unit designed for soil matric potential measurements. This procedure applies to all users who have received verbal instruction from the cognizant scientist.

Precautions and Limitations

Operational flexibility is built into this procedure where process steps or sections can be omitted from Process steps can be completed out of order. The sole requirement is that the matric potential of the medium surrounding the sensor be known. There are two elements to the HDU calibration: 1) a normalization procedure is used for removing variation between the HDU sensors (the normalization of temperature rise is sensor specific, and thus all sensors need to be normalized and 2) a calibration procedure is used to develop the relationship between soil matric potential and the normalized temperature rise measured by the HDU. Normalization and calibration procedures are adapted from Scanlon et al. (2002) and Flint et al. (2002).

Work Instructions

1.0 Normalization

1.1 Place one or more HDUs over-dried desiccant in a sealed container and allow to equilibrate for a minimum of 24 hours. Desiccant should be indicating DRIERITE, which is impregnated with cobalt chloride so that it changes from blue when dry to pink upon absorption of moisture. If the HDU ceramic has been previously wetted, the HDU is best dried in an oven for not to exceed $60^{\circ} \mathrm{C}$. Full dryness of ceramic can be gauged when weight is static on a two place balance, typically not more than 24 hours.

1.2 Measure temperature rise of each HDU using the same $50 \mathrm{~mA}$ source current and using a heating time of 30 seconds. This is the temperature rise for dry ceramic $(\Delta \mathrm{Td})$.

1.3 Place one or more HDUs in de-aired water under vacuum and allow to equilibrate for a minimum of 24 hours. Water can be de-aired either by boiling or by degassing under vacuum until air bubbles are no longer visible.

1.4 Measure HDU temperature rise using the same heat source current and heating time to be used for the field measurements. This is the temperature rise for saturated ceramic $(\Delta T w)$.

\subsection{Calibration}

2.1 Prepare 5 bar ceramic pressure plate by soaking in de-aired water for at least 24 hours.

2.2 Place ceramic plate in 5 bar pressure kettle.

Note: Pressure kettle operates under 40 psi and therefore no additional requirements are applicable as specified in the PNNL HDI/SBMS subject area, Pressure Systems. 
2.3 Arrange 1 or more HDUs on ceramic plate providing sufficient separation between adjacent sensors so that there no contact between them.

2.4 Pack fine grain soil such as silt loam or silica flour on top of ceramic plate and completely surrounding all sensors. Pack should be carried out under water by alternating application of water and soil, maintaining constant saturated conditions.

2.5 Seal the top of the pressure kettle and attach to pressure control system.

2.6 Set pressure to first pressure step.

2.7 Measure HDU temperature rise using the same heat source current and heating time to be used for the field measurements. Continue measurements until equilibrium is obtained.

2.8 Repeat steps 2.1 through 2.7 using different pressures until all desired calibration points are obtained and recorded in an excel file. Obtain a minimum of three calibration points. The calibration points should span the anticipated HDU measurement range in the field. The calibration curve will be printed and added to a project laboratory record book.

2.9 Fit appropriate calibration curve to paired soil water pressure and normalized HDU data points. The most commonly used function is:

$$
\psi=e^{\left(\alpha^{*} \Delta T+\beta\right)}
$$

With $\psi$ the soil water potential, $\Delta T$ is the temperature rise, and $\alpha$ and $\beta$ are fitted parameters. The equation suggested is not required and alternative functional descriptions may be used.

NOTE: The upper measurement range of the HDUs is controlled by the air-entry pressure (bubbling pressure) of the matrix material of the probe, which is generally $-10 \mathrm{kPa}(-1 \mathrm{~m})$. Matric potentials above the air-entry pressure (i.e., between 0 and $-10 \mathrm{kPa}[-1 \mathrm{~m}]$ ) cannot be measured because the matrix material is essentially saturated. The lower measurement limit is generally considered to be about -1 MPa (-100 m) (Reece 1996). However, less-accurate measurements can be made between -1 and $-35 \mathrm{MPa}(-100$ and $-3500 \mathrm{~m})$.

\section{Exhibits/Attachments}

None 
Source Information/References

Campbell Scientific, Inc. 2009. 229 Heat Dissipation Matric Water Potential Sensor Instruction Manual.

Flint AL, GS Campbell, KM Ellett, and C Calissendorff. 2002. “Calibration and temperature correction of heat dissipation matric potential sensors.” Soil Sci. Soc. Am. J. 66:1439-1445.

Scanlon BR, BJ Andraski, and J Bilskie. 2002. "Miscellaneous methods for measuring matric or water potential.” In: Methods of Soil Analysis Part 4 Physical Methods, JH Dane and GC Topp (eds.). P. 643-654. Soil Science Society of America Inc., Madison, Wisconsin. 



\section{Appendix C}

\section{Raw Data of the TY Tank Farm HDU Normalization/Calibration}

Operator: Chris Strickland

Date: Jan. to Feb., 2010 



\section{Appendix C: Raw Data of the TY Tank Farm HDU Normalization/Calibration}

TY Farm HDU Calibration - Initial Temperature $\left({ }^{\circ} \mathrm{C}\right)$

\begin{tabular}{|c|c|c|c|c|c|c|c|c|c|c|}
\hline \multirow{2}{*}{ TIMESTAMP } & \multirow{2}{*}{ RECORD } & \multirow{2}{*}{$\begin{array}{c}\mathrm{P} \\
\text { (psi) }\end{array}$} & \multicolumn{8}{|c|}{ Sensor Number } \\
\hline & & & 1 & 9 & 11 & 12 & 13 & 14 & 15 & 16 \\
\hline 1/26/2010 13:20 & 9829 & 3 & 21.7 & 22.33 & 21.7 & 22.33 & 21.7 & 22.33 & 21.7 & 22.33 \\
\hline 1/26/2010 13:30 & 9830 & 3 & 21.78 & 22.34 & 21.78 & 22.34 & 21.78 & 22.34 & 21.78 & 22.34 \\
\hline 1/26/2010 13:40 & 9831 & 3 & 21.87 & 22.38 & 21.87 & 22.38 & 21.87 & 22.38 & 21.87 & 22.38 \\
\hline 1/26/2010 13:50 & 9832 & 3 & 21.91 & 22.37 & 21.91 & 22.37 & 21.91 & 22.37 & 21.91 & 22.37 \\
\hline 1/26/2010 14:00 & 9833 & 3 & 21.92 & 22.36 & 21.92 & 22.36 & 21.92 & 22.36 & 21.92 & 22.36 \\
\hline 1/26/2010 14:10 & 9834 & 3 & 21.91 & 22.38 & 21.91 & 22.38 & 21.91 & 22.38 & 21.91 & 22.38 \\
\hline 1/26/2010 14:20 & 9835 & 3 & 22 & 22.43 & 22 & 22.43 & 22 & 22.43 & 22 & 22.43 \\
\hline 1/26/2010 14:30 & 9836 & 3 & 22.01 & 22.43 & 22.01 & 22.43 & 22.01 & 22.43 & 22.01 & 22.43 \\
\hline 1/28/2010 7:00 & 10079 & 6 & 21.87 & 22.45 & 21.87 & 22.45 & 21.87 & 22.45 & 21.87 & 22.45 \\
\hline 1/28/2010 7:10 & 10080 & 6 & 21.89 & 22.45 & 21.89 & 22.45 & 21.89 & 22.45 & 21.89 & 22.45 \\
\hline 1/28/2010 7:20 & 10081 & 6 & 21.94 & 22.48 & 21.94 & 22.48 & 21.94 & 22.48 & 21.94 & 22.48 \\
\hline 1/28/2010 7:30 & 10082 & 6 & 22.01 & 22.52 & 22.01 & 22.52 & 22.01 & 22.52 & 22.01 & 22.52 \\
\hline 1/28/2010 7:40 & 10083 & 6 & 22.05 & 22.53 & 22.05 & 22.53 & 22.05 & 22.53 & 22.05 & 22.53 \\
\hline 1/28/2010 7:50 & 10084 & 6 & 22.08 & 22.55 & 22.08 & 22.55 & 22.08 & 22.55 & 22.08 & 22.55 \\
\hline 1/30/2010 9:50 & 10384 & 12 & 21.19 & 21.65 & 21.19 & 21.65 & 21.19 & 21.65 & 21.19 & 21.65 \\
\hline 1/30/2010 10:00 & 10385 & 12 & 21.12 & 21.66 & 21.12 & 21.66 & 21.12 & 21.66 & 21.12 & 21.66 \\
\hline 1/30/2010 10:10 & 10386 & 12 & 21.23 & 21.7 & 21.23 & 21.7 & 21.23 & 21.7 & 21.23 & 21.7 \\
\hline 1/30/2010 10:20 & 10387 & 12 & 21.27 & 21.72 & 21.27 & 21.72 & 21.27 & 21.72 & 21.27 & 21.72 \\
\hline 1/30/2010 10:30 & 10388 & 12 & 21.29 & 21.78 & 21.29 & 21.78 & 21.29 & 21.78 & 21.29 & 21.78 \\
\hline 1/30/2010 10:40 & 10389 & 12 & 21.41 & 21.88 & 21.41 & 21.88 & 21.41 & 21.88 & 21.41 & 21.88 \\
\hline 1/30/2010 10:50 & 10390 & 12 & 21.41 & 21.83 & 21.41 & 21.83 & 21.41 & 21.83 & 21.41 & 21.83 \\
\hline 1/30/2010 11:00 & 10391 & 12 & 21.48 & 21.99 & 21.48 & 21.99 & 21.48 & 21.99 & 21.48 & 21.99 \\
\hline 2/1/2010 10:30 & 10676 & 15 & 22.08 & 22.44 & 22.08 & 22.44 & 22.08 & 22.44 & 22.08 & 22.44 \\
\hline 2/1/2010 10:40 & 10677 & 15 & 22.1 & 22.5 & 22.1 & 22.5 & 22.1 & 22.5 & 22.1 & 22.5 \\
\hline 2/1/2010 10:50 & 10678 & 15 & 22.14 & 22.54 & 22.14 & 22.54 & 22.14 & 22.54 & 22.14 & 22.54 \\
\hline 2/1/2010 11:00 & 10679 & 15 & 22.18 & 22.59 & 22.18 & 22.59 & 22.18 & 22.59 & 22.18 & 22.59 \\
\hline 2/1/2010 11:10 & 10680 & 15 & 22.22 & 22.64 & 22.22 & 22.64 & 22.22 & 22.64 & 22.22 & 22.64 \\
\hline 2/1/2010 11:20 & 10681 & 15 & 22.25 & 22.68 & 22.25 & 22.68 & 22.25 & 22.68 & 22.25 & 22.68 \\
\hline 2/1/2010 11:30 & 10682 & 15 & 22.27 & 22.69 & 22.27 & 22.69 & 22.27 & 22.69 & 22.27 & 22.69 \\
\hline 2/1/2010 11:40 & 10683 & 15 & 22.3 & 22.71 & 22.3 & 22.71 & 22.3 & 22.71 & 22.3 & 22.71 \\
\hline 2/1/2010 11:50 & 10684 & 15 & 22.32 & 22.71 & 22.32 & 22.71 & 22.32 & 22.71 & 22.32 & 22.71 \\
\hline
\end{tabular}


TY Farm HDU Calibration -Temperature Change $\left({ }^{\circ} \mathrm{C}\right)$

\begin{tabular}{|c|c|c|c|c|c|c|c|c|c|c|}
\hline \multirow{2}{*}{ TIMESTAMP } & \multirow{2}{*}{ RECORD } & \multirow{2}{*}{$\begin{array}{c}\mathrm{P} \\
(\mathrm{psi})\end{array}$} & \multicolumn{8}{|c|}{ Sensor Number } \\
\hline & & & 1 & 9 & 11 & 12 & 13 & 14 & 15 & 16 \\
\hline 1/26/2010 13:20 & 9829 & 3 & 1.388 & 1.321 & 1.256 & 1.273 & 1.265 & 1.38 & 1.394 & 1.362 \\
\hline 1/26/2010 13:30 & 9830 & 3 & 1.38 & 1.354 & 1.272 & 1.265 & 1.265 & 1.38 & 1.411 & 1.354 \\
\hline 1/26/2010 13:40 & 9831 & 3 & 1.379 & 1.345 & 1.264 & 1.265 & 1.265 & 1.388 & 1.419 & 1.37 \\
\hline 1/26/2010 13:50 & 9832 & 3 & 1.371 & 1.337 & 1.247 & 1.273 & 1.248 & 1.371 & 1.41 & 1.362 \\
\hline 1/26/2010 14:00 & 9833 & 3 & 1.371 & 1.329 & 1.256 & 1.257 & 1.265 & 1.371 & 1.402 & 1.354 \\
\hline 1/26/2010 14:10 & 9834 & 3 & 1.371 & 1.329 & 1.264 & 1.273 & 1.265 & 1.387 & 1.41 & 1.362 \\
\hline 1/26/2010 14:20 & 9835 & 3 & 1.379 & 1.337 & 1.256 & 1.248 & 1.264 & 1.371 & 1.394 & 1.345 \\
\hline 1/26/2010 14:30 & 9836 & 3 & 1.371 & 1.337 & 1.264 & 1.264 & 1.264 & 1.371 & 1.41 & 1.362 \\
\hline 1/28/2010 7:00 & 10079 & 6 & 1.493 & 1.435 & 1.353 & 1.37 & 1.378 & 1.477 & 1.5 & 1.467 \\
\hline 1/28/2010 7:10 & 10080 & 6 & 1.469 & 1.435 & 1.353 & 1.378 & 1.378 & 1.485 & 1.508 & 1.467 \\
\hline 1/28/2010 7:20 & 10081 & 6 & 1.493 & 1.434 & 1.345 & 1.354 & 1.362 & 1.477 & 1.508 & 1.467 \\
\hline 1/28/2010 7:30 & 10082 & 6 & 1.493 & 1.434 & 1.345 & 1.354 & 1.362 & 1.493 & 1.508 & 1.467 \\
\hline $1 / 28 / 20107: 40$ & 10083 & 6 & 1.493 & 1.442 & 1.353 & 1.37 & 1.378 & 1.485 & 1.507 & 1.451 \\
\hline 1/28/2010 7:50 & 10084 & 6 & 1.493 & 1.459 & 1.353 & 1.354 & 1.354 & 1.477 & 1.491 & 1.459 \\
\hline 1/30/2010 9:50 & 10384 & 12 & 1.756 & 1.6 & 1.527 & 1.552 & 1.56 & 1.643 & 1.69 & 1.641 \\
\hline 1/30/2010 10:00 & 10385 & 12 & 1.667 & 1.616 & 1.519 & 1.56 & 1.552 & 1.659 & 1.698 & 1.649 \\
\hline 1/30/2010 10:10 & 10386 & 12 & 1.658 & 1.6 & 1.518 & 1.544 & 1.544 & 1.651 & 1.681 & 1.641 \\
\hline $1 / 30 / 201010: 20$ & 10387 & 12 & 1.65 & 1.608 & 1.526 & 1.552 & 1.544 & 1.642 & 1.697 & 1.649 \\
\hline 1/30/2010 10:30 & 10388 & 12 & 1.65 & 1.624 & 1.526 & 1.535 & 1.543 & 1.658 & 1.705 & 1.664 \\
\hline 1/30/2010 10:40 & 10389 & 12 & 1.682 & 1.615 & 1.518 & 1.543 & 1.535 & 1.642 & 1.696 & 1.648 \\
\hline $1 / 30 / 201010: 50$ & 10390 & 12 & 1.658 & 1.607 & 1.526 & 1.543 & 1.543 & 1.642 & 1.697 & 1.656 \\
\hline 1/30/2010 11:00 & 10391 & 12 & 1.657 & 1.631 & 1.534 & 1.551 & 1.534 & 1.633 & 1.688 & 1.648 \\
\hline 2/1/2010 10:30 & 10676 & 15 & 1.786 & 1.735 & 1.638 & 1.663 & 1.647 & 1.762 & 1.824 & 1.776 \\
\hline $2 / 1 / 201010: 40$ & 10677 & 15 & 1.769 & 1.727 & 1.646 & 1.655 & 1.647 & 1.761 & 1.824 & 1.776 \\
\hline 2/1/2010 10:50 & 10678 & 15 & 1.769 & 1.743 & 1.638 & 1.663 & 1.671 & 1.761 & 1.824 & 1.776 \\
\hline 2/1/2010 11:00 & 10679 & 15 & 1.777 & 1.727 & 1.637 & 1.654 & 1.662 & 1.745 & 1.832 & 1.784 \\
\hline 2/1/2010 11:10 & 10680 & 15 & 1.777 & 1.718 & 1.653 & 1.662 & 1.654 & 1.769 & 1.824 & 1.767 \\
\hline 2/1/2010 11:20 & 10681 & 15 & 1.76 & 1.726 & 1.637 & 1.646 & 1.654 & 1.753 & 1.832 & 1.776 \\
\hline 2/1/2010 11:30 & 10682 & 15 & 1.769 & 1.734 & 1.637 & 1.646 & 1.654 & 1.761 & 1.832 & 1.767 \\
\hline 2/1/2010 11:40 & 10683 & 15 & 1.777 & 1.726 & 1.637 & 1.662 & 1.654 & 1.761 & 1.815 & 1.767 \\
\hline 2/1/2010 11:50 & 10684 & 15 & 1.76 & 1.726 & 1.629 & 1.646 & 1.654 & 1.744 & 1.815 & 1.767 \\
\hline
\end{tabular}


TY Farm HDU Normalization - Initial Temperature $\left({ }^{\circ} \mathrm{C}\right)$

\begin{tabular}{|c|c|c|c|c|c|c|c|c|c|}
\hline \multirow{2}{*}{ TIMESTAMP } & \multirow{2}{*}{$\begin{array}{c}\text { RECOR } \\
\text { D }\end{array}$} & \multicolumn{8}{|c|}{ Sensor Number } \\
\hline & & 1 & 9 & 11 & 12 & 13 & 14 & 15 & 16 \\
\hline \multicolumn{10}{|l|}{ Wet } \\
\hline 1/22/2010 3:30 & 9194 & 21.95 & 22.28 & 22.12 & 22.17 & 22.17 & 22.22 & 22.28 & 22.31 \\
\hline 1/22/2010 3:40 & 9195 & 21.93 & 22.29 & 22.11 & 22.16 & 22.17 & 22.21 & 22.26 & 22.3 \\
\hline 1/22/2010 3:50 & 9196 & 21.93 & 22.28 & 22.1 & 22.14 & 22.16 & 22.19 & 22.24 & 22.28 \\
\hline 1/22/2010 4:00 & 9197 & 21.91 & 22.27 & 22.08 & 22.14 & 22.14 & 22.17 & 22.24 & 22.28 \\
\hline 1/22/2010 4:10 & 9198 & 21.89 & 22.26 & 22.08 & 22.13 & 22.13 & 22.17 & 22.22 & 22.27 \\
\hline 1/22/2010 4:20 & 9199 & 21.9 & 22.23 & 22.07 & 22.12 & 22.13 & 22.16 & 22.21 & 22.25 \\
\hline 1/22/2010 4:30 & 9200 & 21.89 & 22.23 & 22.07 & 22.12 & 22.12 & 22.16 & 22.22 & 22.25 \\
\hline 1/22/2010 4:40 & 9201 & 21.88 & 22.22 & 22.06 & 22.12 & 22.11 & 22.14 & 22.2 & 22.25 \\
\hline 1/22/2010 4:50 & 9202 & 21.84 & 22.21 & 22.04 & 22.08 & 22.09 & 22.11 & 22.17 & 22.23 \\
\hline $1 / 22 / 20105: 00$ & 9203 & 21.84 & 22.21 & 22.02 & 22.07 & 22.07 & 22.12 & 22.18 & 22.22 \\
\hline 1/22/2010 5:10 & 9204 & 21.83 & 22.2 & 22.03 & 22.07 & 22.07 & 22.1 & 22.17 & 22.23 \\
\hline 1/22/2010 5:20 & 9205 & 21.85 & 22.23 & 22.03 & 22.06 & 22.06 & 22.1 & 22.17 & 22.22 \\
\hline 1/22/2010 5:30 & 9206 & 21.82 & 22.19 & 22 & 22.05 & 22.07 & 22.1 & 22.17 & 22.23 \\
\hline $1 / 22 / 20105: 40$ & 9207 & 21.82 & 22.21 & 22.02 & 22.07 & 22.06 & 22.08 & 22.15 & 22.2 \\
\hline $1 / 22 / 20105: 50$ & 9208 & 21.81 & 22.2 & 22 & 22.04 & 22.04 & 22.09 & 22.15 & 22.2 \\
\hline 1/22/2010 6:00 & 9209 & 21.81 & 22.2 & 21.99 & 22.04 & 22.05 & 22.09 & 22.18 & 22.21 \\
\hline 1/22/2010 6:10 & 9210 & 21.79 & 22.19 & 22.01 & 22.05 & 22.06 & 22.1 & 22.19 & 22.23 \\
\hline 1/22/2010 6:20 & 9211 & 21.81 & 22.17 & 21.99 & 22.04 & 22.05 & 22.08 & 22.13 & 22.17 \\
\hline $1 / 22 / 20106: 30$ & 9212 & 21.81 & 22.15 & 21.99 & 22.04 & 22.04 & 22.06 & 22.1 & 22.14 \\
\hline 1/22/2010 6:40 & 9213 & 21.79 & 22.14 & 21.96 & 21.99 & 21.99 & 22.02 & 22.07 & 22.14 \\
\hline Average & & 21.86 & 22.22 & 22.04 & 22.09 & 22.09 & 22.12 & 22.19 & 22.23 \\
\hline \multicolumn{10}{|l|}{ Dry } \\
\hline 1/19/2010 5:30 & 8774 & 21.52 & 21.55 & 21.83 & 21.95 & 22 & 21.96 & 22.06 & 21.91 \\
\hline $1 / 19 / 20105: 40$ & 8775 & 21.55 & 21.56 & 21.82 & 21.93 & 22 & 21.95 & 22.04 & 21.88 \\
\hline 1/19/2010 5:50 & 8776 & 21.53 & 21.57 & 21.84 & 21.94 & 22 & 21.96 & 22.04 & 21.92 \\
\hline 1/19/2010 6:00 & 8777 & 21.53 & 21.58 & 21.83 & 21.94 & 21.99 & 21.96 & 22.07 & 21.94 \\
\hline 1/19/2010 6:10 & 8778 & 21.57 & 21.61 & 21.85 & 21.98 & 22.04 & 22.01 & 22.1 & 21.96 \\
\hline 1/19/2010 6:20 & 8779 & 21.59 & 21.62 & 21.84 & 21.94 & 22.02 & 21.98 & 22.07 & 21.94 \\
\hline 1/19/2010 6:30 & 8780 & 21.56 & 21.59 & 21.84 & 21.95 & 22.01 & 21.96 & 22.05 & 21.93 \\
\hline $1 / 19 / 20106: 40$ & 8781 & 21.55 & 21.62 & 21.85 & 21.94 & 22 & 21.95 & 22.05 & 21.94 \\
\hline 1/19/2010 6:50 & 8782 & 21.56 & 21.63 & 21.85 & 21.95 & 22.01 & 21.99 & 22.06 & 21.94 \\
\hline 1/19/2010 7:00 & 8783 & 21.58 & 21.62 & 21.85 & 21.96 & 22.02 & 21.98 & 22.07 & 21.94 \\
\hline 1/19/2010 7:10 & 8784 & 21.57 & 21.65 & 21.87 & 21.97 & 22.01 & 21.97 & 22.09 & 21.97 \\
\hline 1/19/2010 7:20 & 8785 & 21.57 & 21.63 & 21.85 & 21.97 & 22.03 & 21.99 & 22.08 & 21.95 \\
\hline 1/19/2010 7:30 & 8786 & 21.61 & 21.66 & 21.88 & 22.01 & 22.06 & 22.01 & 22.1 & 21.97 \\
\hline $1 / 19 / 20107: 40$ & 8787 & 21.66 & 21.68 & 21.93 & 22.05 & 22.11 & 22.04 & 22.14 & 22 \\
\hline 1/19/2010 7:50 & 8788 & 21.68 & 21.73 & 21.98 & 22.09 & 22.15 & 22.08 & 22.18 & 22.06 \\
\hline $1 / 19 / 20108: 00$ & 8789 & 21.73 & 21.76 & 22.02 & 22.14 & 22.17 & 22.13 & 22.24 & 22.11 \\
\hline 1/19/2010 8:10 & 8790 & 21.78 & 21.82 & 22.05 & 22.18 & 22.25 & 22.18 & 22.27 & 22.16 \\
\hline 1/19/2010 8:20 & 8791 & 21.81 & 21.86 & 22.09 & 22.22 & 22.27 & 22.21 & 22.32 & 22.19 \\
\hline 1/19/2010 8:30 & 8792 & 21.86 & 21.89 & 22.16 & 22.26 & 22.3 & 22.25 & 22.35 & 22.23 \\
\hline 1/19/2010 8:40 & 8793 & 21.9 & 21.95 & 22.21 & 22.3 & 22.35 & 22.29 & 22.39 & 22.26 \\
\hline Average & & 21.64 & 21.68 & 21.92 & 22.03 & 22.09 & 22.04 & 22.14 & 22.01 \\
\hline
\end{tabular}


TY Farm HDU Normalization -Temperature Change $\left({ }^{\circ} \mathrm{C}\right)$

\begin{tabular}{|c|c|c|c|c|c|c|c|c|c|}
\hline \multirow{2}{*}{ TIMESTAMP } & \multirow{2}{*}{ RECORD } & \multicolumn{8}{|c|}{ Sensor Number } \\
\hline & & 1 & 9 & 11 & 12 & 13 & 14 & 15 & 16 \\
\hline \multicolumn{10}{|l|}{ Wet } \\
\hline 1/22/2010 3:30 & 9194 & 0.768 & 0.768 & 0.759 & 0.71 & 0.702 & 0.751 & 0.776 & 0.783 \\
\hline $1 / 22 / 20103: 40$ & 9195 & 0.76 & 0.76 & 0.743 & 0.71 & 0.719 & 0.751 & 0.784 & 0.759 \\
\hline $1 / 22 / 20103: 50$ & 9196 & 0.768 & 0.768 & 0.751 & 0.71 & 0.711 & 0.751 & 0.793 & 0.792 \\
\hline $1 / 22 / 20104: 00$ & 9197 & 0.776 & 0.776 & 0.743 & 0.686 & 0.719 & 0.751 & 0.776 & 0.783 \\
\hline $1 / 22 / 20104: 10$ & 9198 & 0.768 & 0.768 & 0.743 & 0.735 & 0.702 & 0.743 & 0.793 & 0.775 \\
\hline 1/22/2010 4:20 & 9199 & 0.776 & 0.776 & 0.743 & 0.718 & 0.703 & 0.751 & 0.776 & 0.767 \\
\hline 1/22/2010 4:30 & 9200 & 0.776 & 0.776 & 0.759 & 0.702 & 0.703 & 0.751 & 0.776 & 0.783 \\
\hline $1 / 22 / 20104: 40$ & 9201 & 0.768 & 0.768 & 0.743 & 0.702 & 0.678 & 0.751 & 0.793 & 0.792 \\
\hline $1 / 22 / 20104: 50$ & 9202 & 0.792 & 0.792 & 0.759 & 0.718 & 0.719 & 0.743 & 0.784 & 0.783 \\
\hline 1/22/2010 5:00 & 9203 & 0.776 & 0.776 & 0.743 & 0.719 & 0.719 & 0.743 & 0.785 & 0.792 \\
\hline 1/22/2010 5:10 & 9204 & 0.784 & 0.784 & 0.767 & 0.719 & 0.694 & 0.735 & 0.776 & 0.792 \\
\hline $1 / 22 / 20105: 20$ & 9205 & 0.752 & 0.752 & 0.743 & 0.71 & 0.703 & 0.76 & 0.793 & 0.792 \\
\hline $1 / 22 / 20105: 30$ & 9206 & 0.776 & 0.776 & 0.759 & 0.694 & 0.686 & 0.743 & 0.793 & 0.784 \\
\hline $1 / 22 / 20105: 40$ & 9207 & 0.76 & 0.76 & 0.751 & 0.71 & 0.711 & 0.735 & 0.801 & 0.784 \\
\hline $1 / 22 / 20105: 50$ & 9208 & 0.784 & 0.784 & 0.743 & 0.71 & 0.694 & 0.752 & 0.793 & 0.784 \\
\hline $1 / 22 / 20106: 00$ & 9209 & 0.768 & 0.768 & 0.767 & 0.719 & 0.703 & 0.752 & 0.801 & 0.767 \\
\hline $1 / 22 / 20106: 10$ & 9210 & 0.768 & 0.768 & 0.751 & 0.702 & 0.694 & 0.752 & 0.785 & 0.784 \\
\hline $1 / 22 / 20106: 20$ & 9211 & 0.776 & 0.776 & 0.759 & 0.694 & 0.711 & 0.743 & 0.785 & 0.792 \\
\hline $1 / 22 / 20106: 30$ & 9212 & 0.76 & 0.76 & 0.759 & 0.71 & 0.711 & 0.752 & 0.793 & 0.792 \\
\hline $1 / 22 / 20106: 40$ & 9213 & 0.768 & 0.768 & 0.743 & 0.702 & 0.703 & 0.743 & 0.768 & 0.767 \\
\hline Average & & 0.771 & 0.771 & 0.751 & 0.709 & 0.704 & 0.748 & 0.786 & 0.782 \\
\hline \multicolumn{10}{|l|}{ Dry } \\
\hline 1/19/2010 5:30 & 8774 & 3.299 & 3.299 & 3.461 & 3.248 & 3.314 & 3.329 & 3.624 & 3.627 \\
\hline 1/19/2010 5:40 & 8775 & 3.307 & 3.307 & 3.445 & 3.256 & 3.322 & 3.337 & 3.615 & 3.627 \\
\hline $1 / 19 / 20105: 50$ & 8776 & 3.291 & 3.291 & 3.453 & 3.256 & 3.33 & 3.338 & 3.632 & 3.627 \\
\hline 1/19/2010 6:00 & 8777 & 3.283 & 3.283 & 3.445 & 3.256 & 3.322 & 3.346 & 3.615 & 3.627 \\
\hline 1/19/2010 6:10 & 8778 & 3.307 & 3.307 & 3.461 & 3.255 & 3.321 & 3.353 & 3.607 & 3.626 \\
\hline 1/19/2010 6:20 & 8779 & 3.282 & 3.282 & 3.444 & 3.256 & 3.346 & 3.354 & 3.607 & 3.618 \\
\hline 1/19/2010 6:30 & 8780 & 3.307 & 3.307 & 3.469 & 3.28 & 3.305 & 3.337 & 3.607 & 3.643 \\
\hline $1 / 19 / 20106: 40$ & 8781 & 3.291 & 3.291 & 3.452 & 3.256 & 3.322 & 3.337 & 3.607 & 3.643 \\
\hline $1 / 19 / 20106: 50$ & 8782 & 3.307 & 3.307 & 3.452 & 3.256 & 3.33 & 3.337 & 3.607 & 3.643 \\
\hline $1 / 19 / 20107: 00$ & 8783 & 3.299 & 3.299 & 3.452 & 3.272 & 3.322 & 3.337 & 3.599 & 3.627 \\
\hline $1 / 19 / 20107: 10$ & 8784 & 3.299 & 3.299 & 3.444 & 3.255 & 3.305 & 3.345 & 3.607 & 3.634 \\
\hline 1/19/2010 7:20 & 8785 & 3.291 & 3.291 & 3.444 & 3.247 & 3.33 & 3.337 & 3.615 & 3.61 \\
\hline 1/19/2010 7:30 & 8786 & 3.298 & 3.298 & 3.46 & 3.263 & 3.329 & 3.345 & 3.623 & 3.618 \\
\hline $1 / 19 / 20107: 40$ & 8787 & 3.298 & 3.298 & 3.452 & 3.263 & 3.321 & 3.337 & 3.615 & 3.626 \\
\hline 1/19/2010 7:50 & 8788 & 3.29 & 3.29 & 3.444 & 3.255 & 3.313 & 3.336 & 3.606 & 3.642 \\
\hline $1 / 19 / 20108: 00$ & 8789 & 3.298 & 3.298 & 3.459 & 3.262 & 3.312 & 3.344 & 3.614 & 3.617 \\
\hline 1/19/2010 8:10 & 8790 & 3.289 & 3.289 & 3.451 & 3.246 & 3.328 & 3.352 & 3.622 & 3.609 \\
\hline 1/19/2010 8:20 & 8791 & 3.289 & 3.289 & 3.451 & 3.262 & 3.32 & 3.336 & 3.614 & 3.617 \\
\hline 1/19/2010 8:30 & 8792 & 3.297 & 3.297 & 3.475 & 3.27 & 3.328 & 3.335 & 3.613 & 3.624 \\
\hline $1 / 19 / 20108: 40$ & 8793 & 3.296 & 3.296 & 3.442 & 3.269 & 3.319 & 3.327 & 3.597 & 3.64 \\
\hline Average & & 3.296 & 3.453 & 3.259 & 3.322 & 3.340 & 3.612 & 3.627 & 3.484 \\
\hline
\end{tabular}




\section{Appendix D}

Suggested Troubleshooting Procedures 



\section{Appendix D: Suggested Troubleshooting Procedures}

If measurements from an instrument or a sensor do not meet the indicators specified, the following suggested troubleshooting steps should be taken in the order presented. Note that troubleshooting Steps 1 through 3 are performed outside the tank farm. If Steps 1 through 3 do not resolve the issue, entrance into the tank farm is required for further troubleshooting.

1. Review the post-processing procedure to verify that the error does not reside in this step.

2. Check the battery voltage data for power supply.

3. Check the datalogger program for potential program error.

4. Manually download the data from the datalogger to confirm that the data error is not created during remote data transmittal to the server.

5. Check the datalogger ports to confirm that they are functioning.

6. Inspect the wiring and connections at the datalogger for disconnections or wiring wear.

7. Inspect the wiring coming out of the top of the probe for disconnection or wiring wear.

8. Test the wiring from the probe to the datalogger for continuity. 


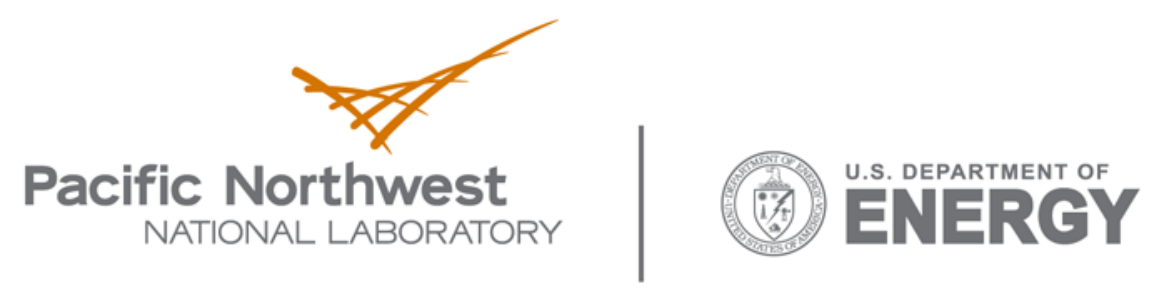

902 Battelle Boulevard

P.O. Box 999

Richland, WA 99352

1-888-375-PNNL (7665)

www.pnl.gov 